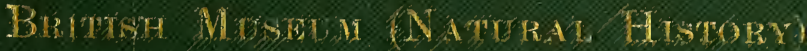

\section{HANDBOOK OF}

Instrugrons mor Comingars 


\section{op \\ Ad \\ 0 \\ $B R I$}

Natural History Museum Library

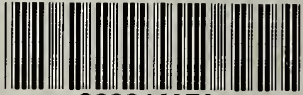

300014370 


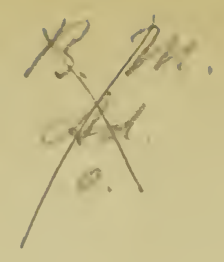

Natural History Specimens intended for the British Museunı should be directed to

THE BRITISH MUSEUM (NATURAL HISTORY),

CROMWELJ, ROAD,

LONDON, S.W.

All communications should be addressed to the DiREctor.

Note.-Boxes of Specimens so addressed are not opened by the Customs Officers at the Docks, but sent on to the Museum under seal. 


\section{HANDBOOK}

OF

\section{INSTRUCTIONS FOR COLLECTORS,}

ISSUED BY

\section{THE BRITISH IIUSEUM (NATURAL HISTORY).}

WITH ILLUSTRATIONS.

\section{LONDON :}

PRINTED BY ORDER OF THE TRUSTEES OF THE BRITISH MUSEUM.

$$
\text { SOLD BY }
$$

LONGMANS \& Co., 39 PATERNOSTER ROW, E.C.;

B. QUARITCH, 15 PICCADILLY, W.; DULAU \& Co., 37 SOHO SQUARE, W.; KEGAN PAUL, TRENCH, TRÜBNER \& Co., CHARING CROSS ROAD, W.C. ;

$$
\text { AND AT THE }
$$

BRITISH MUSEUM (NATURAL HISTORY), CROMWELL ROAD, S.W.

1902.

All rights reserved. 
PRINTED BY

IIAZHLL, WATSON AND VINEY, LD., LONDON AND AYLESBURY. 


\section{PREFACE.}

In past years the Museum collections have been greatly augmented and enriched by the donation of valuable series of specimens obtained by travellers and others whose vocations have necessitated their residence abroad in all parts of the world.

It often happens that military and naval officers, explorers, missionaries, and others have leisure time which they would be willing to devote to collecting natural history objects if they had a better knowledge of the manner in which such things should be collected and preserved.

In order to meet this requirement, it has been thought advisable to prepare a series of pamphlets treating upon the collecting and preservation of specimens in all branches of natural history. These can be obtained separately; but for the convenience and use of those who are willing to take up more than one branch of collecting, they are now united and issued in book form, thus forming an introductory manual of instructions on the subject generally.

Although primarily written for the use of voluntary collectors, this work will prove equally useful to those 
professionally engaged in collecting, as showing the approved manner in which the various objects referred to should be treated.

The various chapters have been written by different members of the staff of the Natural History Museum, with the hope that the distribution of this work will lead to the formation of important collections which will ultimately come to us for study and comparison, and possibly enrich the series preserved in the Museum.

E. RAy LANKESTER, DiRECTOR.

British Museum (Natural History),

Cromwell Road,

LoNDON, S.W.

June 1st, 1902. 


\section{TABLE OF CONTENTS.}

Hints on Removing and Preparing Skins of Mammals . , 7 Instructions for the Preservation of Birds . . . . 20

How to Determine the Sex of A Bird . . . . . . 30

Instructions for Collecting Reptiles, Batrachians, and Fishes 33

INSTRUCTIONS FOR COLLECTING INSECTS . . . . . . 48

How to Collect Diptera (Two-Winged Flies) . . . . 60

How to Collect Mosquitoes . . . . . . . . 80

Instructions for Collecting Spiders, Centipedes (Arachyida, MYRIOPODA), AND PERIPATUS . . . . . . . . 92

Methods of Collecting and Preserving Various Soft-Bodied

INVERTEBRATE ANIMALS . . . . . . . . . 96

Hints for Collecting And Preserving Shells of Molluscs 112

Directions for Collecting and Preserving Plants . . . 115

Suggestions as to Collecting and Preserving Fossils • . 125

On Collecting Microscopic and Other Organisms in Rocks • 130

Notes on Collecting Minerals . . . . . . . . . 132

$\operatorname{INDEX}$. . . . . . . . . . . 135 



\section{HINTS ON REMOVING AND PREPARING SKINS OF MAMMALS.}

\section{SECTION A.-LARGE MAMMALS.}

Sportsmen are, as a rule, by no means careful enough about the proper labelling of their specimens, which consequently lose much of their scientific value. Large Mammals, like small ones, should be carefully labelled, with all particulars of date, sex, locality, altitude, etc. Specimen labels are shown beyond (page 15). The proper reference of each skull to its own particular skin is also of much importance.

For skinning large Mammals the implements required are very few and inexpensive - a shoemaker's knife, a scalpel, a sinall saw, and a pair of pliers, with perhaps the addition of a pair of cutting-pincers, being all that are requisite. Any addition to this simple outfit only tends to encumber the traveller unnecessarily, everything really depending upon the skill with which the knife is wielded rather than upon the number and nature of the implements themselves.

The great principle the operator should bear in mind is to make as few incisions as possible in the skin, and that these, so far as practicable, should be confined to the middle line of the under surface of the body, and to the inner sides of the limbs. If this be attended to, the slits will be but little conspicuous when the specimens are mounted. In Mohammedan countries the natives have a practice of cutting the throats of animals from ear to ear immediately they fall, in order that they may be bled after the orthodox fashion. Such gashes have, of course, to be sewn up when the specimen is mounted, with the result that the region of the throat is disfigured 
by ugly seams. In his book entitled "Seventeen Trips to Somaliland," Major Swayne has shown that by a little gentle persuasion the natives can be induced to so modify the halal (as the operation is called) that the damage to the specimen is reduced to a minimum; and probably a similar modification might be assented to by the Mohammedans of other countries.

In the case of hornless animals, such as a Lion or Tiger, preparatory to commencing operations, the carcase about to be skinned should be turned on its back, and the fore and hind limbs held outwards by assistants, as far as they can be easily stretched. The operator should then make a straight incision with the knife from the chin along the middle line of the under surface of the body to the tip of the tail. In making this and the other incisions great care should be taken to avoid cutting more than possible into the flesh, and, above all, not to lay open the cavity of the abdomen. The next procedure is to make cuts diverging from the main incision, in order to enable the limbs to be stripped. In the case of the fore legs the lateral cuts should be carried from the middle line through the armpits down the inner side of each limb, the knife being , held pointing somewhat outwardly, in order that the seams made in sewing up the cuts should be as inconspicuous as possible in the mounted specimens. In the hind limbs the incisions should be carried through the groin, and so downwards in the same manner as in the fore limbs.

In the case of horned animals (exclusive of Rhinoceroses, in which the horns are removed with the skin) it will be necessary, when the carcase is again turned, to make an incision from the crown of the head down the middle line of the neck to such a distance as will admit of the horns or antlers being passed through the slit thus made when the skin is removed from the head. In no case should the head-skin be severed from that of the body.

When all the above-mentioned cuts have been made, the skin of the chest will be left in the form of lappets. Commencing by the application of the knife to the point of one of these lappets, the skin should be gradually stripped from the body, tail, and limbs, special care and attention being requisite in order to avoid damaging the feet, of which the natural contour should be so far as possible preserved. In the case of the smaller specimens, whether Deer, 
PREPARING SKINS OF MAMMALS.

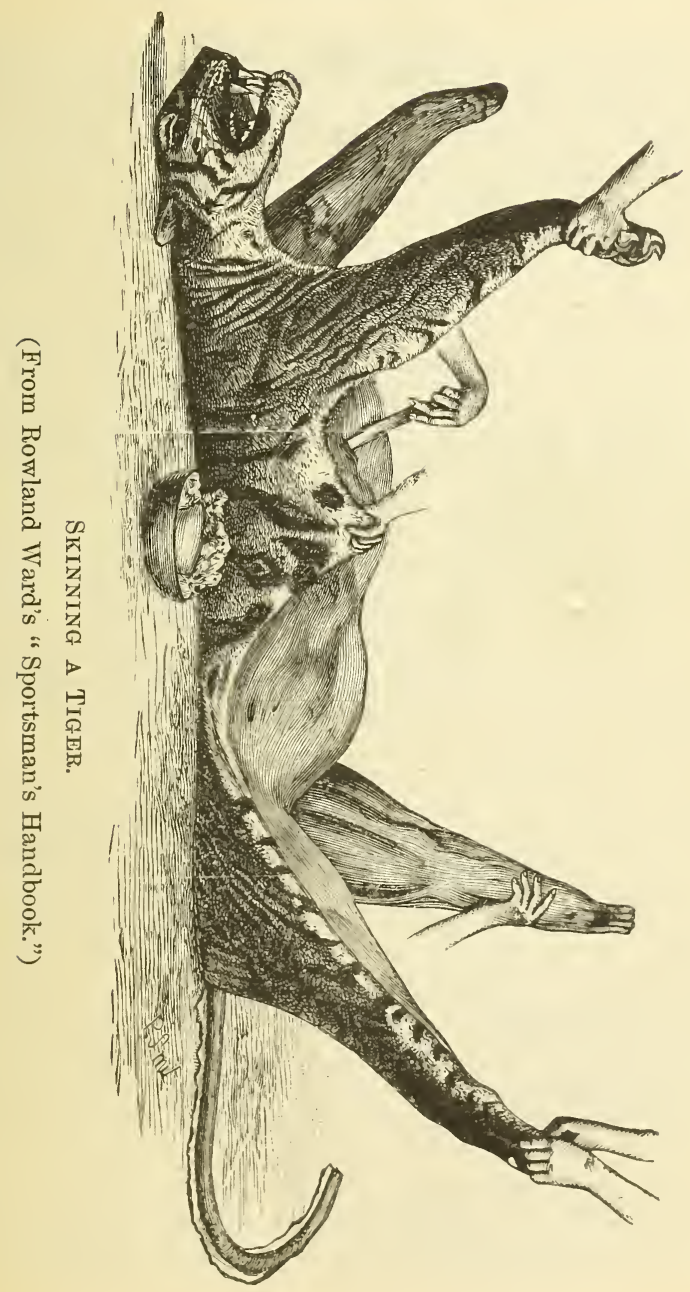


Antelopes, Carnivora, or Monkeys, the terminal toe-bones may be left in the skin; but their complete removal is desirable in the larger representatives of these groups, as well as in still bigger animals, such as Elephants, Hippopotami, and Rhinoceroses. Special measures have to be taken with the three latter, but in the case of Carnivora and Monkeys the skin of the toes should be drawn over them by turning it inside-out, and the joints cut with the pliers where required.

The next process is to turn over the carcase and draw the skin forwards over the head, when the separation of the ears and the severance of the closely adherent skin round the eyes will demand somewhat delicate manipulation. The conchs of the ears should be severed close to the skull, in order to avoid forming apertures of too large size in the skin; and in the case of the eyelids particular care should be taken in order to avoid gashing the skin, since even the smallest slit in this region will tend to spread to a great extent, and thus cause almost irreparable injury to the specimen. The lips should be cut off as close as possible to the gums.

It may be added that, in the case of animals of the approximate size of a Fox, the skin of the tail may be stripped off entire, without slitting the under surface; but for animals of this size not intended for mounting, see page 18 .

Having now removed the skin from the carcase, the next process is to cut away completely all fragments of flesh and fat which may have been left adhering to its inner surface. The cartilages of the ears must also be dissected out with the scalpel, by turning back the skin over them; after which the inner surface should be well anointed with some preservative-powder, paste, or liquid. The scalpel must also be passed between the outer skin and the inner mucous lining of the lips, and the slit thus made well dressed with the same fluid. The eyelids have likewise to be thoroughly dressed with preservative; and if necessary on account of their thickness, they should be slit open with the scalpel from the inside.

The skin has now to be dried, which may be effected, if that of a large animal, either by pegging it out (without undue stretching) hair-downwards on the ground, or by folding and drying it in such 
a manner that large creases should not be formed. Smaller skins should always be folded and dried without creasing. Some preservative, such as alum, or one of the special preparations sold for the purpose by dealers, should now be well rubbed in, especially on the ears, mouth, feet, etc., and the whole specimen sprinkled with the same. The hairy side of the skin has next to be well anointed with turpentine, and the specimen will be ready for packing: When skins are shot during the rainy season, they are very difficult to get dried, and it is then recommended that, if possible, they should be pickled in brine.

In addition to the skin, it is essential that the skull, and, if possible, the bones of the limbs, should be preserved and sent home. The flesh should be carefully cut away, the brain taken out, and the bones soaked for a few hours in water, after which they may be dried in the sun and sprinkled with alum. In hot, dry climates the teeth should be coated with wax in order to prevent their splitting. A wash of turpentine over the skulls and other bones will prevent the ravages of insects.

The following list contains the names of many of the larger Wild Mammals of which specimens are wanted by the Museum. In addition to these, skins and skeletons or skulls of well-established breeds of Domesticated Mammals from all parts of the world are required.

Skins of a considerable number of species of the larger Mammals are required for mounting in the exhibition galleries, either to replace indifferent specimens now exhibited, or as representatives of forms at present not shown at all. Such are indicated by a cross $(\uparrow)$ in the list.

In addition to this (and more especially in view of the approaching partial, if not complete, extermination of many species), it is of the highest importance that the Museum should acquire a series of skins of all the larger species of Mammals as a study-collection, and also a duplicate set for future mounting, thus making three sets in all. Skins of all species will therefore be acceptable. Some of those more urgently needed for the store and study series are introduced into the list below, being distinguished from those required for present mounting by the absence of a cross. But the omission of any species 
from this list must not be considered to signify that specimens of it are not wanted, for at present properly labelled skins of all species, even the commonest, are most acceptable for purposes of study.

\section{Africa and Arabia.}

† Gelada Baboon (Theropithecus gelada). Abyssinia.

$\uparrow$ Baboons (Papio). All species.

$\uparrow$ Brown Hyæna (Hycena fusca).

$\uparrow$ Caracal (Felis caracal).

$\uparrow$ Abyssinian Wolf (Canis simensis).

$\dagger$ Long-eared Fox (Otocyon megalotis). S. Africa.

$\uparrow$ Fennec (Vulpes cama). S. Africa. Aard-Wolf (Proteles cristatus).

North African Bear (Ursus crowtheri). Morocco.

$\uparrow$ African Elephant (Elephas africanus).

† Northern Giraffe (Giraffa camelopardalis). N.E. Africa.

+ Southern Giraffe (Giraffa capensis). S. and S.E. Africa. Okapi (Okapia johnstoni). Eastern Congo Forest. Senegambian Buffalo (Bos planiceros). Gambia. Abyssinian Buffalo (Bos occidentalis). Abyssinia. Abyssinian Ibex (Capra wali). Abyssinia. Jackson's Hartebeest (Bubalis jacksoni). E. Africa.

† Western Hartebeest (Bubalis major). Gambia, etc. Tiang (Damaliscus tiang). Sudan.

Bontebok (Damaliscus pygargus).

Blesbok (Damaliscus albifrons).

$\uparrow$ Brindled Gnu (Connochoetes taurinus).

White-tailed Gnu (Connochoetes gnu).

Waterbuck (Cobus ellipsiprynnus).

Mrs. Gray's Waterbuck (Cobus maric ). White Nile.

White-eyed Cob (Cobus leucotis). . White Nile.

+ Mountain-Reedbuck (Cervicapra fulvorufula).

$\uparrow$ Vaal Rhebok (Pelea capreolus).

† Grysbuck (Rhaphiceros melanotis).

† Steinbuck (Rhaphiceros campestris).

† White Oryx (Oryx leucoryx). N.W. Africa. 
$\uparrow$ Beatrix Oryx (Oryx beatrix). Arabia. Gemsbuck (Oryx gazella). S. Africa.

† Fringe-eared Beisa (Oryx callotis). E. Africa.

† Swift Gazelle (Gazella mohr). Morocco.

+ Dama Gazelle (Gazella dama). Senegambia.

† Derbian Eland (Taurotragus derbianus). Senegambia.

† Situtunga (Tragelaphus spekei). E. Central Africa.

$\uparrow$ Broad-horned Antelope (Tragelaphus euryceros). W. Africa.

Kudu (Strepsiceros kudu).

Sable Antelope (Hippotragus niger ).

Roan Antelope (Hippotragus equinus).

West African Roan Antelope (Hippotragus equinus gambianus).

† Water-Chevrotain (Dorcatherium aquaticum).

$\uparrow$ Aard-Vark (Orycteropus capensis).

\section{Asra.}

† Slaty Snub-nosed Monkey (Rhinopithecus bieti). Mekong Valley. Binturong (Arctictis binturong). Eastern Himalaya and Malaysia,

† Caracal (Felis caracal). India and Persia. Persian Leopard (Felis pardus panthera). Persia, etc. Javan Rhinoceros (Rhinoceros sondaicus). Bengal and Malaysia.

$\uparrow$ Indian Rhinoceros (Rhinoceros unicornis). Assam.

† Shou (Cervus affinis). ? District north of Bhutan.

+ Sambar (Cervus unicolor). India.

† Swamp-Deer (Cervus duvauceli). India.

† Schomburgk's Deer (Cervus schomburgki). Siam.

† Luzon Sambar (Cervus philippinus). Luzon.

$\uparrow$ Philippine Spotted Deer (Cervus alfredi). Philippines. Altai Wapiti (Cervus eustephanus). Altai. -Manchurian Wapiti (Cervus anthopygus). Manchuria.

$\uparrow$ Pekin Sika (Cervus hortulorum). Manchuria.

† Formosan Sika (Cervus tciëvanus). Formosa.

$\uparrow$ Formosan Sambar (Cervus swinhoei). Formosa.

$\uparrow$ Mesopotamian Fallow Deer (Cervus mesopotamicus). Luistan.

$\uparrow$ Duchess of Bedford's Elk (Alees bedfordice). Siberia.

† Tibetan Tufted Deer (Elaphodus cephalophus). Tibet. Siberian Roe (Capreolus pygargus). Altai. 
† Fea's Muntjac (Cervulus fece). Tenasserim.

† Indian Buffalo (Bos bubalis). Assam.

$\uparrow$ Banteng (Bos sondaicus). Burma and Malaysia.

† Takin (Budorcas taxicolor). Mishmi Hills.

$\uparrow$ Nilgiri Thar, or Ibex (Hemitragus hylocrius). Nilgiri Hills.

$\uparrow$ Suleman Markhor (Capra falconeri jerdoni). Suleman and neighbouring ranges.

Persian Gazelle (Gazella subgutturosa). Persia, etc.

† Mongolian Gazelle (Gazella gutturosa). Mongolia.

† Przewalski's Gazelle (Gazella przewalskii). Central Asia.

† Indian Gazelle (Gazella bennetti). India.

Kamchatkan Bighorn (Ovis nivicola). Kamchatka.

Armenian Sheep (Ovis gmelini). Armenia, etc.

Asiatic Ibex (Capra sibirica).

Europe.

$\uparrow$ Pallas's Ture (Capra cylindricornis). E. Caucasus.

$\uparrow$ Caucasian Chamois (Rupricapra tragus). Caucasus.

\section{North America.}

† Mule-Deer (Dorcelaphus hemionus).

† Black-tailed Deer (Dorcelaphus columbianus).

$\uparrow$ Jirginian Deer (Dorcelaphus americanus).

$\uparrow$ Coyote (Canis latrans).

\section{South America.}

Peccary (Dicotyles torquatus). Brazil.

† Pampas-Deer (Dorcelaphus bezoarticus). Argentina.

$\uparrow$ Wood-Brocket (Mazama nemorivaga), or any other species.

$\uparrow$ Pudu Deer (Pudua pudu). Chilian A.ndes.

Guanaco (Lama huanacus). Patagonia.

$\uparrow$ Tapir (Tapirus). All species.

$\dagger$ Bush-Dog (Speothos venaticus). Brazil.

+ Spectacled Bear (Ursus ornatus). Andes.

Marine Mammals.

$\uparrow$ Pacific Walrus (Odobcenus obesus). N. Pacific. 


\section{SECTION B. - SMALL MAMMALS.}

1. With the freshly killed carcase before you, write the label. This should bear on the front the date, sex, locality, altitude above sea (in metres or feet), and your signature; on the back your initials, with a current number, and the following measurements in millimetres, taken in the flesh: (1) length of head and body; (2) of tail without end hairs; (3) hind foot without claws; and (4) ear, from notch at base to tip. In the case of the first two measurements, the body should be straightened out as much as possible, and the tail bent upwards at a sharp angle, and the measurements should then be taken from a point in the angle (see illustrations on page 17). The label should also have on its back any notes that may strike you about the habits of the animal, its native name, or the character of the locality.

\section{Example of LABEL.}

FRONT.
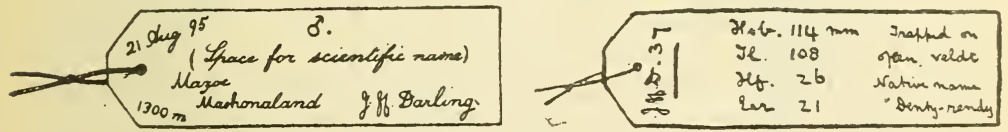

It is important that the positions of the different items, the method of writing dates, and the direction of the writing (away from the thread) should be exactly as in the example, so that skins from different sources may all be similarly labelled.

2.-Open the skin by cutting up the belly from the anus to the hinder end of the breast-bone; first push one and then the other knee through the opening, and cut through the legs at the kneejoints; clear off the chief muscles of the leg-bones, and separate the skin from the body all round the tail; then, holding the skin at the base of the tail firmly between the finger- and the thumbnails, or in the fork of a cleft stick, pull out the rertebræ from inside with the forceps; then, gradually turning the skin inside-out, skin it up over the body, shoulders, and head, separating the fore limbs at the elbow-joint, and taking great care not to cut it in passing 
over the eyes; skin it entirely off over the mouth, cutting carefully round the lips. Throughout the operation plenty of fine sawdust will be found of great assistance in keeping the hands, and consequently the fur, dry and unsoiled.

3.-Clean with sawdust the inside of the skin from blood, fat, etc., and then brush it all over with arsenical soap, being especially careful that the insides of the limbs get some put on them. Do not put any poison, especially powdered arsenic, on the outer, furry side of the skins. But pepper, naphthaline, or camphor may be used to keep off moths from the skin when travelling.

4.-Turn the skin back right side out, and fill the cavity of the body with cotton-wool, putting it in as far as possible in one piece. Or the skin may be reversed over the wool by putting the forceps up the furry side of the skin from the tail-end, and grasping the wool body through the mouth. Take care just to fill out the skin without over-stretching it, and try to get all your skins filled out to about the same degree. Take a piece of straight wire long enough to extend from the front end of the belly-opening to the tip of the tail; sharpen, if necessary, one end of it, and wind round it enough cotton-wool to fill out the skin of the tail ; then brush it with arsenical soap, and push the pointed end down to the extreme tip of the tailskin, and fit the near end into the belly, packing it round with the wool of the body. Put some wool into the empty skin of the arms and legs, winding it round the bones and connecting it with the wool of the body. Then stitch up the opening down the belly. Tie the label on to the right hind foot above the ankle.

5.-Lay the skin on a board or piece of cork, draw out the fore paws forwards, and pin them down to the board by a pin passed. boldly through the middle of the paw. Take care that they are pinned close in to the sides of the neck or head, in order to prevent their claws catching in other skins when all are packed together in boxes. Similarly, pin back, soles downwards, the hind feet by the sides of the tail. It is of considerable importance that neither fore nor hind feet should project laterally outwards, nor should curl up in drying, and that the fingers and toes should be kept close together and parallel, not spread out sideways.

6.-As the skin dries, try to get the face to assume as naturai 

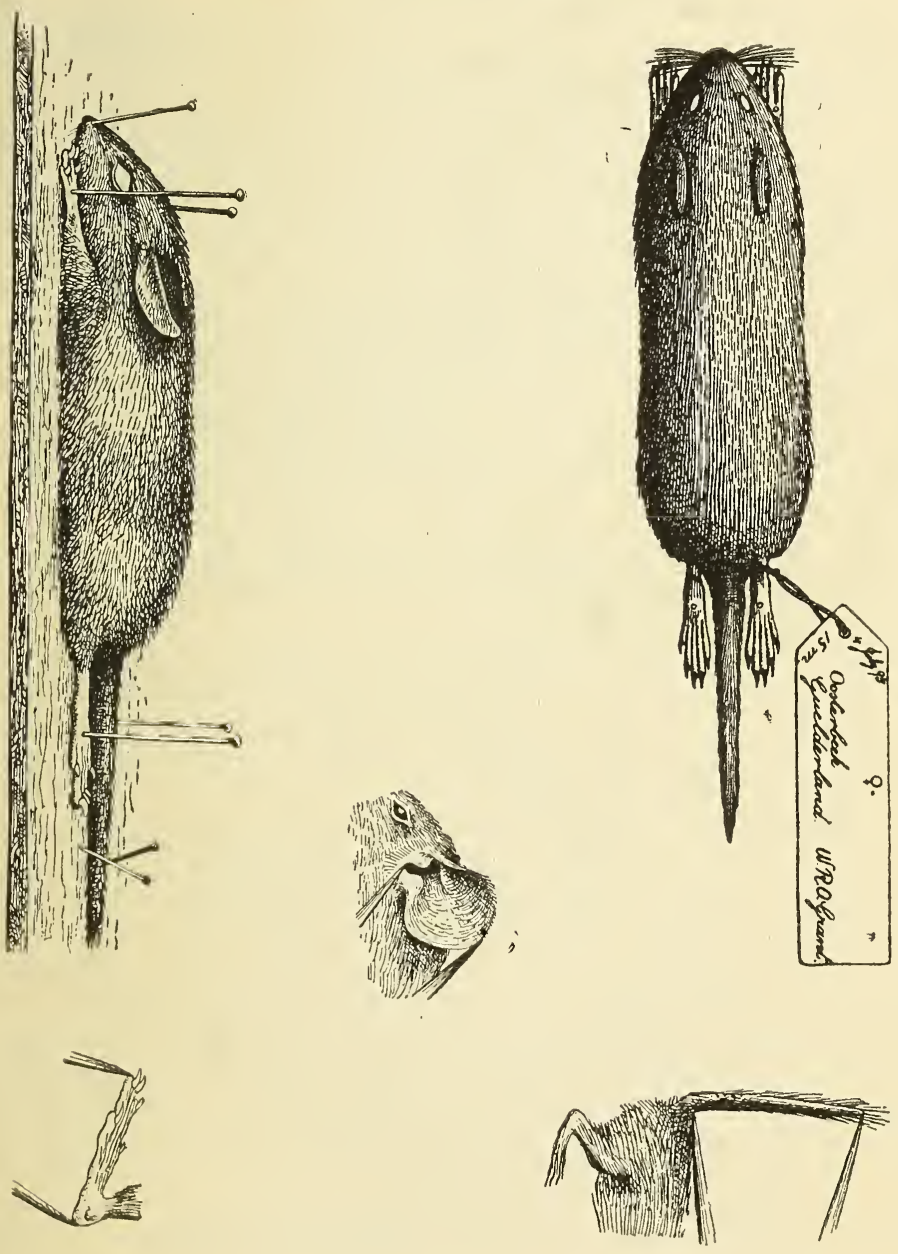
a shape as possible. The ears in Foxes, Hares, Rats, and Mice may be neatly folded backwards; in Bats, Squirrels, and other animals they should stand up in an erect position.

7.-Disarticulate the skull from the trunk, label it with your initials and the corresponding number to that on the skin, and then let it dry. In a dry climate this may be done almost without any cleaning; and even in a wet one, if the skull be dropped into some sawdust artificially dried, little cleaning need be done: at most the eyes and brain may be taken out, the tongue being always left in to protect the palate-bones. In a general way try to do as little to the skull as the climate will admit of - but, of course, it must not be allowed to become rotten. Drying naturally or artificially is the best, and arsenic or other chemicals should not be put on it, insects being kept off by the use of naphthaline or other disinfectant. Fly-blown skulls should not be dropped into the same box with other drying skulls.

8. - Pack the skins up carefully in small boxes when they are dry, with enough wool between them to prevent their shaking about. Do not roll them up separately in paper.

It is a good plan to have with you an ordinary cork-lined insectbox, in which the pieces of cork can be pinned for travelling. When the skins are partly dry, they can be taken off the separate pieces of cork, and pinned close together in the box, where they can safely travel and dry at the same time.

9.- Bats should be skinned like other animals, but the limbs are separated at the shoulders and hip-joints instead of the elbows and knees. They are also pinned down in the usual way, the pins running through the wrist-joint and the hind feet. The wings should not be spread out, but should be folded up on each side of the body in such a way as not to hide the fur of the belly. The thumbs should be made to point inwards or backwards, not outwards. The hind legs may be spread sufficiently to stretch the membrane between them, and then their breadth taken as a guide for the folding of the wings. One or two specimens of each species should also, if possible, be preserved in spirit.

The skinning of larger animals must necessarily be somewhat different from the above; but the labelling and make-up of skins 
should be as described, except that when the combined lengths of body and tail exceed thirty-nine inches the tail should be bent round sideways on itself or along the side of the body.

WANTED, generally, all small Mammals, however common-i.e. Squirrels, Rats, Mice, Shrews, Moles, Bats, Weasels, Stoats, etc., etc. Domesticated animals are, however, not wanted, nor are Rats or Mice caught in houses in towns. Do not be afraid of sending too many of the same sort, if carefully prepared and labelled as above described. This direction, however, would necessarily be modified in the case of specimens collected for sale. Series of skins representing the different seasons are always of interest.

Such animals are to be obtained chiefly by setting traps in likely places, runs and mouse-holes being specially looked for. A stock of small metal traps should be taken out by the collector, who should also look out for effective native traps. Pitfall-traps, made out of glass or metal jars sunk in flush with the ground, are also very often successful. 


\section{INSTRUCTIONS FOR THE PRESERVATION OF BIRDS.}

\section{General Remarks.}

A LITTLE patience and a little practice are all that is wanted to make a good skin of a bird. Also it should be remembered that no more time is wanted to make a good skin than a bad one. Thus it should be the aim of every naturalist to attain perfection in the art of preparing specimens ; and, after all, this is very easy.

The skinning of a bird demands but few tools. Many collectors require a penknife only; but the tyro should at least be provided with a sharp knife or scalpel, a pair of stout nail-scissors, as well as some arsenical soap, bleached wool, tow, and a sharp-pointed awl or darning-needle.

The knife is needed for making the first incision, and it is useful for scraping off fat from the skin. The nail-scissors are wanted for cutting through the flesh, and severing the tendons and the bones at their joints.

Arsenical soap is the best preservative; but powdered arsenic is also largely used, and has this advantage-that it dries the skins quickly in a damp climate, whereas arsenical soap keeps the skin moist for a longer period. There is always a certain danger in carrying powdered arsenic about; but it is also certain that the best skins now in our museums are those made by American naturalists, who always preserve with this ingredient. For the purposes of mounting, arsenical soap is much to be preferred, as the skin is always more lissom, while specimens preserved with powdered arsenic shrink and dry, and are never so easy to mount. Burnt 
alum has the same effect, but, like pepper, it does not serve to keep away the attacks of moths and beetles, as arsenic does to a great extent. No other preparation for preserving skins is recommended, for collections so prepared either arrive in England utterly destroyed, or, if they happen to survive the voyage, are sooner or later eaten by insects. Carbolized specimens are also all but worthless, as they fall to pieces after some time. Corrosive sublimate is frequently recommended as a preservative, but skins so prepared become exceedingly brittle, and after a lapse of years scarcely bear handling, ultimately falling to pieces. Arsenic is, undoubtedly, the best preservative for bird-skins.

Fine bleached cotton-wool is necessary for the filling in of the eye-sockets of the specimens. Nothing conduces more to the neat appearance of a properly prepared skin of a bird than the aspect of the head and eyes. For small birds there is nothing better than cottonwool for the filling out of the skin. Ordinary cotton-wadding is also necessary for wrapping round the skins after they have been made up. It helps to keep the skin in good shape and to dry it quickly.

Tow is useful for filling out skins of larger birds; and if possible, the neck should always be made of tow, instead of wool, for, if the specimen should ever be required for mounting, the wires of the taxidermist can easily be worked through a neck made of tow; whereas wool is impervious.

Fine white sawdust should be always handy for sprinkling on the body of a bird while it is being skinned, and some plaster of Paris is an almost indispensable adjunct in skinning wading and swimming birds, which are often covered with fat. As, however, these materials cannot always be procured in the tropics, dry sand may be used as a substitute, and, in an emergency, tobacco ash, or even dry earth, can be made available. Care must be taken to prevent the edges of the feathers becoming soiled by contact with the body of the bird as it is being taken out. Little wisps of cotton-wool should be at hand, to interpose along the base of the feathers while the skin is removed, as they serve to keep the feathers back and prevent them touching the flesh of the body. With a little practice the collector will find that he knows instinctively what feathers will be affected by his action as he removes the skin from the different parts of 


\section{INSTRUCTIONS FOR THE PRESERVATION OF BIRDS.}

the body, and his fingers will naturally intervene between the feathers and the flesh.

Supposing, therefore, that the bird to be skinned is a Thrush or some other small bird, the collector should begin operations by seeing that all his necessary appliances are at hand-box-wood, sawdust, or dry sand, tow, wool, nail-scissors, and knife. Some taxidermists begin by plugging the nostrils. This should be avoided, if possible, as the shape of the nostrils and their adjacent parts should be left undisturbed. Many genera of birds are characterized by the shape of the nostrils and their bristles, and every care should be taken to keep these exactly as they are in life. If, as is often the case, there is a discharge of mucus from the nostrils, it should be carefully soaked up with wool before the skinning begins; but no more than a tiny wisp of wool should be inserted, care being taken not to disturb the actual shape of the aperture. A far better way of preventing any discharge during the preparation of the bird's skin is to open the bill and, while plugging the mouth, insert a tiny piece of wool into the cleft in its roof.

The mouth must always be carefully filled with cotton-wool before commencing to skin.

Any shot-wounds should be either dusted with sand or lightly plugged with wool; but it should be remembered that blood-stains are more easily removed by taxidermists in England than by the collector in the field, and therefore that it is better not to try to clean skins on the spot. Any discharge from the nostrils must, however, be looked after carefully, as it spoils the skin when the head is being turned back, and the stain of mucus cannot be eradicated. If the eyes too have been damaged, it is well to sprinkle them with plaster of Paris or dry sand, and plug them under the eyelids with a tiny wisp of cotton-wool before commencing.

\section{To Skin a Small Bird.}

The next object is to remove the skin from the body, get rid of the latter, and restore the skin to its natural appearance. Through the incision now to be made the whole of the bird's body has to be drawn out, and the only thought is how to do this as neatly and 
expeditiously as possible. Many taxidermists make the incision down the side of the body under the wing. This has the advantage of preserving the feathers of the breast and abdomen intact, but there is also a risk of making the skin lop-sided. Another method is to cut the bird open along the breast-bone, from just where the fat of the neck appears to the top of the abdomen. This cut must be made high enough (but not too high), or the skin will tear across the sides of the neck while it is being removed, and the damage is irreparable. Some taxidermists make the incision from the vent up to the middle of the breast-bone, and begin operations above the tail-bone. Again, another excellent way is to make an incision from the vent on either sile to the upper edge of the thigh. By this means a triangular flap is made of the abdominal skin, which falls back into place after the body has been taken out, and the feathers of the breast are not disturbed at all. If the incision be made under the left wing, the joints should be cut through in the following order:-left shoulder, neck, right shoulder, left thigh, right thigh, tail; or left thigh, tail, right thigh.

After making a median incision, the skin must be pushed back till the left shoulder is exposed: this must be divided at the shoulder-joint, the humeral bone being always left with the wing (see fig. 2). Then the skin must be carefully pushed back by the fingers and thumb-nails till the neck is exposed. This must be cut through with the nail-scissors, care being taken not to make a hole with their sharp points in the skin below the neck; the right wing must then be attacked, and also severed at the shoulder. All this time, with each motion of the fingers, the feathers of the breast will be doing their best to soil themselves against the moist surface of the body. It is, therefore, necessary to have some sawdust or sand handy to sprinkle over the raw flesh as it becomes exposed; and if this be not available, a wisp of wool laid along the base of the feathers will keep them back in a most unexpected way : but, as said before, after a few attempts at skinning a bird, the fingers will be found to interpose by instinct, and prevent the feathers from becoming soiled by contact with the flesh.

The two wing-joints and the neck being stvered from the trunk, the skin can easily be pushed off the back of the bird till by degrees 


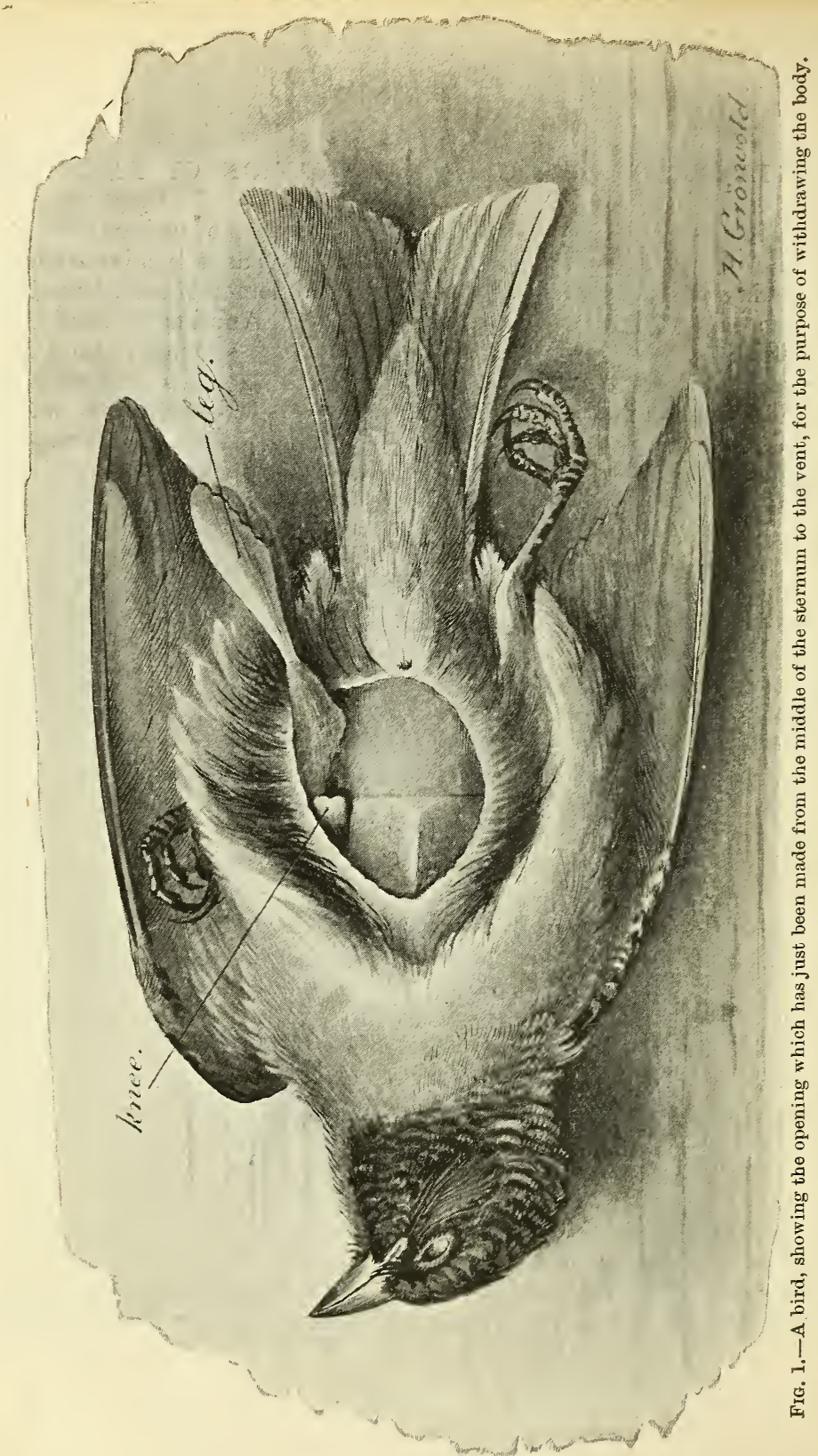


the thigh-bones aree approached. In many birds-such as Thrushes, for instance - the skin is very firmly attached to the lower back, and any attempt to hurry will end in splitting the skin right across: Although an accident of this sort may not ultimately destroy the appearance of the skin, it is difficult to restore the natural set of the feathers of the upper surface. As the skin is pushed off the lower back and thighs, the latter come prominently into view, and they should be severed at the knee-joint (see fig. 1). The tibial bone itself, when not broken by a shot, should always be kept in the skin, as it becomes a support for the legs when the skin is made up. By the severance of first one thigh and then the other, nothing is left to cut but the tail ; and when the skin has been pulled down sufficiently to expose the oilgland, it may be detached by a sharp cut above the latter. It should be noted that a good deal of flesh can be left on the root of the tail without damage to the skin, provided that it be thoroughly well dressed with arsenical soap. It is a maxim in the preservation of animals and birds that all fat should be removed from the skin as far as possible; but at the same time this requires great care, and the arsenical soap will account for many small layers of fat and destroy them.

It now remains to remove the flesh from the legs and wings, and turn the head and neck inside-out. By pushing the leg up from the outside, the flesh is soon exposed and is easily removed along with the tendons. A wisp of cotton or tow is wrapped round the bone, as a substitute for the flesh, and the legs are then drawn back to their natural position. The wings are then dealt with : the flesh is removed from the humerus, and by a certain amount of pressure the skin which conceals the flesh of the other wing-bones can be pushed back, and the flesh which lies between them must be cut out as far as possible. In the case of large birds it will be found best to make an incision along the wing-coverts from the under side of the wing. The flesh can thus easily be removed, and the cut is not noticed when the skin is made up and the wings folded close to the body. The wing-bones and the skin of the wing should be thoroughly dressed with arsenical soap, as any flesh remaining is apt to decay, and then the wing-coverts and the quills fall out. In small birds there is not so much risk of this misfortune, but large birds are of ten spoilt through inattention to these details. 


\section{INSTRUCTIONS FOR THE PRESERVATION OF BIRDS.}

The preparation of the head is usually considered by beginners to be very difficult, but in reality it is quite easy. The first care is not to stretch the neck, as a skin with an elongated neck is always ugly; and the neck, when once unduly stretched, can never be got back to its proper length. By gently forcing the head back from the outside, the skull is gradually exposed, and, except in the case of very small birds, it is necessary to skin down to the base of the bill. When the skin has been pushed back as far as the eyeballs, it will be found attached firstly to the ear (see fig. 2). This must be detached by placing the point of the knife under the tightly stretched skin and carefully scooping it out. The next difficulty is the eyelid. Still stretching the skin towards the bill, make a light cross cut behind the point of attachment above the eyeball, taking care not to cut into the latter. This cut will partially separate the eyelid from the eye, and a second upward cut from in front backwards completes the operation. It is very important to preserve the eyelid intact, as nothing spoils the appearance of a skin so much as a torn or damaged eyelid. When the eyeballs have been removed from the orbits, it is time to cut away the back of the skull, and with this goes the neck, which has not yet been detached. The tongue must also be removed at the same time. Mr. William Davison, who always made beautiful skins, and had one of the widest experiences in the preparation of specimens during the fifteen years that he was collecting for $\mathrm{Mr}$. Allan Hume, always recommended that the skull should be attacked from below, and that a triangular piece should be taken out from the end of the jaw-bones to the palate, cutting away the roof of the mouth, and that the brain should be removed through the opening thus made; and he advised that the eyeballs should then be extracted with the aid of a pair of forceps through the same opening in the base of the skull. The skull and the skin of the body should then be everywhere carefully dressed with arsenical soap, and the head turned back by means of a little gentle manipulation. Great care must be taken not to stretch the skin of the neck in pulling the head back into position; and the head and neck should always be drawn back towards the body before the skin is made up. Mr. Davison thus proceeded to make up the skin. Opening the bill, he put into the eye-socket, through the triangular cut made in the base of the skull, small tufts of pure white 


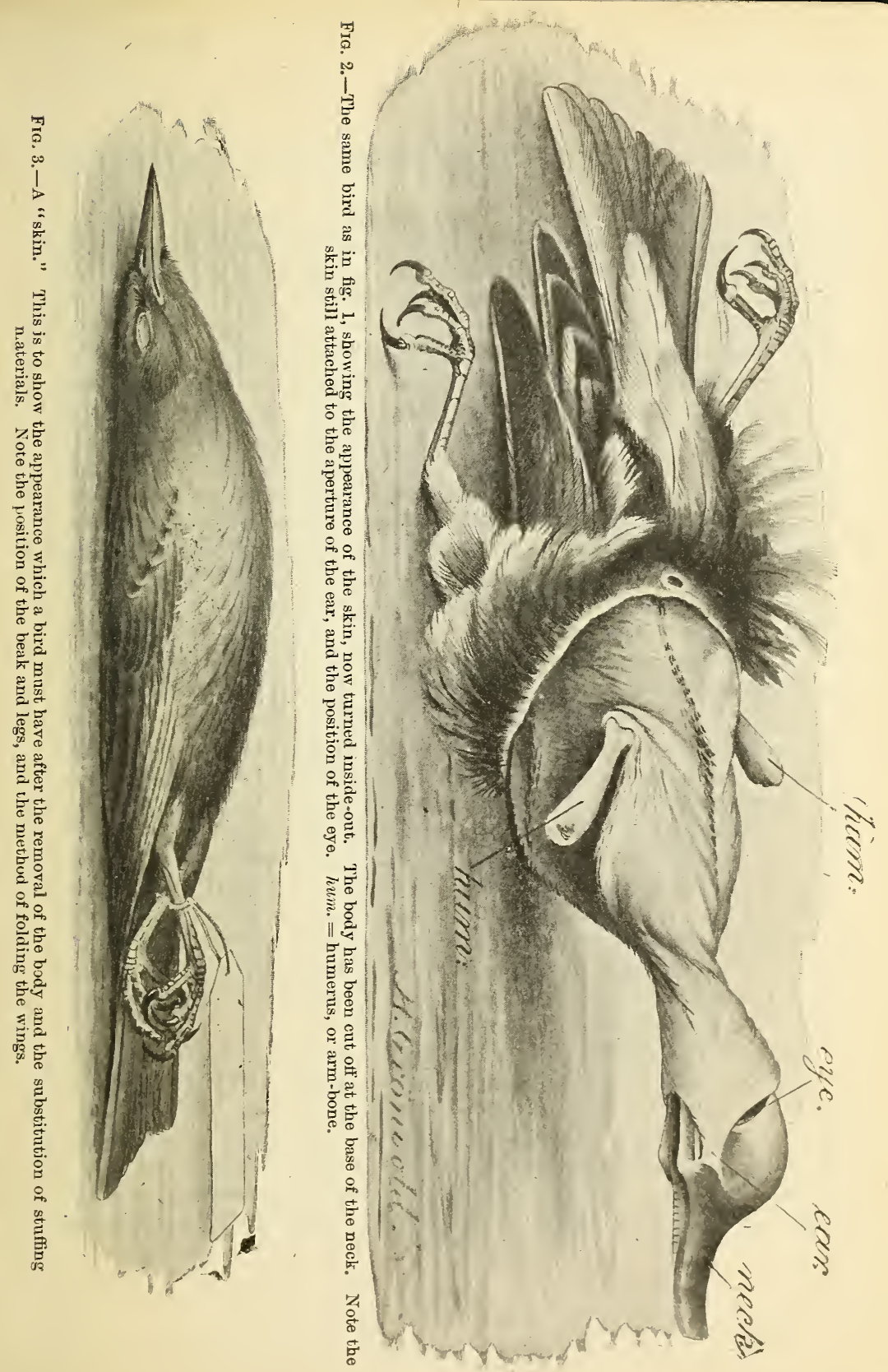




\section{INSTRUCTIONS FOR THE PRESERVATION OF BIRDS.}

bleached wool, which filled out the contour of each eye in turn; and this method has the advantage of filling out the eyelid, and bringing. into relief any eyebrow which may be a specific feature of the bird. This is certainly a great advantage, and conduces to the pretty appearance of the skin when finished. He next provided himself with a small stick (in very little birds a match will do), one end of which was sharply pointed. The length of the stick was proportioned to reach from the skull of the bird to the tail-bone, the part destined to form the neck being wrapped round with tow and then well covered with arsenical soap. Holding the skin by the beak, the artificial neck was then coaxed up the skin of the neck, and the sharp point firmly imbedded in the skull of the bird, while the other end of the stick was fixed against the tail-bone. This is an excellent plan for making skins which have to be packed and transported for a long distance, as the stick serves as a support and renders the head and neck less liable to be broken in transit.

Another method of filling the eyes and the neck is to put bleached wool into the sockets as soon as the head is ready for turning back; and a neck of tow is made (a little larger than the natural one), and rammed tightly into the skull. Then the skin is pulled back over the artificial neck of tow, which has been well anointed with arsenical soap. By pulling the tow neck back towards the body, the head and neck can be well drawn in. Our own experience is that Mr. Davison's way of filling out the eyes with wool from the palate has the best results, and disturbs the set of the eyelid less than the last-mentioned method; but the collector will soon find out in which way he can produce the best results. In no case should the eye-socket be filled in from the outside after the skin of the head has been restored to its proper place, as the eyelid is sure to be destroyed or forced inwards, and the appearance of the skin will suffer.

Before filling in the body of the bird, it is very important that the set of the wings should be attended to, so that the skin may not become lop-sided. Running parallel to the two bones of the humerus, as the skin lies on its back, will be found two broad rough patches of fat on the back of the bird, marking feather-tracts. If the two humeri are laid along these patches, and kept in position by a little wool laid upon them, it will be found that the wings will fall naturally 
into their place, and will not move. It is also well to take a fine needle, and gently lift the skin of the crown and sides'of the hand, so that the ear-coverts fall into their natural position. Then the body of the bird can be filled in with wool or tow to its natural size, and finally wrapped round with a thin layer of cotton-wadding, and left to dry.

The two mandibles of the bill should be restored to their exact position as in life, and either tied together with cotton (not through the nostrils) or fastened by means of a tiny piece of cobbler's wax placed in the tip of the upper mandible.

It is advisable to unwrap all the skins the next day to see that the feathers are smooth and the wings are in position, before they are finally laid in their tin case for transmission to England. To each specimen should be attached a small label with the locality, date, altitude, and sex clearly marked on one side, and, on the other, the colour of the bill, feet, and iris. The plan adopted by some collectors of attaching a number to the specimen and keeping a corresponding entry in a book is not to be recommended, as, if the number or the book gets lost, the history of the specimen is lost also. 


\section{HOW TO DETERMINE THE SEX OF A BIRD.}

T'He body having been removed from the skin, make a long incision down one side with a pair of scissors, and gently force the cut edges apart; then with the handle of a scalpel force the intestines gently away so as to expose the wall, or rather the roof, of the cavity in which they rest. If there is much blood, wash it away with a little water, to which, if possible, should be added a little salt. All this must be done very gently: the water should be poured in, and then soaked up by a piece of sponge; or if this is not to be had in the field, drain off the water by overturning the body. Never use the sponge to rub with. As soon as the roof of the body-cavity is thoroughly exposed, the sexual organs may be sought for, but, except in the breeding-season, the search must be conducted with much care.

Attention must first be directed to an examination of the organs lying at the upper end of the kidneys, which are the dark red masses forming the roof of the cavity.

In the male will be found two egg-shaped, white, or sometimes black bodies lying side by side, just over the arch formed by the convergence of two large blood-vessels, which can be seen running up from the tail end of the kidneys - these are the testes (fig. 4, t.). In the breeding-season there can never be any doubt about these; but in young birds, and in old ones also after the breeding-season, the testes can often hardly be made out. In such cases the greatest care must be taken lest two other small yellowish bodies, known as the "adrenals" or "suprarenals" (fig. 4, s.r.), lying a little higher upat the extreme erlge of the front border of the kidney-be mistaken for the testes. 


\section{HOW TO DETERMINE THE SEX OF A BIRD. 31}

In the female, in the breeding-season, on the left side of the body, in a position corresponding to that of the testes of the male, there will be found a large yellowish mass, made up of eggs of various sizes, from tiny granules to a full-sized yolk (fig. 5, ovy.). Earlier in the year the mass is granular only, and of course much smaller,

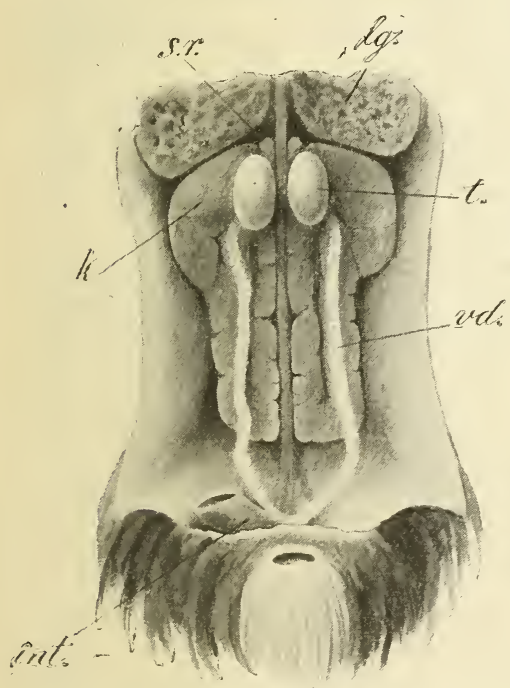

FIG. 4.-A portion of the body-cavity of a bird exposed to show the position of the male sexual organs. s.r. suprarenals, or adrenals ; $t$. testes ; $k$. kidney ; $v d$. vas deferens, or sperm-duct ; int. intestine.

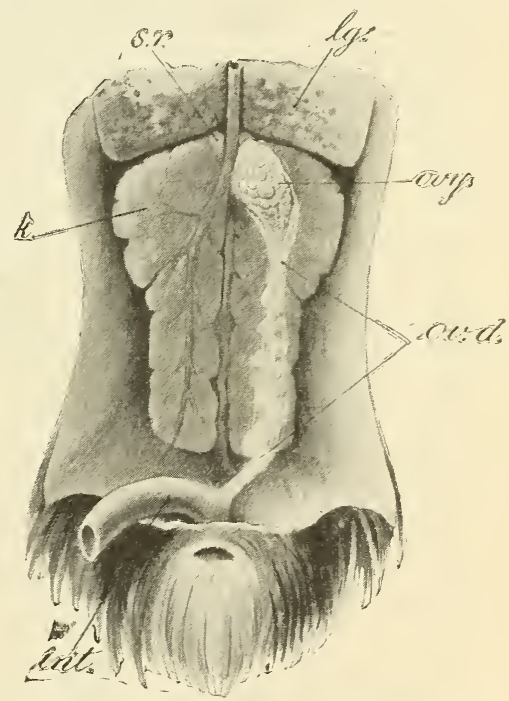

FIG. 5.-A portion of the body-cavity of a bird exposed to show the position of the female sexual organs. $l g$. lung; $k$. kidney; ovy. ovary; ov.d. oviduct.

sometimes extremely small. If the ovary has been destroyed by shot, or is, as often happens, but slightly developed, look carefully on the left side of the body for a long and more or less coiled tube (the oviduct), one end of which-that towards the head-is free, the other joined on to the intestine, quite close to where it leaves the body (fig. 5, ovd.). A vestige of a similar small tube will be found in the 
corresponding position of the opposite side, but this is very short. Reference to the figures should make this quite clear. As it is often of the greatest importance to determine the sex, and there may be still some uncertainty after the above directions have been followed, place the body in a dish of salt and water-salt is advisable, but not absolutely necessary--hold it down on one side, and look into the cavity through the cut; the oviduct will probably now float up quite separate from the intestines.

In the male there can generally be traced, from the testes backwards to the end of the gut, a pair of neatly and closely coiled tubes on either side of the body, of a glistening white colour (fig. $4, v d$.). These, in the absence of distinct testes, will serve to identify the sex as certainly as the presence of an oviduct in the female.

Unless the sexual organs can be recognized without any doubt, it is better not to mark the sex on the label. If, however, it has been certainly determined, write it down at once. $\delta$ is the sign for male, and $q$ for female. 


\section{INSTRUCTIONS FOR COLLECTING REPTILES, BATRACHIANS, AND FISHES.}

\section{I.-REPTILES AND BATRACHIANS.}

REPTILES should be preserved in spirit whenever practicable.

Spirit.-The collector should provide himself with the best and strongest alcohol procurable. This can be afterwards diluted with water or with weaker spirit, until it is reduced to the degree of strength required in each case. As the collector would often have difficulty in obtaining spirit while travelling, he is advised to take ic sufficient supply with him. Methylated spirit may be recommended on account of its greater cheapness; but specimens do not keep nearly so well in this liquid, and it should not be used for the preservation of particularly valuable specimens, or such as are intended to be used afterwards for anatomical investigation. In default of spirit the collector may use arrack, brandy, rum, or any other spirituous liquid which he can procure, provided it possesses the requisite strength. Any spirit which takes fire immediately on the application of a light, without having been previously warmed, is strong enough to be used for the preservation of animals.

The following is a simple method of diluting alcohol to any desired per cent. :-

Of alcohol of known per cent. take the number of cubic centimetres represented by the figures in the required per cent., add enough water. to bring the whole up to the number of cubic centimetres represented by the figures in the known per cent. The mixture will be of the required per cent. To illustrate:

To rnake $50 \%$ alcohol from $95 \%$ alcohol, add to 50 c.c. of $95 \%$ 
alcohol enough water to make 95 c.c. The result will be 95 c.c. of $50 \%$ alcohol.

'To make $40 \%$ alcohol from $70 \%$ alcohol, add to 40 c.c. of $70 \%$ alcohol enough water to make 70 c.c. The result will be 70 c.c. of $40 \%$ alcohol.

If one of these illustrations is firmly fixed in the mind, one can, working by analogy, make up very quickly alcohol of any desired per cent. without laborious calculation or reference to tables. Larger or smaller quantities than those indicated in the illustrations can be made by using different units of measurement, or by multiplying or dividing those quantities by the proper number.

However, the collector is recommended to provide himself with one or two of those simple instruments, hydrometers or alcoholometers, with which chemists and distillers test the strength of spirit. By this means it is easy to ascertain whether the spirit is fit for use. Spirit in which specimens are finally packed for transmission should be $15^{\circ}$ or $20^{\circ}$ above proof.

It is sometimes found advisable to mix some emetic, crushed colocynths or other disagreeable ingredient, with the spirit, in order to deter pilferers from appropriating it.

A collector who resides in a locality for some time would find a small distilling-apparatus extremely useful, with which he could redistil his supply of weak or foul spirit, or the bad liquor sold to him as rum, and thus bring it to the proper strength.

Cases and Vessels. - The most useful are four-sided zinc boxes, 18 inches high and 12 inches by 6 broad. On the upper surface they should have a round opening of 4 inches diameter, which is closed with a screw cover : to fit tightly, a ring of rubber or leather is fastened round its margin. Each of these zinc boxes should be placed in a closely fitting wooden case, with a lid secured by hinges and a bolt, and furnished on two opposite sides with a handle of leather or rope.

The traveller will require from two to four of these cases, using them for the reception, and first immersion in spirits, of specimens obtained from day to day. The specimens should be kept in them for some time, and repeatedly examined until the case is full, or the 
specimens are ready to be finally packed. The spirit, which gets weaker with every specimen immersed in it, has to be renewed occasionally. These cases are very convenient and practical; but they can be replaced by simpler arrangements, such as common earthenware jar's closed with cork or rubber. 'The conditions which any such vessels ought to fulfil are: (1) that they are spacious; (2) that they have a wide opening; and (3) that they can be closed tightly so that the spirit cannot evaporate, but yet that they can easily be opened at any moment.

Specimens which are to remain permanently packed or to be sent home should be placed in zinc cases, of varying sizes, with closely fitting wooden outer covers. But these cases must not be made too large, because the specimens might suffer if the pressure of the contents was too great, and because the risk of damage to the cases themselves increases in proportion to their size. Such a case ought not to have a greater internal capacity than 18 cubit feet at the utmost; and when the specimens require the length of the case to be increased, the depth or breadth must be reduced in proportion. The traveller may take a certain number of cases ready made with him, packing them with articles needful for the journey; or, to savespace, he may take only zinc plates cut to the proper size, which he can put together when required: the wooden outside boxes may be obtained almost anywhere. But under all circumstances he must provide himself with a soldering-apparatus, after having learnt its use. A pair of shears for cutting the zinc is also useful.

Wooden casks are unsuitable, especially in hot countries, for the transport of specimens in spirit. They should not be employed, except in cases of necessity, or for packing large or salted specimens.

Very small specimens, or those which are specially liable to be damaged, must not be packed with larger ones, but must be kept separately in small bottles or jars. In closing these, sealing-wax should never be used, as spirit readily dissolves it.

Method of preserving. - All reptiles-except large Turtles, Crocodiles and Alligators above 4 feet lorig, and Snakes above 10 feet longare suitable for preserving in spirit. A deep incision should be made in the region of the stomach, and a second at some distance 
before the vent, so that a portion of the contents of the stomach and intestine, which might conduce to putrefaction, is emptied out, and the spirit is allowed free access to all internal parts. The specimens are then placed in one of the preparatory vessels or boxes described above. In a few days (or in hot climates after not more than one or two days) the specimens must be removed to a second vessel containing stronger spirit, and must remain there from eight to fourteen days. If they then appear to be sound and well preserved, they may be left in the same spirit till the time comes for finally packing them; but if they are soft and flabby, and discharge mucous matter discoloured with blood, they must be placed for a longer or shorter time in fresh spirit at least $10^{\circ}$ above proof. Specimens which show distinct signs of putrefaction must be thrown away, as they endanger the whole contents of the box. Similarly, specimens which are already decomposing when obtained must not be taken for preserving unless disinfected by a solution of chloride of soda (a tablespoonful of the solution in one pint of water) poured into the mouth and injected in the stomach.

Of course the spirit which is used in this preliminary process becomes weaker and weaker. So long as it is $15^{\circ}$ under proof (or $10^{\circ}$ in hot climates) it can still be used for the first stage of preservation. If it sinks below this strength, it is of no further use to a collector who has not the means of redistilling, unless he filters it through powdered charcoal, and then brings it up again to the needful strength by the addition of very strong alcohol. Sediments on the bottom of the vessel or contaminated and badly smelling spirits are better thrown away.

As soon as the collector has accumulated a sufficient quantity of well-preserved specimens, they should be sent home at the earliest opportunity. For transport home they must be wrapped separately in old unstained linen or paper, and packed as tightly as possible. No empty space should be left in the cases above or at the sides, so that the contents may receive no injury from the unavoidable shaking during transit. When the case is full, the cover is soldered down, after a hole of about half an inch in diameter has been made. The case is then filled through the hole with spirit $20^{\circ}$ above proof, and care must be taken that all the air is driven out by the liquid; when 
this is ascertained, a small square piece of zine is soldered over the hole. In order to make quite sure that the case is securely closed, it is turned upside-down, and left thus for the night, when it soon becomes manifest if any leak exists.

\section{Preservation of very Large Rieptiles.}

1. Tortoises and Turtles.-It is no easy matter to kill a large Tortoise or Turtle which is to be prepared for a collection. The traveller will perhaps consider whether it may not be possible to bring the animal to Europe alive, as it can live for ten or twelve months without food in some corner of the ship. If this is impracticable, a long knife should be thrust into the base of the neck in the direction of the heart, in order to sever some of the large blood-vessels. Both the skeleton and the skin of the same individual may be preserved; but if one or the other has to be sacrificed, it is of more importance to preserve the former. First the abdominal shield must be removed by sawing through the narrow isthmus on each side, and then carefully loosening with a knife the skin which is attached to the bone in front and behind. A straight cut is made along the middle of the skin from the chin backwards; and after the skin has been turned aside to the right and left, it is easy to remove all the soft parts, as well as the greater part of the muscles of the neck, extremities, shoulder-blades, and pelvis. The head is the only part which is troublesome, as, in removing the soft parts, skin and bones may be easily injured. If the skin is to be preserved, as well as the carapace and the bones, the whole of the inner surface must be painted with arsenical soap. Finally, all the parts are bent back into the hollow of the carapace, and allowed to dry in that position. When they are dry, the plastron is restored to its natural position, and is retained there by tying a string round the carapace. This method may also be adopted in the case of small Tortoises, if the traveller has to be very economical with his supply of spirit; otherwise small Chelonians can be placed bodily into spirits.

2. Crocodiles and Lizards. - In the case of large Crocodiles and Alligators, it is impossible to preserve both the skin and the skeleton 
of the same individual. To prepare the skin, it must be cut through along the middle of the under side from the chin to the end of the tail. Care must be taken not to damage the skull, so that this part at least may be saved, in case the skin should happen to be spoiled. The inside of the skin should be brushed over several times with a strong solution of alum, to which a few grains of corrosive sublimate have been added.

It is rather strange that perfect skeletons of large Crocodiles and Alligators are somewhat uncommon in collections. The Gavials of India and of the larger islands of the Easter'n Archipelago (Sumatra or Borneo, for example), and also the narrow-snouted Crocodiles of North Australia, are particularly valuable to palæontologists and zoologists. The collector should endeavour to procure skulls and skeletons of these reptiles of different ages. In preparing such a specimen for a skeleton, the bulk of the flesh is cut off the bones, and the bones themselves are left in their natural connection. The body is then divided into several portions of a convenient size for packing. These reptiles possess "abdominal ribs," which are unconnected with the rest of the skeleton and inserted in the muscles of the abdomen. In order to preserve them in their entirety, the skin of the abdomen, with the muscular layer attached to it, is cut away in toto and dried, to be macerated at home.

In the case of the South American Alligators the collector should endeavour to preserve the external dorsal and ventral plates of each specimen in their natural connection, as the correct determination of the species cannot be otherwise secured.

3. Snakes of a greater length than 10 feet cannot be preserved in spirit; and Pythons and Boas, which have a comparatively large girth, are unsuitable for this mode of preservation if they approach the size mentioned. They must therefore be skinned, but not in the manner frequently adopted, by making a short cut behind the head and then skinning the animal like an eel, as thus the scales are too much injured. The animal should be split open along the whole median line of the belly and tail with a pair of strong scissors, and the skin be removed with a knife from the line of the cut towards the back. A skin thus prepared does not occupy much space, and, 
if circumstances permit, is better preserved in spirit than dry. Of course the head requires then no further preparation.

Large Pythons and Boas are so frequently brought to Europe alive that most museums have opportunities of obtaining good skeletons; and therefore it is not worth while for a traveller to preserve them, unless they are of a size to verify reports in which Pythons exceeding 25 feet and Anacondas of over 30 feet are mentioned.

The attention of the traveller may be called to a few other points.

The determination of the large River-turtles (Trionyx) which inhabit the fresh waters of Asia and Africa is a matter of considerable difficulty and uncertainty, which cannot be dispelled except by collecting afresh large numbers of all the species without exception. The traveller should try to obtain as many specimens as possible of all ages, with their exact localities, and always with the skulls. It would also be particularly interesting to receive specimens taken in copulâ.

Collecting Sea-turtles seems little likely to lead to important results. However, very large specimens of the Leathery Turtle (Dermochelys), and more especially its skeleton, are much sought for by museums. It would also be important to obtain embryos in the shell in different stages of development.*

Comparatively little is known at present of the habits and mode of reproduction of Lizards ; and when the traveller has an opportunity of observing any of these animals for some time, he should note down everything which appears to him remarkable.

Of Snakes it is urgently recommended that the small and obscurely coloured species should be searched for. Many of these live habitually underground, or are nocturnal animals which can only be obtained by digging up the soil or by searching for them among decaying substances. The Sea-snakes are very numerous in species and varieties, and should receive special attention. The collector should obtain all the specimens he can (except the common Platurus and IIydrus); but he must be careful to note the exact locality,

* Embryos of all species which are enclosed in egg-shells should be preserved in the strongest spirit, after several holes have been pierced in the shell, in order to empty it of the fluid portion of its contents. 
respectively the latitude and longitude, where each specimen was obtained. Some of the Sea-snakes found to the north of Australia attain to a considerable size, and it is desirable that the traveller should preserve even the largest in spirit. Such specimens require to be immersed for a comparatively long time in strong spirit, which should also be changed several times.

Many Snakes are adorned with very bright and variegatcd colours during life, which disappear after death. If the traveller is a draughtsman, and can spare time, he should make a sketch of the Snake, and indicate the colours which it presented during life, so far that a complete drawing of the species can afterwards be made with the assistance of the sketch.

\section{BATRACHIANS.}

The majority of Frogs and Salamanders and their larvæ are covered with a very soft skin; they should be placed in weaker spirit than reptiles, in order to prevent the shrinkage of those parts which are particularly soft. Although spirit of $10^{\circ}$ under proof may be used for the first few days, it is necessary to examine the specimens every day, as the intestinal canal frequently contains much food and water. The spirit must be changed three times at least, and often still more frequently, and finally replaced by spirit $5^{\circ}$ or $10^{\circ}$ above proof. There are many remarkable facts connected with the reproduction and sexual relations in this class of animals. If the traveller has an opportunity of observing examples of one or more species during the breeding-season, he should, if possible, obtain eggs, watch their development, and collect larvæ in different stages of growth. Larvæ correctly identified as to species are most valuable for the study of these animals, while those of whose origin nothing is known are almost always worthless.

\section{II.-FISHES.}

The treatment of fishes which are intended for preservation in spirit is very similar to that of reptiles and batrachians. The same kinds of spirit and cases may be userl; but it is advisable to 
keep fishes, batrachians, and reptiles separate, at least during the preliminary stages of conservation. It must always be remembered that fishes contain much more water than reptiles, and consequently the spirit employed becomes diluted much more rapidly and requires to be changed more frequently. In the case of comparatively large ( 2 feet long) and very fleshy fishes, the spirit penetrates very slowly into the interior; and although the specimens may appear to be in the best condition externally, the inner layers of muscle above and around the vertebral column may be decomposing. It is therefore necessary to make several deep incisions in the muscular part of the back and tail in addition to those made along the abdomen. Fishes which are loaded with fat, either in the muscles or liver or abdominal cavity, should be placed by themselves in very strong spirit until the greater portion of fat is extracted; to accelerate this process, the liver should be deeply incised and the masses of fat in the abdominal cavity removed. Before being placed in spirit, the fish should be washed in water to remove as much as possible of the slime with which it is usually coated.

Fishes which have lost their scales should not be kept; such as lose them easily, like the Clupeida, should be wrapped in a piece of paper or linen before they are put in spirit.

It occasionally happens in hot climates that, from some cause, the collector cannot succeed in preserving his specimens from decomposition even with the strongest spirit. In such cases it is advisable to add some arsenic or corrosive sublimate to the spirit; but the traveller should inform his correspondents that he has adopted this mode of preserving.

If the colour of the flesh is remarkable, the traveller is recommenderl to take a coloured sketch before skinning it. It is generally important that coloured drawings made from life should accompany a collection; drawings the originals of which have not been preserved at the time have only a subordinate value.

Dried skins of fish admit only of a superficial and incomplete examination, and are easily damaged. This mode of preservation, therefore, should only be adopted when it is impossible to obtain a sufficient supply of spirit and cases, or when there are no facilities for transpor ting heary boxes. 
The traveller is urgently recommended to collect the largest specimens of a species which he can procure. If they are too large for preservation in spirit, they must be prepared as skins. Scaly fishes are skinned thus:-With a strong pair of scissors an incision is made along the median line of the abdomen from the foremost part of the throat, passing on one side of the base of the ventral and anal fins, to the root of the caudal fin, the cut being continued upwards to the back of the tail close to the base of the caudal. The skin of one side of the fish is then severed with a scalpel from the underlying muscles to the median line of the back; the bones which support the dorsal and caudal fins are cut through, so that these parts remain attached to the skin. The removal of the skin of the opposite side is easy enough. More difficult is the preparation of the head and scapulary region; the two halves of the scapular arch, which have been severed from each other by the first incision, are pressed towards the right and left, and the spine is severed behind the head, so that now only the head and shoulder-bones remain attached to the skin. These parts have to be cleaned from the inside, all soft parts, the branchial and hyoid apparatus, and all smaller bones being cut away with the scissors or scraped off with the knife. In many fishes which are provided with a characteristic dental apparatus in the pharynx (Labroids, Cyprinoids), the pharyngeal bones ought to be preserved and tied with a thread to the specimen. The skin being now prepared so far, its entire inner surface, as well as the inner side of the head, is rubbed with arsenical soap; cottonwool or some other soft material is inserted into any cavities or hollows; and, finally, a thin layer of the same material is placed between the two flaps of the skin. The specimen is then dried under a slight weight to keep it from shrinking.

The scales of some fishes-as, for instance, of many kinds of Herrings-are so delicate and deciduous that the mere handling causes them to rub off easily. Such fishes may be covered with thin paper (tissue-paper is the best), which is allowed to dry on them before skinning. There is no need for removing the paper before the specimen has reached its destination.

Large scaleless bony fishes, such as the Siluroids and also the Sturgeons, are skinned in the same way; but as their scaleless skin 
can be rolled up, they can be packed in spirit, which saves the traveller the trouble of cleaning the head.

Skeletons of large bony fishes are quite as valuable as the skins. In order to prepare a skeleton, it is only necessary to remove the soft parts of the body-cavity and the larger masses of muscle, leaving the bones in their natural continuity. The rest of the flesh is left to dry on the bones, as it can be removed afterwards by maceration at home. As the bones which support the ventral fins are not attached to the skeleton, but lie between the muscles, care must be taken that they are not lost or damaged. All the fins are preserved as in the preparation of a skin; and, in the cases of scaly fishes, so much of the skin should be preserved as is required to identify the species, as without this it is generally impossible to do more than determine the genus. For morphological investigations a skeleton which is thus simply dried is not sufficient. For this purpose the skeleton, or at least the head, must be preserved in strong spirit after removal of the large masses of muscle.

Some Sharks attain a length of 30 feet, and some Rays a width of 20 feet; and, according to very reliable reports, they may even exceed these limits. It is extremely desirable to obtain such gigantic specimens for museums. Sharks are skinned in nearly the same manner as bony fishes. In Rays it is not sufficient to make only one longitudinal incision from the tip of the snout to the end of the fleshy part of the tail, but a second transverse cut has to be made across the broadest part of the lower surface of the body. Besides this, other incisions which are necessary for removing the soft parts can be made on the under surface of the fish, and the collector need not be over-particular in this respect. After the removal of the soft parts, the skin is put into a barrel filled with concentrated brine, to which some alum has been added. The head, to which still many soft parts are attached, should be kept at the upper end of the barrel, so that it can be kept constantly under observation. When the liquid is perceptibly diluted by the extraction of water and blood, it must be renewed in toto. Finally, the skin is removed from the barrel, spread out, and the fluid allowed to drain off ; its whole inner surface is covered with a thin layer of dry salt; it is rolled up (this time with the head inside), and packed 
tightly in a barrel with a layer of salt at the bottom, all the interstices being filled up with salt. The barrel itself must be water-tight. Specimens too large for being packed in barrels should receive a thorough dressing of salt and alum, after removal of the whole of the cranium with all the soft parts adhering to it; they can then be dried and folded into a package of manageable size.

In the case of all specimens which are preserved dried or salted, the various dimensions of the animal must be carefully noted, and a sketch of the head should be made, to enable the taxidermist to mount the specimen with its proper proportions.

None of the marine fishes are more interesting than those which live habitually in the open sea and only rarely approach the coasts (pelagic fishes), and those which are adapted to living at great depths and never come to the surface (deep-sea fishes). The latter can only be obtained with the aid of a ship specially fitted out for exploring the fauna of the deep sea. Collectors who are restricted to their own and limited resources can hardly do more than dredge or trawl in depths of from 100 to 200 fathoms. However, two other modes of collecting deep-sea fishes may be recommended. One of them is in actual use by the fishermen of the Portuguese coasts and of Madeira, who employ a strong line (long-line, spiller, trot), sometimes as much as 800 fathoms long, with a weight at one end, and supporting-hooks of rarious sizes on thinner short lines (snoods), which are fastened to the main line at regular distances of 1 or 2 fathoms; in fact, a long line such as is used in cod-fishing. The second method would be to sink baskets constructed of withes or galvanized zinc, like lobster-pots, ${ }^{*}$ and to examine them after twelve or twenty-four hours.

The majority of deep-sea fishes are so fragile that their preservation requires special care; they should be wrapped in linen, and kept singly, or only a few specimens together, in a separate jar. A long cut should be made in the abdominal cavity, and strong spirits of wine (from $20^{\circ}$ to $30^{\circ}$ above proof) should be used to ensure the preservation of the internal organs.

* 'These baskets are dome-shaped with flat bottoms, of from 2 to 3 feet in riameter, and with an opening 6 inches in diameter sloping inwards from the top. The bait is fixed opposite to, and somewhat sideways of, the opening. 
No opportunity should be lost to obtain pelagic forms, especially the young larvalike stages of development abounding on the surface of the open ocean. They can be obtained without difficulty by means of a small narrow-meshed net dragged behind the ship. The sac of the net is about 3 feet deep, and fastened to a strong brass ring 2 or $2 \frac{1}{2}$ feet in diameter. The net is suspended by three lines passing into the strong main line. It can only be used when the vessel moves very slowly, the speed not exceeding 3 knots an hour, or when a current passes the ship whilst at anchor. To keep the ring of the net in a vertical position, it must be weighted at one point of its circumference; and by using heavier weights two or three drag-nets can be used simultaneously at different depths. This kind of fishing should be tried at night as well as in the daytime, as many fishes come to the surface only after sunset. The net must not be left long in the water, from five to twenty minutes only, as delicate objects are sure to be destroyed by the force of the water passing through the meshes.

By the examination of the contents of the stomachs of large fishes (Tunnies, Dolphins, etc.) caught in the open sea, rare forms can be discovered. Objects found floating on the open sea, such as pieces of wood, baskets, larger or smaller masses of weed, etc., deserve the collector's attention, as small fishes and marine creatures of all kinds generally swarm round them. Shallow banks situated at a considerable distance from land are likely to yield a valuable store of fishes of all kinds, which may be obtained either with hook and line or with the above-described fish-baskets.

The latitude and longitude should be carefully noted in the case of all specimens obtained in the open sea.

It may be useful to conclude these instructions with drawing the attention of the traveller to a few points on which information is particularly desired.

Important information may be gathered relating to fishes which either are actually used as food (fresh or for exportation) or which may become an important article of trade. The following fishes, therefore, deserve special attention : the Sturgeons, the species of Gadus, the Thyrsites, the Chilodactylus of the Southern Seas, the Tunnies and Sword-fishes of the Indo-Pacific, the Salmonids, the Clupeids, etc. 
On the other hand, it is well known that the flesh of various seafishes possesses poisonous properties, either constantly or at certain seasons or in certain localities. Observations should be made on the causes of these properties, on the nature of the poison, and its operation on other animals.

Other fishes, the flesh of which is quite harmless or even well flavoured, are armed with special poison-organs. It would be very desirable to investigate this poison in fresh fishes, and to experiment with it as to its effect on other fishes.

All observations relative to sex and propagation are of interest; observations on secondary sexual differences, hermaphroditism (whether normal or abnormal), the numerical relation of the sexes (whether monogamous or polygamous), spawning, and migrations ; nest-building, care for the young, etc. The ova of pelagic fishes, many with peculiar appendages on the outer integument, are frequently met with floating on the open sea, sometimes singly and sometimes in clusters. Every opportunity of observing their development, and of tracing the stages of growth of the young fishes, should be taken advantage of.

As long as a species of fish is allowed to exist in a district without molestation, it attains to a much greater size than subsequently, when it is diligently sought after, and when none of the individuals are allowed to reach their full growth. On this ground alone it is desirable to collect the largest individuals; but if the traveller is unable to preserve them, he should at least record their length and weight.

In hot countries, where the streams and ponds are liable to dry up, many fishes are compelled to temporarily breathe air, or travel considerable distances overland, or fall into a state of torpidity. Observations on such habits, which are verified by the traveller himself, are of incomparably greater value than what he learns by hearsay from the natives. It would also be interesting to know whether the fishes of the Arctic and Antarctic zones are able to maintain life when enclosed in ice, and, if so, for how long.

Many pelagic fishes are provided with smooth white or pearly organs imbedded in the skin, which are small and round on the body of the fish, but larger and of various shapes on the head, especially 
REPTILES, BATRACHIANS, AND FISHES.

near the eyes, where they are sometimes of a pinkish or greenish colour. These are the so-called phosphorescent organs; and although their luminous properties are now generally admitted, it is desirable to obtain corroborative evidence as to their function from the living fishes, with special reference to the question whether the luminosity is subject to the will of the fish.

\section{Labelling of Specimens.}

It is most important that every specimen should bear an indication of the place, date, and circumstances under which it was collected, as well as the native name, if it can be ascertained. This is best done by keeping a notebook or diary, in which the entries are made, each entry bearing a number corresponding to a label attached to the specimen. Threaded parchment labels, a quarter of a square inch in size, are most suitable for the purpose, the numbers being inscribed beforehand in ink, which, when allowed to dry well, will not run. Pencil-marks are liable to become illegible through rubbing off. In the case of fishes a second label may be inserted under the left gillcover, as a precaution in case the threaded label should become detached and lost. 


\section{INSTRUCTIONS FOR COLLECTING INSECTS.}

In the following instructions the orders of insects are generally referred to by their scientific names ; viz.Bees.

Hymenoptera. Saw-flies, Gall-flies, Ichneumons, Ants, Wasps,

Diptera. Gnats, Daddy-long-legs, Horse-flies, House-flies, and other two-winged flies.

Lepidoptera. Butterflies and Moths.

Trichoptera. Caddis-flies.

Neuroptera. Termites (White Ants), Stone-flies, Ant-lions, Lacewings, May-flies, Dragon-flies.

Orthoptera. Earwigs, Cockroaches, Mantides, Phasmas, Stick insects, Crickets, Locusts, Grasshoppers.

Coleoptera. Beetles.

Hemiptera. Bugs.

Hoмoptera. Cicadas, Lantern-flies, Froth-flies, Aphides, Scaleinsects.

\section{Collecting Material and Apparatus.}

Nets, pill-boxes, glass tubes, cyanide killing-bottle, collecting-tin, collecting-bottle, strong knife or digger, lantern.

Pins, corked boxes, forceps (curved and fine), brushes, gum, card, round punch, pocket-lens, fine-pointed scissors.

Naphthaline in flakes, carbolic acid, chloroform, spirit. 
Nets of at least two kinds are necessary for general collecting: an umbrella-net for beating, sweeping, etc.; and a cane-net for catching insects on the wing. It is, however, desirable to have a large kite-net for catching butterflies, and a strong iron ring-net for water insects.

Pill-boxes of all sorts are useful, and common chip-boxes are very handy; but it is especially desirable to have as many glass-bottom boxes as practicable. To prevent these getting damp, they should have at least the top and edges painted with shellac or enamel paint.

Cyanide Killing-bottle.-This should be a wide-mouthed bottle. At

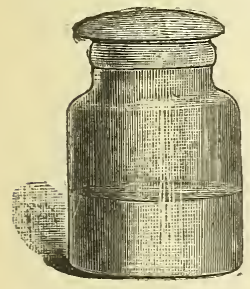

CYANIDE KILLINGBOTTLE.

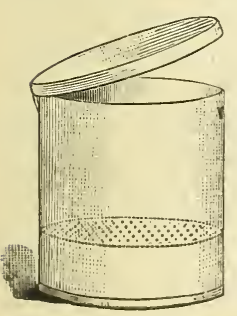

COLLECTING-TIN. the bottom put about 1 ounce of fused cyanide of potassium, then enough dry plaster of Paris nearly to cover it (filling in the interspaces), and on to the top of this pour some plaster mixed with water to the consistency of thick cream, to make about $\frac{1}{4}$-inch thickness over the cyanide. As some heat is generated during this process, it is well to stand the bottle in warm water to prevent it cracking. Besides this portable bottle it is well to have a larger jar, similarly made, for killing specimens when taken home.

Collecting-tin.-This is very useful for some purposes, It has a false bottom of perforated zinc. In the space at the bottom is placed some blotting-paper, with a few drops of chloroform or pure benzole. The insects are put into the upper part; and to prevent them rolling about, it is well to put some crumpled pieces of blotting-paper in first. 


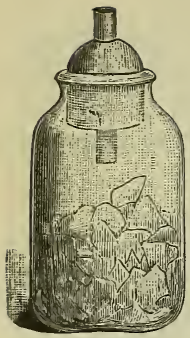

COLLECTING-BOTTIE.

Collecting-bottle. - This is a bottle specially made for entomologists. It is compressed, so that it may be carried conveniently in the pocket. It has a glass tube or large quill passed through the cork, fitted with a plug. It is very useful for collecting small Coleoptera, etc. A piece of crumpled muslin should be placed in it for the insects to cling to. The cork should be covered with sealing-wax on the inside to prevent insects burrowing into it.

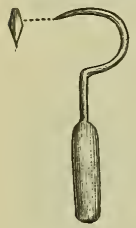

Trowel and Digger.-One or both of these are necessary for digging in the ground, for ripping off bark of trees, etc. A narrow fern-trowel answers best.

DIGGEk.

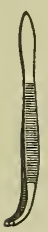

Forceps.--Entomological forceps are made with curved points for taking hold of pins : straight, fine pointed forceps for setting are very necessary; they should have very little spring, and are best made of brass.

FORCEPS.

Gum.-For gumming small insects on card some entomologists use gum-tragacanth, as it is less conspicuous; but it has the great disadvantage of being very difficult to wash off. Gum-arabic, with a very small quantity of powdered loaf-sugar and one or two drops of glycerine, is perhaps the best mixture. If pure gum-arabic is used, the insects are liable to spring off. The sugar and glycerine prevent this; but the latter must be used very sparingly, as it has a tendency to attract moisture, which is one of the entomologist's greatest foes.

C'ard.-A hard white card or two-sheet Bristol board should be used. Round Punch.-This should have a diameter of about $\frac{3}{4}$ inch for 
cutting out circles of card the use of which is explained further or A 20-bore gunwad-punch answers well.

Larva-preserving Apparatus.-This consists of spirit-lamp, small oven, and inflator. Instead of an oven a piece of copper gauze placed over the flame of the spirit-lamp answers very well. The whole apparatus can be obtained from entomological agents.

\section{Collecting.}

Besides those which may be caught on the wing with a butterflynet, insects should be looked for on flowers, under bark of trees, in rotten wood, in decaying animal and vegetable matter, under stones, under fallen leaves (where there is moisture), at the roots of grass and trees, in ants' nests, in ponds and streams. When circumstances permit, and small insects are being sought for in dead leaves, etc., the leaves should be sifted over a sheet of paper. If the insects appear numerous, the siftings should be put into a hollana bag, and examined at home. Many small insects which would be overlooked out of doors may be found in this way. Many insects are obtained by sweeping herbage with a net; others by beating trees while a large net or umbrella is held beneath.

Ground-beetles may often be caught by putting a piece of meat or bone in a pickle-bottle, and burying it so that the mouth is just on a level with the ground.

Moths, some beetles, and other nocturnal insects are obtained by painting patches of sugar on the trunks of trees, and looking for them with a lantern after dark. The mixture used should be made with brown sugar, beer, and a little rum. Apples cut into quarters, smeared with sugar and hung up, also attract moths.

Moths may also be caught by hanging up a sheet with a lantern behind it. They are attracted by the light, and, settling on the sheet, may be picked off with glass-bottom boxes or with the killing-bottle.

Some beetles and other insects may be obtained by hanging up skins of animals, or the carcases of small mammals or birds. Strangely enough, some butterflies are attracted in this way, as well as by strong cheese.

Killing.

Most insects can be easily killed by putting them into the cyanide- 
bottle; but care must be taken to see that the sides of the bottle and surface of the cyanide are not wet, as the more delicate insects are apt to stick to the surface and get spoiled. To prevent this when collecting Coleoptera and Hemiptera, the upper space may be partly filled with crumpled pieces of blotting-paper, among which the insects may bury themselves. This also prevents them rolling about and injuring one another. Under no circumstances should the specimens be left in the cyanide a moment longer than necessary. Cyanide changes the colour of some insects, green becoming yellow, yellow becoming red.

Coleoptera, Hemiptera, Orthoptera, and other non-hairy insects may be killed by throwing them into boiling water; but they must be taken out as quickly as possible, and placed on blotting-paper to drain off the water.

Butterflies may be killed by pinching the thorax laterally while the wings are in an upright position; but although this is necessary sometimes, it requires to be done with care, as it is apt to distort the body and render the specimens difficult to set.

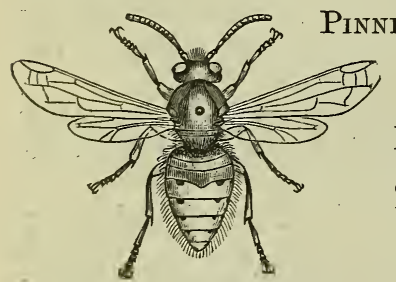

HYMENOPTERA,

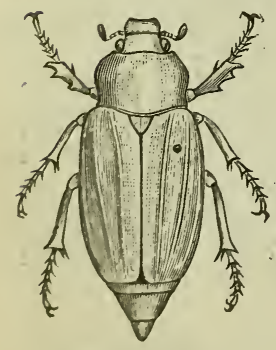

Coleoptera should be pinned through the right wing-case near the base, and in such a way that the pin comes out below behind the middle pair of legs. As a rule the pin should be equally distant from the base and the side of the wingcase. Neuroptera should be pinned through the middle of the thorax. The position of the pin is indicated in the illustrations by a black dot.<smiles>C1CCCC1</smiles> 
COLLECTING INSECTS.

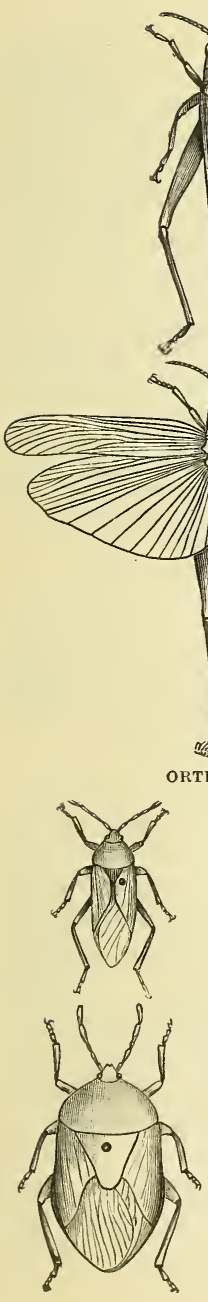

Orthopterc should be pinned in the middle, between the bases of the wings. Of course, if they are pinned without being set, the pin must pass through the wings; in which case it is better through the right wing. In some instances the pronotum is produced backwards, so as to cover a great part of the body; in which case the pin must necessarily pierce this part. In most cases it is desirable to have specimens pinned in both ways.

Hemipterc should as a rule be pinned through the right wing in the same way as Coleoptera; but where the scutellum is large, it is necessary to pierce this part a little to the right of the centre, so as to avoid any central spot or mark. When the wings are set out, the pin may be in the centre. 


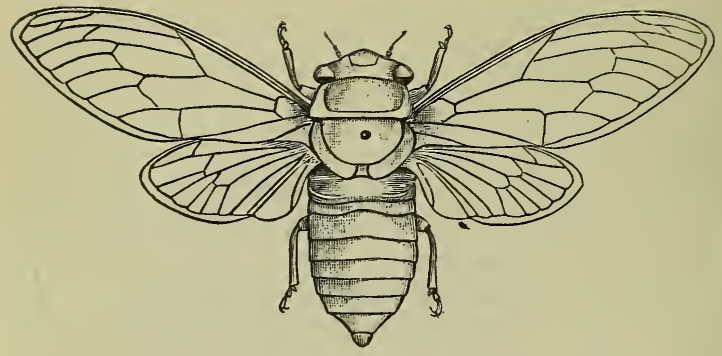

Homoptera.The Cicadas and other species with large mesothorax should be pinned through this part; others may be pinned between the bases of the wings, and some
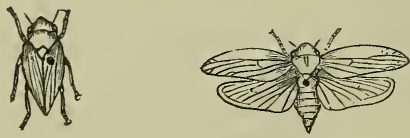
(if unset) through the base of the right wing.

HOMOPTERA.

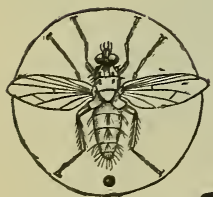

When pinning Hymenoptera and Diptera, it is very useful to use circular card dises of about $\frac{3}{4}$ inch in diameter, upon the under side of which the locality, date of capture, etc., can be written. After the insect is pinned, the pin is passed through the middle of the disc until the insect is within a short distance of the card. By this method the legs are not only protected and prevented from hanging down, but they can be spread out so as to be ready for examination. 


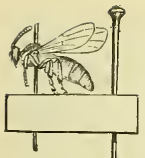

Staging.-This is a very convenient method of dealing with small insects, for which a very fine pin is used. The insect is pinned in the usual way, and the pin is passed through one end of a narrow strip of card, cork, or pith, and a strong full-length pin through the other end of the strip. In this way the smaller insects can be kept at the same level as the larger ones, and there is plenty of room on the longer pin for labels. A very suitable material for staging is a fungus called Polyporus, which is cut into strips and sold for the purpose by staging. dealei's.

Carding.—Small Coleoptera, Hemiptera, and some
other insects are most easily mounted by being gummed
on card. The card should only be sufficiently large to
carry the specimen safely, with just room to take hold
of the pin without risk of touching the insect. But
a better way is to place the insect across a very narrow
strip of card. This, although not quite so safe, has the
advantage of allowing some of the under side of the
insect to be seen. The specimen should always be on
the left hand of the pin when the head is turned from
the operator.

\section{Habits.}

Notes on the habits of insects, number of broods, whether common or otherwise, if taken singly or paired, are always of interest.

Nests, cocoons, and galls are of very small value, unless accompanied by the insect which constructs or causes them.

In collecting Termites, the kind of nest they were taken from should be noted, or photographs of the nest taken. Termites' nests with the specimens are much wanted. Specimens taken from one nest should be kept together, either in a tube or tied in a muslin bag. The same precaution should be taken with regard to the true ants (Formicidce). 


\section{LABELLING.}

Specimens should be distinctly labelled with the locality in which they were taken, date of capture, elevation, etc. It is also important to mention whether they were obtained during the wet or dry season. These particulars should accompany the specimens themselves, and not be merely noted in a book.

\section{LARVE.}

Persons residing in one place for any length of time can do great service by rearing insects from their larvæ. With many caterpillars this is often quite easy. Larvæ of unknown species, unless possessing some remarkable feature, are of very little interest.

Larvæ of Hymenoptera, Diptera, and Coleoptera may be killed in boiling water, and after remaining in it from one to three minutes (according to the size of the larvæ) may be preserved in spirit.

Caterpillars may be killed in the cyanide-bottle or collecting-tin, and the skins preserved as dry specimens by means of the "larvæpreserving apparatus."

The contents of the body are removed thus:-The dead larva is laid on a piece of blotting-paper, with the tail farthest from the operator; a pencil (or similar thing) is laid across the tail end, and the contents rolled out of that part: this process is repeated, each time placing the roller a little nearer the head, until the whole body is emptied. Care should be taken, by shifting the position of the larva on the paper, not to let the outside of the skin get wetted. The roller must not be too much pressed. A glass tube drawn out to a point is now inserted in the posterior opening of the skin, and held with the spring, and air is forced into it with the inflator, while the skin is held over the drying-apparatus or in the small oven. When dry the specimen is ready for mounting on a dry stem of grass or other suitable object. Care should be taken not to distend the skin unnaturally.

\section{Methods of sending Specimens Home.}

It is desirable to send home small consignments at a time, and the parcel-post should be used wherever this is practicable. Strong 
wooden boxes * travel very well in this way; but if pinned specimens are put in a box, it must be put into another rather larger one, with cotton-wool or other material firmly (but not too tightly) packed round it. Small boxes or bottles are always preferable to large ones, as an accident to one does not involve serious loss.

Boxes containing pinned specimens must of course be lined at the bottom with cork or thick pith, into which the pins may be stuck firmly; and it is desirable to pin a piece of sponge dipped in strong carbolic acid in the box, taking care of course not to let the acid run on to the specimens. Lumps of camphor or naphthaline are very dangerous in a box with pinned insects, and if used at all should be enclosed in a muslin bag, and very firmly fixed in the corner of the box.

For the transit of certain insects, such as Coleoptera, which have not been pinned, spirit may be used; but this should be avoided when possible. The best way is to use coarse sawdust from which all fine dust has been sifted. Some naphthaline should be mixed with the sawdust, or, when there is risk of the specimens becoming mouldy, carbolic acid should be used. The boxes or tins containing the specimens in sawdust must be quite filled, otherwise the insects are liable to be injured by shaking about.

When spirit is used, it is desirable to change it at least once after the specimens have been put into it, as the moisture from the insects weakens it. The spirit must bear a fair proportion to the bulk of the insects; in other words, too many specimens must not be put into one bottle. Any space left at the top of the bottle should be filled loosely with soft paper to prevent the insects shaking about in transit.

Cotton-wool must never be allowed to come in contact with insects, wet or dry. Too much stress cannot be laid on this point.

Bees, flies, and other hairy insects should never be put into spirit or sawdust.

Lepidopterc should be put into triangular envelopes with their wings folded together over their backs. These envelopes may be made thus: taking an oblong piece of paper (almost any sort will

* If cigar-boxes are used, care must be taken that they are strong enough, as they are otherwise apt to be crushed in transit. 
do), fold it as in fig. 1, then double one edge up, and the other down as in fig. 2. This makes them much more convenient for opening than if both edges are folded the same way. A stock of these of different sizes should be prepared ready for use.

These envelopes may then be packed in tins or strong wooden

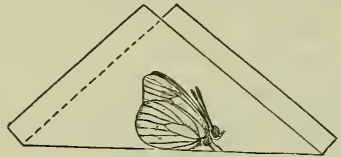

FIG. 1.

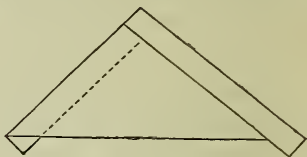

FIG. 2.

boxes, with some naphthaline sprinkled among them. If tins are used, extra care must be taken that the specimens are not damp when the tin is closed. Care must be taken not to crush the specimens by putting too many into one box; on the other hand, they must be sufficiently tightly packed to prevent them shifting about.

Neuroptera should if possible be pinned; but if this is impracticable, they may be put into papers in the same way as Lepidoptera; or they may be laid in chip-boxes, and kept from rolling about with chips of tissue-paper.

Orthoptera wanted for study of the structure may be put into spirit; but those intended for the dry collection are almost useless if they have been preserved in this manner. They should be dried quickly and put into sawdust. Sometimes they travel well in papers in the same way as Lepidoptera; but they must not be pressed. In the case of large-bodied species, such as Locusts, in a damp climate, it is advisable before doing this to make an incision with a pair of fine scissors along the under side of the abdomen, and, after emptying it of its contents, fill it.with cotton-wool.

Wasps and other smooth, non-hairy Hymenoptera may be put into sawdust. 
Bees should if possible be pinned, and sent home in corked boxes; but when this is not practicable, they should be put into pill-boxes, with some chips of tissue-paper to prevent them rolling about.

Diptera.-A few of the larger Diptera may be dealt with in the same way as bees; but as a rule they require special modes of treatment. 


\section{HOW TO COLLECT DIPTERA (TWO-WINGED FLIES),}

\section{WJTH NOTES ON THE HABITS OF THE PERFECT INSECTS AND LARV $Æ$.}

\section{List of ARticles Required.}

An entomologist's collecting-net.-This can be obtained from any dealer in natural-history apparatus. Any net used for collecting butterflies will do for Diptera ; but, on the whole, perhaps an ordinary umbrella-net will be found the most serviceable. One or two spare net-bags should be taken in case the one in use gets torn.

Two dozen glass-bottomed cardboard pill-boxes (assorted sizes, up to $2 \frac{1}{4}$ inches in diameter, packed in nests one inside another).*

* These boxes can be obtained from Messrs. Watkins \& Doncaster, 36 , Strand, London, W.C. ; but care should be taken to see that the bottomsand not the tops, as is often the case-are made of glass. Since the boxes are constructed of cardboard, they áre liable in tropical countries to go to pieces in the rains; and to prevent this they should be covered with jaconet in the following manner, the important point to remember being that the jaconet must be cut in strips on the cross:-Obtain, say, a square yard of the material, and fold it into a triangle by bringing two opposite corners together. Consider how wide the strips must be, according to the varying depths of the boxes to be covered, and rule them off in pencil by drawing lines parallel to the base of the triangle. Cut up the strips, or if possible get them cut by a bookbinder's machine. Paint the box over with liquid glue, and wrap the jaconet round it: it is particularly important that the edges of the glass and lid should be well protected; and it will be found that by gently pulling the jaconet it will wrap itself round these without difficulty. When quite dry, say the following day, the box should be given a coat of Aspinall's enamel, or of paint, 


\section{HOW TO COLLECT DIPTERA (TWO-WINGED FLIES). 61}

One or two cyanide killing-bottles, not too large to be carried in the pocket when required; or a larger-sized cyanide killing-jar, or materials for making same, as follows: $\frac{1}{4} \mathrm{lb}$. of cyanide of potassium, * $1 \mathrm{lb}$. of plaster of Paris, a glass jar with wide mouth and closely fitting lid. $\uparrow$

a second (and if necessary a third) coat of paint being added after the first is dry: Any paint or glue on the glass can be removed with a penknife; if the jaconet protrudes too far over the glass, cut it round with a penknife and remove it. (Glass-bottomed boxes already protected in this manner can be obtained from Miss E. M. Bowdler Sharpe, Entomological Agency, 345, Fulham Road, London, S.W.)

A simpler method of protecting the boxes is to coat them (especially the joints) with shellac dissolved in absolute alcohol.

Glass-bottomed boxes of this kind constructed of tin are sometimes sold; but these are not to be recommended, since when in use in warm climates they are apt to become very hot, with the result that flies contained in them are killed and become dry prematurely.

* If it is intended to take cyanide to a damp tropical climate, it should be conveyed in the form of lumps, in a bottle with a tightly fitting glass stopper. Cyanide of potassium is also sold in rods, and, in this form, might be conveniently carried in short lengths in hermetically sealed tubes of thin glass and diameter and length just sufficient to take the section of cyanide rod.

$\uparrow$ Cyanide killing-bottles can be procured ready for use from Hinton \& Co., Bedford Street, London, W.C., or any other chemist will prepare one to order; but when Diptera are collected in the manner advised below, it is preferable to use a large-sized killing-jar, which should be made as follows:-Take any fairly large glass jar (such as a pickle-bottle) with a wide mouth and closely fitting lid (a lever-lid such as those often fitted to pickle-bottles would answer admirably), and cover the bottom with a layer of dry plaster of Paris to the depth of $\frac{1}{2}$ inch; pour in above this a layer equal in depth consisting of powdered cyanide of potassium, mixed with rather more than its bulk of dry plaster of Paris; cover this mixture with a layer of dry plaster of Paris to the depth of $\frac{1}{4}$ inch or so; and pour in above the whole a layer $\frac{1}{2}$ inch in depth, consisting of plaster of Paris mixed with water to the consistency of cream. As soon as the top layer of plaster is dry the jar is ready for use : the plaster, however, should be covered with several thicknesses of blotting-paper, to avoid risk of injury to specimens in case the surface should at any time become wet. To obviate the danger of cracking the jar owing to the heat evolved xhen plaster of Paris is mixed with water, it may be advisable co stand the jar in warm water before adding the final layer. The exact amount of cyanide of potassium to be used is of no great consequence; but in 


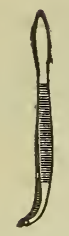

\begin{abstract}
Entomological forceps (two pairs), with curved ends for holding pins (from G. Buck, 242, Tottenham Court Road, London, W.).
\end{abstract}

ENTOMOLOGICAL

FORCEPS.

Fine-pointed forceps (one or two pairs): these are useful for arranging the legs and wings of specimens when pinned; they can be obtained with the above.

Needles (two or three) mounted in handles,-also for arranging legs and wings.

Entomological pins (D. F. Tayler \& Co., New Hall Works, Birmingham), Nos. 5 ( $1 s .6 d$. per ounce), 7 (2s. $6 d$. per ounce), and 20 ( $7 s .6 d$. per ounce). The No. 20 pin should be used for all but the very largest Diptera, such as Horse-flies (Tabanidæ) and Robberflies (Asilidæ); as it is exceedingly fine, an ounce will go a very long way.

Common pins - a thousand or two, in paper packets.

Gun-wad punches, Nos. 4, 12, and 20 bores (from any gun-maker), for punching discs of card.

Cards (3-sheet Bristol board), from which to punch discs; a supply of the latter should be prepared ready for use.

A platyscopic lens (Messrs. Baker, 244, High Holborn, London,

the case of a properly prepared jar the odour should be readily perceptible on removing the lid: if it is not, the reason may be that the mixture is too dry, when a little water poured on to the top layer will probably set matters right. After some months' use the cyanide loses its efficacy (to obviate this so far as possible the jar should never be allowed to remain open), and the mixture must then be renewed.

A rough-and-ready method of making a killing-jar or bottle is to cover the bottom with a layer of powclered cyanide, and to place above this a number of layers of blotting-paper. The layers of blotting-paper immediately in contact with the cyanicle must be slightly damped; but only sufficient water should be used to cause the cyanide to give off its odour. The top layer of blottingpaper raust on no account be wet, and the less water used the better. 
W.C. ; or John Browning, 63, Strand, London, W.C. : price about 15s.). The magnifying-power should not be too high-from 10 to 15 diameters is about the best.

Cork-carpet or pith.-Two or three sheets about 6 inches square, on which to perform the operations of pinning, etc. (Cork-carpet can be obtained at Harrod's Stores, Brompton Road, London, S.W.)

Two or three cork-lined entomological store-boxes. - These can be obtained from Messrs. Watkins \& Doncaster, or any other dealer in natural-history apparatus. For a collecting trip or expedition of some duration the boxes should not be smaller than about 18 inches by 12 , and they must be sufficiently deep to prevent the heads of the pins from coming into contact when both sides of the box are filled. Should the collector run out of store-boxes, cigar-boxes, in the bottom of which is fixed a layer of cork-carpet or pith, make efficient substitutes; but if pith is used, it should not be less than $\frac{1}{2}$ inch thick.

\section{How to distinguish Diptera from other Insects.}

Diptera may be distinguished from all other insects by the fact that they possess only one pair of wings. Thus, besides ordinary flies, such as Blue-bottles and House-flies (Muscidce), the order also includes Midges (Chironomidce), Gnats or Mosquitoes (Culicidce), Daddy-long-legs ('Tipulidke), Horse-flies (Tabanidce), etc.

\section{How to Distinguish the Sexes.}

In the majority of Diptera the sexes may easily be distinguished by the fact that the eyes meet together (or nearly so) on the forehead in the male, but are more or less widely separated in the female. With the exception, however, of a few small families, this does not apply to the Orthorrhapha Nematocera [Gall-midges (Cecidomyidce), Fungus-midges (IIycetophitidce), Chironomidee, Culicidre, and Tipulidae], the Diptera that are gnatlike in shape and possess long antennæ; neither is the character found in the Robber-flies (Asilidce), the Dolichopodidee (shining green, narrowbodied, long-legged flies, usually found in the vicinity of water), nor 
in the vast army of Diptera (chiefly of small or moderate size) included in the families which it is customary to designate comprehensively by the term Acalypterate Muscidce. In these cases, where no sexual distinction is furnished by the eyes, it is usually possible to determine the sex by an examination of the terminal segments of the abdomen: in the male the abdomen ends more bluntly, while the clasping organs are often very conspicuous; in the female the tip of the abdomen is generally more or less tapering, showing indications of the presence of an ovipositor, which is often extruded. In the Mosquitoes (Culicidae ${ }^{*}$ ) the sexes can be readily distinguished by the antennæ, which in the male are plumose, forming tufts in front of the head, while in the female they are nearly bare; in the Midges also (Chironomida) the antennæ in the male form plumes, while in the female they are quite short and inconspicuous. In certain families (Dolichopodidce, Empidae) secondary sexual characters are often furnished by the legs; where this is the case,.it usually takes the shape of abnormal expansions of some of the tarsal joints in the male.

As a rule among Diptera the sexes of the same species are alike in coloration, or at any rate resemble one another pretty closely, striking sexual differences in this respect (such as are commonly seen among butterflies) being exceedingly rare.

\section{WheN AND WHERE TO LOOK FOR DiPTERA.}

With the exception of Mosquitoes, Midges, and similar forms, Diptera are most active when the sun is shining. In hot countries the hours from 8 o'clock till noon and from about 4.30 till sunset are usually the best for collecting. In England the best months for collecting are May, June, and July; but many species are to be found until late in September, while others occur in April or even in March: much of course depends upon the year, the season being sometimes a full month earlier or later than usual.

The following hints on collecting have been kindly furnished by

* For collecting this family, see special instructions ("How to collect Mosquitoes"). 


\section{DIPTERA (TWO-WINGED FLIES).}

Lieut.-Colonel J. W. Yerbury, who has had great experience in collecting Diptera both in this country and abroad:

"Diptera are to be found everywhere. Still, the following points should always be considered :-

"Locality.-In temperate climates virgin soil is best, with a south or west aspect for choice.

"In the tropics shelter from the prevailing wind is the most important point.

"Shelter, however, is an important factor everywhere, and the line taken should be selected with due regard for the direction of the wind.

"Habits.-The habits of the various families differ greatly, and, as a natural consequence, their favourite localities vary also. Before discussing these in detail, it may be advisable to enumerate some of the general attractions for the order.

"Flowers.- Some flowers are particularly attractive to Diptera, and these are as a rule white or yellow in colour.

"In England the flowers of the following may be enumerated as specially attractive: common and Portugal laurel, holly, blackthorn, hawthorn, bramble, plane, barberry, and at times rhododendron and dog-rose; but the attraction of the two latter does not as a rule last long. Probably all these are equally attractive in Europe, and to them may be added dane-wort (Sumbucus ebulus).

"In the tropics Diptera should be looked for on the flowers of several palms and various species of Bher-trees (Zizyphus), etc.

"Sugar, as applied by Lepidopterists, has not as a rule much attraction. Still, occasionally it is attractive to Calypterate Mruscidce, and in a lesser degree to Stratiomyidce; while at night many Daddylong-legs (particularly Limnobia) come to sugar.

"Ordure.-Many Diptera are attracted by this-not only S'catophagidce and Muscidce, but Diptera of families which one would not expect to see, the moisture being the probable attraction.

"Living Animals. - Many species of Tabanidce and other families are to be seen round living animals, but as a rule are not to be caught, the exception being the Hippobuscidce, which can often be taken with ease. It is seldom possible to catch flies round animals, 
domestic or otherwise, with a butterfly-net; but occasionally they can be caught with the hand, or boxed.

"Dead Animals. - Carrion is sometimes very attractive, and many rare species not met with elsewhere are to be taken on it. Here again the moisture is probably the attraction. A place where blood has I'un over the ground is generally attractive, though, strange to say, the wet mud and sand in river-beds, so attractive to butterflies in the tropics, has no attraction for Diptera.

"Other Attractions-Sweeping-Beating.-Other attractions, such as leaves, tree trunks, bare sandy places, etc., had perhaps better be considered under the head of attractions to families. One method of capture should not be omitted, however, and this is sweeping. Many species of Acalypterate Muscidre, and also many small Syrphidoe, which otherwise would probably be entirely overlooked, may be taken in this manner. The best places to sweep over are damp marshy spots, overgrown with rushes, flags, cotton-grass, etc. Beating seldom repays, though Cyrtidce may now and again be obtainable by this means only.

"Habits of Various Families.-Syrphidoe (Hover-flies, Droneflies, etc.).-For this family sunshine is absolutely essential, and the majority will be found at flower heads, in company with many species of Muscidae. Some few, however (e.g. Xylota, Calliprobola BrachyLedcozoxa lUcordm. palpus), prefer leaves and tree trunks; while species
etc.) will probably be taken chiefly by sweeping. Many species of LEUCOzoNa LUCORUM. palpus), prefer leaves and tree trunks; while species
belonging to certain genera (Pelecocera, Melanostoma, Syrphus, Eristalis, etc., may be taken hovering in the air.

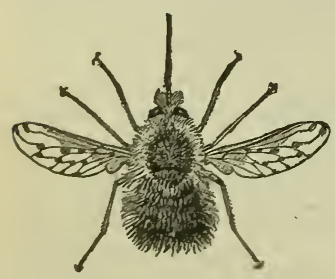

BOMBYLIUS DISCOLOR.

"Bombylida (Bee-flies, etc.).-The species of the Anthracinæ branch of this family are generally to be found hovering in.the hottest sunshine over bare spots on heaths, seashores, etc. The Bombylinæ, on the other hand, affect flowers-e.g. primroses, Potentilla, etc. At Aden Bombylius analis was found hovering over the flowers of the garden turnip run wild, and probably other: Cruciferæ will be found attractive, 


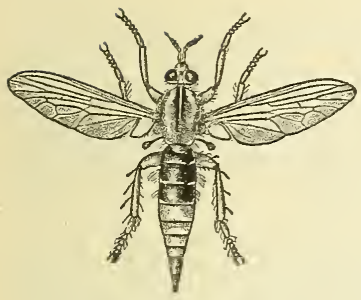

ASILUS CRABRONIFORMIS.

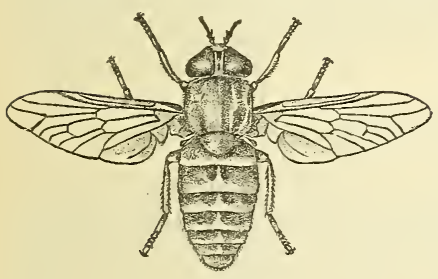

TABANUS BOVINLS.

"Asilidce (Robber-flies) affect many and varied situations. Roads, bare sandy places, etc., are attractive to some species; others sit on tree trunks, stones, and telegraph posts and wires. Others, again, prefer dry sticks and branches near the ground; while the species of Damalis and some few other genera love to sit on bare twigs at about the height of one's eye.

"Tabanidce (Horse-flies) are often to be seen flying round living animals ; but few are to be caught in this situation, most of the species of this family being taken flying round oneself or one's companions. A few may be caught sitting on tree trunks, leaves, walls, etc., and a few males taken hovering like Syrphida in the air.

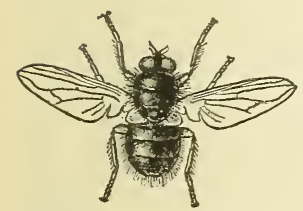

MESEMBRINA MERIDIANA.

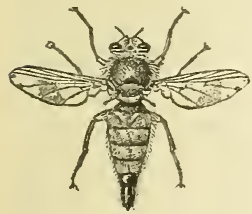

GASTROPHILUS EQCI.

"Muscidce Calypteratce may be met with in most situations. The species of many genera (Idia in particular) love flowers; others, again (Lucilia, Calliphora, Polietes, etc.), are to be found round ordure and carrion. Mesembrince and Rutilia, in company with many species of Anthomyinæ and Tachinida, love to sit on tree trunks, and prefer the sunny side.

"Estridce (Bot- and Gad-, or Warble-flies) are said to hover over mountain-tops. Hypoderma, however, is generally to be taken sitting on bare sunny places, in roads, heaths, etc. Gas. trophilus is often to be seen round horses, and may sometimes be taken with a net; but it may be noted that it is labour wasted to attempt to catch specimens of this genus with a white net. Cephenomyia sits on stones in spots frequented by deer, and is 
said to settle not infrequently on human beings who enter its haunts.

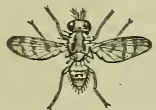

"Muscidce Acalypteratce are to be taken as a rule by sweeping, though a few Ortalidae, Micropezida, Trypetidce, etc., may be captured on leaves and flowers, tRYPETA CORNUTA. as well as on carrion and ordure.

"Other Families.-As regards other families, many of them will be met with while seeking for those already mentioned; and though the habits, etc., of the remainder are as varied as in the case of the latter, still the specimens encountered fortuitously will probably mount up to a considerable number."

\section{Method of Collecting.}

If possible, Diptera should always be brought home alive in the glass-bottomed pill-boxes (to which they are to be transferred on being captured in the net), and should then be killed in the cyanidebottle or jar immediately before being pinned. As soon as a fly is taken in the net by a dexterous sweep, a sharp turn of the wrist must be given (following a smart downward or lateral stroke in order to bring the fly to the end of the net), in such a way that the end of the net containing the insect falls over the rim and so makes a closed bag from which it cannot escape. The end of the net can then be gathered up in the hand, and the fly forced into a still smaller space, in which it will not be difficult to get it into a pill-box, and then to slip on the lid. If the specimens are small, it is possible with care to get several into one pill-box. Flies may also be transferred direct from the net to the killing-bottle, and so brought home derrl; but this method is not to be recommended, since prolonged exposure to the effects of cyanide of potassium is apt to injure the specimens, the ultimate condition of which, when so treated, is rarely as satisfactory as if they had been brought home alive in pill-boxes. If, however, it is necessary for any reason to dispense with pill-boxes, and to use the killing-bottle in the open, a little crumpled tissuepaper should be placed inside it; this affords a lodgment for the specimens, and so lessens the risk of their being injured by rolling 


\section{DIPTERA (TWO-WINGED FLIES).}

about. It may be noted that Anthracinæ when placed in pill-boxes are very apt to injure their wings by buzzing about; large Tabanide, Estridce, and certain other Diptera are liable to suffer in the same way. On the other hand, the hairy and scaly body-covering of these species is very easily rubbed off, so that if carried in the killing-bottle they must be treated with especial care. It is always advisable when out collecting to carry a killing-bottle for use in case of need, in the event of the supply of pill-boxes running short. Diptera on windows may be captured in pill-boxes; if the edge of the box is slightly raised from the glass on one side, and a little tobacco smoke blown into it so as temporarily to stupefy the fly, it will be found easy to slip on the lid without allowing the insect to escape.

\section{SPIRIt Not to be USED.}

Unless intended for dissection, Diptera must on no account be placed in spirit. Since all descriptions of Diptera have been based upon dried specimens, flies in spirit have to be taken out, dried, and pinned before they can be examined and compared with descriptions. In drying, however, they invariably shrivel; while immersion in spirit often causes colour-markings to disappear, and inevitably results in hairs, scales, etc., being washed off or matted. Specimens intended for dissection (as when it is desired to examine some specially remarkable structure, such as the proboscis or genitalia) should, however, always be placed in a small tube of spirit, with a plug of cotton-wool on the top of them to prevent their being injured by washing about. Other specimens of the same species should be pinned and labelled with a reference to those in spirit, so that the latter may be identified.

\section{Killing.}

Diptera brought back alive after a day's collecting should be killed by being placed for a few minutes in the closed cyanide-bottle or jar. If the cyanide-jar is sufficiently large, the pill-boxes themselves may be placed therein, first opening them a fraction of an inch on one side to allow the cyanide to take effect. In the case of large sluggish 
Diptera, such as Stratiomys, the pill-box may be opened without fear of the insect effecting its escape; after which a smart tap on the bottom of the box will cause the fly to drop into the jar. Diptera should never be allowed to remain exposed to the effects of the cyanide longer than is necessary to ensure their being quite dead. If the poison is of reasonable strength, four or five minutes should be sufficient to kill even the largest and strongest flies; on the other hand, it is necessary to make sure that the insects are really dead, since, if the exposure to cyanide has been too short, flies will often appear to be dead when in reality they are only stupefied. As soon as the insects are really dead, they should be removed from the killing-jar; those in pill-boxes may be allowed to remain therein until one is ready to pin them, while the loose specimens should be turned out on to a sheet of cork-carpet or pith.

\section{Methods of Preserving Diptera other than by pinning.}

Diptera should always be pinned, and this should be done as soon as they are dead. If preserved in any other way, they will never make such satisfactory specimens.

When, however, it is impossible to pin them, Diptera may be preserved in fine sawdust, on which a few drops of dilute carbolic acid should be sprinkled to prevent mould. Each specimen, before being placed in the sawdust, should be loosely screwed up in fine tissue-paper (cigarette-paper would do), on which the necessary data (see below under "Pinning") should be written in pencil. To contain the specimens a small tin box (such as those in which tobacco is sold) should be used; and to prevent injury from shaking, the box should be packed quite full of sawdust and specimens.

Diptera may also be put away for transport in three-cornered envelopes of soft paper (newspaper), after the manner in which butterflies are packed by collectors; but this method, though it answers fairly well for Tipulidce, does not suit thick-bodied flies, such as Tabanidre, as these are often crushed by it, and if once flattened cannot be restored to their natural shape. Envelopes containing Diptera or other insects may be conveniently packed in tin tobacco- or biscuit-boxes for transmission by parcel-post from 


\section{DIPTERA (TWO-WINGED FLIES).}

abroad. A few drops of weak carbolic acid should be sprinkled over each layer of envelopes, and the box should be packed quite full.

It is never advisable to put Diptera for transmission from abroad into small boxes containing wool, as when flies are once in contact with wool, and have become dry, it is very difficult to remove them without pulling off legs, bristles, etc.

\section{Pinning.}

Take a card disc, and write on it all the data connected with the specimen to be pinned, as follows: (1) name of locality, including altitude if necessary; (2) date-day, month, year-thus, 6. 3.99; (3) collector's name; (4) any brief remarks of interest (which may if necessary be written on the other side)-e.g. "Very common"; "Only specimen seen"; "On dead antelope"; "At — blossom"; "Running on banana leaves." Longer notes on habits, etc., should be entered in a note-book, with a number corresponding to one written on the disc. Specimens taken in coitı, for which a good look-out should always be kept when collecting, should have the fact noted on the disc of each, thus: "A-in coiti with B"; "B-in coitı with A."

Place the disc on which the above particulars have been written on a sheet of cork-carpet or pith, and, picking up with the forceps an entomological pin (a No. 20 if the specimen is not larger than a Blue-bottle, otherwise a No. 7 or No. 5), thrust about $\frac{1}{3}$ inch of it through the centre of the disc; in doing this the pin should be held by the forceps below the middle, otherwise it may bend and fail to pass through the card. Lay the specimen on its back (turning it over with the aid of a needle or an entomological pin held in the forceps), and thrust the pin, which now carries the disc, through the centre of the thorax, between the bases of the legs, until the tip of the pin projects from $\frac{1}{6}$ to $\frac{1}{4}$ inch beyond the dorsal surface of the thorax. It is important that, in this method of pinning, the pin should project well beyond the thorax, otherwise, when the specimen is dry, it may become loose and fall off. Inrert the disc (the specimen will then be right side up), and thrust an ordinary pin through it near the margin for the purpose of carrying both disc and specimen, drawing the disc a good half-ray up the carrying-pin. 


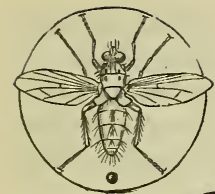

Should it be found impracticable to proceed in the manner here advised, owing to the difficulty of making the specimen lie in the required position on its back, or from any other reason, it may be pinned in the ordinary way through the middle of the thorax from the dorsal side. In this case,

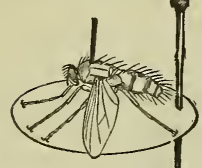
however, the specimen must be pinned first (i.e. before it is mounted on the card disc); and if the fly has rows of bristles on the thorax, care should be taken to insert the pin between them, and not to damage them in any way. The specimen should be drawn two-thirds of the way up the pin, and the latter should then be thrust through the disc, holding the pin with the forceps below the specimen; mount the disc on a common pin, as in the first method.

USE OF DISCS.

The last thing to be done is to arrange the legs and wings as far as possible. The wings must be made to project at an angle from the body, and not allowed to remain closed over it; if they can be got to remain at right angles to the body, so much the better. In the case of any specimen that is not too small and fragile, the wings can be best arranged, by means of the fine-pointed forceps, by making a gentle simultaneous pressure with the tips of the forceps at the base of each wing, repeating it until the wings assume the desired position. The legs also must be disposed symmetrically (and as far as possible in a natural position) on the card disc, so that all parts of them can be readily seen, and must not be allowed to remain crumpled up beneath the body, since important characters are often found upon them. In the case of a specimen with strong claws (such as one of the Robber-flies) it will generally be found possible to cause the legs to remain in the desired position by hooking the claws on the edge of the disc, gently drawing the legs out one after another by aid of a needle or one leg of the fine-pointed forceps. The manipulations in connection with the legs and wings must be performed as gently as possible, and care must be taken that bristles, hairs, or scales are not rubbed off in the process. As soon as these operations are 
completed, the specimen should be transferred to a store-box, or to one lined with cork-carpet or pith, as described above. Since, however, the tissues contract in dying, the legs and wings are very apt to get pulled out of place, and, to correct these changes, the specimens should be examined once or twice during the next day o1 two after being pinned.

Very minute or fragile specimens are best pinned from the side, and the legs should then be straightened out by means of a No. 20 pin held in the entomological forceps.

\section{Diptera COLleCted in the Tropics:}

\section{Attacks by Ants-Mould-Transmission to England.}

In the tropics boxes of pinned insects are very liable to the attacks of minute ants, which, if they once gain access to a box unobserved, will soon play havoc with its contents. In Brazil it has been found that ants can be prevented from entering insect-boxes by smearing the outside round the line where the box opens, or any other possible place of entrance, with andiroba oil, repeating the process as often as necessary; similar methods might be employed elsewhere in case of need.

Mould, however, is an even greater enemy to collections of Diptera. Pinned specimens of Diptera, like those of other insects, rapidly develop mould during the rainy season in tropical countries; and since mouldy specimens are practically worthless for purposes of scientific determination, Diptera should always be sent home as soon as possible after being collected. The risk of mould may, howerer, be diminished by pinning in a corner of the box a small piece of sponge saturated with the strongest carbolic acid, which should be constantly renewed. The greatest care must be taken to prevent specimens getting loose and rolling about in transit, since in this way a single loose disc might easily do irreparable injury to many other specimens in the box. To prevent this the pins supporting the discs should be inserted as tightly as possible into the corkcarpet or pith, and they should all be driven in to the same level, after which a sheet of soft paper (newspaper does very well) can be fixed into the box, resting on the heads of the supporting pins, in 
order to minimize the damage should a disc happen to get loose. The box containing the specimens should be well wrapped in cottonwool or similar material, and firmly packed in an outer case for transmission (by parcel-post if possible and the package is not too large) to Engliand.

\section{Number of Specimens of each Species Required.}

At least half a dozen specimens of each sex of a species should, if possible, always be obtained, and a good look-out should be kept for specimens showing any abnormality in structure, coloration, or size. When the collector remains long enough in one spot, he should always endeavour to obtain specimens of a species on different dates, in such a way as to throw as much light as possible on the duration of its seasonal occurrence. Similarly the attempt should be made to illustrate the geographical range or local distribution of a species, by collecting specimens in as many different localities as possible. Specimens of species taken in new localities, though common elsewhere, will always be valuable.

\section{LARVF AND THEIR HABITS.}

The habits of Dipterous larvæ are as varied as the outward appearance of the larvæ themselves. The latter may be met with almost everywhere, but especially in decaying matter of all kinds, in water both running and stagnant, in the ground, attacking the roots and bulbs of plants, or mining in the stems and leaves. It is worth noting, especially as a means of distinction from Coleopterous larvæ, that no Dipterous larva is possessed of true (thoracic) legs, though in many species (e.g. Eristalis, Helophilus) prolegs or transverse ridges having a similar function are distinctly visible.

The following notes as to the mode of life of the larvæ of some of the best-known families of Diptera may be useful :-

The tiny pink- or scarlet-coloured grubs of the Gall-midges (C'ecidomyidoe), as their name implies, form galls on the leaves and stems of plants. 
The white grubs of the Fungus-midges (Nycetophilidce) have black heads, and are to be found for the most part in fungi and boleti.

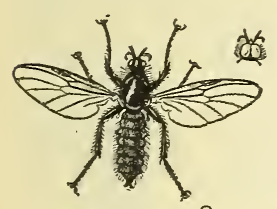

BIBIO MARCI, + , WITH HEAD OF $\delta$.

The larvæ of Bibionidce-a family that includes "St. Mark's fly" (Bibio marci, L.) and other species of black flies, which in England are exceedingly common in meadows in spring and early summer, sometimes hovering in the air, dancing in swarms, or feeding on the heads of Compositæ-are similar in appearance, and may be met with in vegetable mould, or in the droppings of cattle.

The greenish, somewhat leech-like larvæ of the Simulidce-a family that includes a number of blood-sucking species-may be found (with the pupæ) in brooks and streams, adhering to the submerged stems of rushes and other water plants.

The mode of life of the larvæ of the true Midges (Chirono-

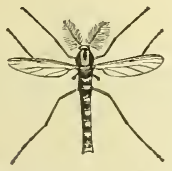

CHIRONOMUS PLUMOSUS. midre) is somewhat varied, those of the genus Chironomus being aquatic or living in the soil or in droppings (the well-known "blood-worm," so common in rain-water, is the larva of Chironomus plumosus, L.) ; the larvæ of the genus Ceratopogon, which includes a number of blood-sucking Midges, are found under the bark of trees and in decaying vegetable matter; the larvæ of Clunio are marine, living in rock-pools and feeding on green sea-weed (Cladophora).

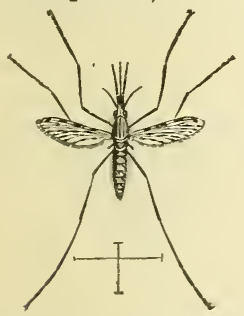

ANOPHELES MACULIPENNIS.

The exceedingly active larvæ and pupæ of Gnats or Mosquitoes (Culicidce) are exclusively aquatic, and are to be found in ponds, tanks, or butts of rain-water, and also in open drains and cess-pools : in the tropics, in casual accumulations of water in old tins, bottles, calabashes, etc. (genus Culex), or in stagnant or nearly stagnant water in pools, at the side of slowly flowing streams, or in permanent puddles (genus Anopheles). 


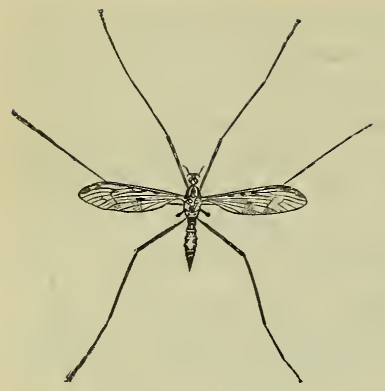

LIMNOBIA NUBECULOSA.

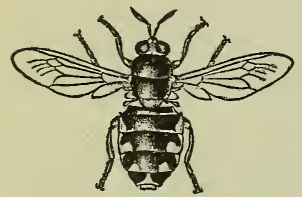

STRATIOMYS FURCATA.

The larvæ of the Horse-flies (Tabanidce) and Robber-flies (Asilidce) are internal parasites of beetle larvæ; they are whitish, soft-bodied grubs, and in the case of the Asilide are sometimes considerably elongated. At a later stage the larvæ of Tabanidce have been found in earth or water, those of the Asilidae in earth or in rotten wood.

The larvæ of the Bee-flies (Bombylidce) are parasitic in the nests of solitary bees, or in the egg-capsules of locusts and grasshoppers.

The habits of the larvæ of the Syrphidre are exceedingly diversified; those of the true Hover-flies (Syrphus) may be found on leaves infested with Aphida, upon which they feed; those of Volucella are inquilines in the nests of humble-bees and wasps; the well-known "Rat-tailed Maggots" (such as the larva of the Common Drone-flv, Erristalis tenax, L.) - so called from the protrusible, telescopic, terminal segments of the body, which carry the breathing-tubeslive in decaying animal or vegetable matter in a liquid or semiliquid state, in foul and stagnant water, drains, and similar places; the larve of other genera (e.g. Brachypalpus, Xylota, Calliprobola) live in rotten trees. The larve of Syrphidce in general (including 
all the foregoing) are more or less soft and grub-like in appearance; but those belonging to the genus Microdon, which live in ants' nests, have a hard, dorsally convex shell, without or with scarcely a trace of segmentation, and are so aberrant in appearance as to have been mistaken for molluses.

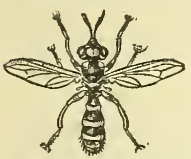

The larva of Conopidce are parasitic in the bodies of imagines of Hymenoptera (and Orthoptera*).

CONOPS FLAVIPES.

The larvæ of the Bot-flies and Gad- or Warble-flies (Estridee) are mammal parasites. They are white and grublike in shape, and live in the nostrils, frontal sinuses, pharynx, stomach and intestine, or beneath the skin. The majority are parasitic upon Ungulates; but the larvæ belonging to the American genus Cutiterebrica are found beneath the skin of Rodents. It may be noted that larvæ belonging to this family rarely survive forcible removal from the host. Pupation invariably takes place upon or in the ground, under stones, etc. ; therefore, in order to breed out the perfect insects, an attempt should be made to obtain the larve as they leave the host in order to pupate, or the pupæ themselves should be sought for in the situations indicated, in places frequented by the animals. In the case of domestic or other animals, kept in captivity and infested by these parasites, the pupæ or larvæ about to pupate may sometimes be obtained by searching in the stalls or sheds at the proper season. According to Brauer the majority of Estrid larve leave their hosts in the early hours of the morning.

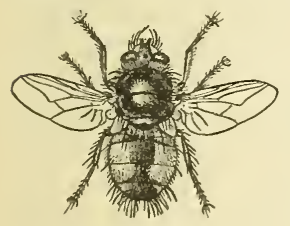

TACHINA FEROX.

The larvæ of the Muscidce (sensî latiore) are well known as maggots, and are to be found in decaying matter of all kinds, and even in festering sores and wounds on living animals; those of the sub-family Tochinince are parasitic in other insects - the majority in caterpillars.

* Physocephala vittata, F., was bred by Boheman from a grasshopper, Sphingonotus cyanopterus, Charp. 
The habits of the larvæ belonging to the families constituting the Acalypterate Muscidce are too diversified to be dealt with in detail. Some are to be found in ordure; others attack the stems of grasses and cereals; while the larvæ of others again (e.g. Trypetidce) live in fruits, in seed-heads, in galls on the stems, or mine in the leaves of various plants.

\section{How to Preserve Larve.}

Specimens of Dipterous larvæ will always be valuable, whenever it is possible to breed out some of them so as to determine the fly to which they belong. Unless, however, the perfect insect is known, it is rarely possible to do more than to determine the family to which a larva belongs. Larvæ for preservation should be killed by immersion for a moment or two in boiling water, and should then be placed in weak spirit (two-thirds spirit and one-third water); after being allowed to remain in this for two or three weeks until thoroughly hardened, they can be transferred to stronger spirit. The larvæ of each species must of course be kept separate, and should be put up in a small corked glass-tube full of spirit, the necessary particulars, with, if possible, a reference to pinned specimens of the perfect insect, being written in pencil on a scrap of paper and placed inside.

\section{Notes on Habits, etc.}

Very little is yet known as to the habits of Diptera in general, so that notes on the habits, distribution, seasonal occurrence, relative frequency, etc., of particular species will always be of great value and interest.* Particular attention should be paid to the habits of bloorl-sucking species and others of economic importance; in this connection it may be noted that information is greatly needed as to the habits and reproduction of Tsetse-flies (Glossina), especially as to whether the bites of all species of Glossina are equally fatal to domestic animals. A good look-out should also be kept for casts of mimicry between Diptera and Hymenoptera, which will be found

* For special points in connection with Mosquitoes as to which information is desired, see "How to collect Mosquitoes." 


\section{DIPTERA (TWO-WINGED FLIES).}

to occur chiefly among the Syrphidce (to a lesser degree also among the Asilidee. The Syrphidce as a family may be said to mimic Hymenoptera, but in some genera-e.g. Volucella, Arctophila, Calliprobola - the resemblance is especially pronounced). Instances of mimicry between Diptera and insects belonging to any order other than Hymenoptera are exceedingly rare. Cases of mimicry between particular species should be specially noted. 


\section{HOW TO COLLECT MOSQUTTOES \\ $(C U L I C I D A E)$.}

INTRODUCTION.

Systematic Position, Distinctive Characters, and Life History of Mosquitoes.

Mosquitoes or gnats (strictly speaking, the terms are synonymous) are the names popularly applied to the family Culicidae, of the order of insects known as Diptera (T'wo-winged Flies), which also includes, besides other families the species of which are more or less gnat-like in form, such as the true midges (Chironomidce), fungus-midges (Mycetophilidce), daddy-long-legs (Tipulidce), etc., a large number the members of which are more "fly"-like in shape, e.g. the blue-bottles and house-flies (Muscidce), tsetse-flies (Glossina), gad-flies (Tabanidce), hover-flies (Syrphidce), etc.

Culicidce are by no means the only blood-sucking Diptera, for the order also comprises the blood-sucking midges (genus Ceratopogon, belonging to the family Chironomidce), the sand-flies or Simulidce, gad-flies or Tabanidce, and blood-sucking Muscidce (Glossina, Stomoxys, Hcomatobia). In the perfect state the females of all of these suck blood, while the males are usually harmless, though in the tsetse-fly the blood-sucking habit is stated to be common to both sexes,* as is the case in certain species of mosquitoes (see "Observations on Habits, Distribution, etc.," p. 88).

* Surgeon-Major David Bruce, A.M.S., "Further Report on the Tsetse-Fly Disease of Nagana, in Zululand," p. 3 (London; Harrison \& Sons, 1897). 
The other blood-sucking Diptera, with the possible exception of Ceratopogon, are sufficiently distinct from Culicidce in outward form to obviate any risk of confusion. In countries in which mosquitoes abound they are recognized without difficulty. In England, however, where some twenty-five species of the family occur, a large amount of confusion apparently exists as to the characteristics of a mosquito, or, as it is more commonly called, a gnat. This confusion is mainly due to the fact that the midges (Chironomidce), which, with the exception of the genus Ceratopogon, are perfectly harmless, often attract attention from the habit of the males of dancing in the air in swarms on fine evenings, and, owing to their similarity in shape, size, and general appearance, are commonly mistaken for gnats (Culicidce).

A fundamental structural difference between Culicidce and Chironomidce consists in the fact that in the former the costal vein (fig. 2,c) runs right round the margin of the wing, while in the latter (as in the vast majority of Diptera) it is confined to the front margin alone, and stops short at the tip (compare plate, figs. 2 and 3). For practical purposes, however, more important differences consist in the possession by the mosquito or gnat (except in Corethra and Mochlonyx) of a greatly elongated proboscis (containing the piercing-stilets, which. enable it to obtain its food), whereas the proboscis of the midge is so short as to be invisible without close examination; and also in the fact that while in Chironomidce the wing is either bare or else uniformly clothed (membrane as well as veins) with fine hairs, in Culicidce the veins are clothed with scales, many of which project (especially towards the tip of the wing) at a characteristic angle of about $45^{\circ}$ (see plate, figs. $1,1^{a}$ ). On the costa (i.e. anterior margin of the wing) and the veins, the variously formed scales differ materially in the different groups. The posterior margin of the wing carries a deep fringe of elongated, feathershaped scales (see figs. 1, $1^{\mathrm{b}}$ ). The body, legs, and palpi are also clothed with hairs and scales; in some species the antennæ also may be wholly or partially scaled.

The preliminary stages (larva and pupa) of all mosquitoes are passed in water,-_generally stagnant fresh water, whether clean or foul, and either in permanent ditches, ponds, or tanks, or in 
temporary pools of rain-water; also in sluggish rivers and in salt water. Species that frequent houses breed in butts or tubs of rain-water or in other vessels of water within or in the precincts of the houses themselves, or in cesspools and wells which are open to the air. In the case of the best-known species of Culex that infest houses, the eggs are laid on the surface of the water in the so-called "boatshaped" masses; Anopheles eggs, on the other hand, are laid separately, and float together into roughly star-shaped groups or in lines; in Punoplites and Stegomyia they are also often laid separately. The eggs of the different genera vary much in form.

The mosquito larva is usually a small greenish, greenish-brown, or brown creature, occasionally red and blue, with a round head, a rounded swollen thorax, and an elongated jointed abdomen, from near the end of which, in Culex, Edes, Megarhina, Stegomyia, Panoplites, and Mucidus, the breathing-tube arises. In the pupa the head and thorax are fused into a mass, on the sides and front of which depend the rudiments of the wings, legs, and proboscis, while from the dorsal side project a pair of funnel-shaped breathing-organs ; the terminal segment of the abdomen bears a pair of swimming-plates. In the case of Culex the larvæ and pupæ are exceedingly active, moving about in the water by a jerking or wriggling motion of the body; they are under the necessity of coming to the surface to breathe at frequent intervals. The larva of Anopheles is more sluggish, and its habit is to float horizontally at the surface of the water, and is devoid of a prominent air-tube.

In the case of Culex fatigans, Wied,, it was found by Howard that the minimum time occupied by the whole life-history cycle was ten days- "namely, sixteen to twenty-four hours for the egg, seven days for the larva, and two days for the pupa." But the period necessary for a generation "is almost infinitely enlarged if the weather be cool," so that it is also permissible to suppose that it is accelerated by heat.

In the perfect state the male insects die quickly in confinement, but the females are longer-lived. Dr. Bancroft has kept $C u$ lex tigripes alive for seventy days in confinement. In cold climates large numbers of the perfect insects pass the winter in a state of hibernation, but a few as larvæ (Anopheles bifurcutus). 


\section{List of Articles Used for Collecting and Preparing Mosquitoes.}

One entomologist's collecting-net of book-muslin (one or two spare net-bags may be taken, in case the one in use gets torn).

A number of glass-bottomed pill-boxes ( $1 \frac{1}{2}$ to 2 inches in diameter is about the best size).

A cyanide killing-jar, or materials for making same, as follows :$\frac{1}{4} \mathrm{lb}$. of cyanide of potassium (in lumps).

$1 \mathrm{lb}$. of plaster of Paris.

A glass jar with wide mouth and closely fitting lid.

Entomological forceps, with curved ends for holding pins, are very useful.

One ounce No. 20 entomological pins (D. F. Tayler \& Co., New Hall Works, Birmingham. These pins are sold in boxes at $7 s .6 d$. per ounce; and as the pins are exceedingly fine, an ounce will go a very long way).

Common pins (three or four packets).

Gun-wad punch, No. 20 bore.

Cards (4-sheet Bristol Board) from which to punch dises; a supply of the latter should be prepared ready for use.

Needles (two or three) mounted in handles, for arranging legs and wings.

A good pocket-lens.

Cork-carpet-one or two sheets, about 6 inches square, on which to perform the operations of pinning, etc.

Medicated cotton-wool for packing mosquitoes in pill-boxes when time does not allow pinning.

A strongly made wooden box (a cigar-box will do), in the bottom of which is fixed a layer of cork-carpet.

A number of glass tubes for collecting larvæ and pupæ.

Importance of Sending Specimens for Determination and Description in tile Best Possible Condition.

It should be borne in mind that, for the purpose of the scientific determination of species, mosquitoes cannot be collected with too great 
care. As important specific characters are furnished by the scales, wings, and legs, it is of the utmost consequence that the scales should not be rubbed off, or the wings and legs injured. Uniless attention is paid to this point the specimens will probably be quite worthless for determination or description.

\section{Spirit Specimens.}

Specimens for determination may also be sent in spirit. Each species should be sent in a separate tube, and the tube numbered to correspond with the number of a dried specimen of the same species. They are best preserved in 70 per cent. alcohol.

\section{Specimens should be Pinned Immediately they are Dead.}

Mosquitoes are best pinned as soon as possible after death. Specimens should be pinned in three positions-(1) to show the dorsal view, (2) the ventral and (3) the lateral aspects. When travelling in haste, specimens may be kept in pill-boxes partly filled with medicated cotton-wool.

\section{Number of Specimens of Each Species Required.}

In collecting specimens of a species of mosquito for determination, some half-dozen examples of each sex should, if possible, always be obtainerl and pinned or preserved dry, and the same number in spirit.

\section{How to Distinguish the Sexes.}

The male mosquitoes can usually be distinguished from the females (which, in the majority of species, alone bite and suck blood) by the possession of plumose antennæ, forming tufts in front of the head (in certain genera, such as Deinocerites and Sabethes, the male antennæ are not plumose; the genitalia must then be examined); in the females the antennæ, though long, are nearly bare (having whorls of only short hair at the bases of the joints), while the palpi in the case of females are quite short, except in the genera Anopheles 
and Cycloleppteron, in which the palpi are as long as the proboscis in both sexes, but are more swollen at the tips in the males.

In Eides, Adeomyia, and Uranotania the palpi are short in both sexes, but the plumose $\delta$ antennæ will separate $\delta$ from $q$. It is particularly requested that males should be sent with their females.

\section{Method of Collecting and Killing.}

Mosquitoes may be captured in the open; an entomologist's collecting-net is then necessary, from which the insects can be transferred to glass-bottomed pill-boxes. In doing this great care must be taken not to pull off the legs. Inside buildings mosquitoes can easily be captured on walls and windows in the pill-boxes themselves. Specimens are, however, best obtained in good condition by breeding them; this can readily be done by keeping the larvæ or pupæ in a basin or jar of water covered over with book-muslin. In any case mosquitoes are best collected alive in the glass-bottomed pill-boxes.* Not more than a single specimen should be put alive in each box. To kill the mosquitoes the box is opened a fraction of an inch on one side, and placed for a few minutes in a cyanide killing-jar, $\uparrow$ which must, of course, be closed. They may also be killed by tobacco smoke or chloroform. If cyanide or tobacco smoke is used, they should not be left in the fumes more than ten minutes.

* These boxes can be obtained from any dealer in natural history apparatus, but care should be taken to see that the bottoms - and not the tops, as is often the case-are made of glass. Since the boxes are constructed of cardboard, the $y$ are liable in tropical countries to go to pieces in the rains, and to prevent this they should be covered with jaconet (cut on the cross and stuck on with liquir glue), and then coated with Aspinall's enamel.

$\dagger$ A cyanide killing-bottle can be procured ready for use from Hinton \& Co., Bedford Street, London, W.C., or any other chemist will prepare one to order; but when mosquitoes (or indeed any Diptera) are collected in the manner here advised, it is preferable to make a large-sized killing-jar for oneself as follows :-Take any fairly large glass jar (such as a pickle-bottle), with a wide mouth and closely fitting lid, and cover the bottom with a layer of dry plaster of Paris to the depth of half an inch; pour in above this a layer, equal in depth, consisting of powdered cyanide of potassium, mixed with rather 
As soon as the insects are quite dead they should be turned out on to a sheet of cork-carpet; they should be touched as little as possible, the manipulations necessary to arranging the wings and legs being performed with a needle.

When travelling, and time and space are of importance, mosquitues need not be pinned, but may be collected in pill-boxes and kept firm by medicated cotton-wool. Glass-top boxes of metal are best for tropical climates. The gnats should be placed, when killed, on the glass, and then a loose plug of medicated cotton-wool placed on them, so as to prevent them from shaking about.

\section{To Pin a Mosquito.}

Take a card disc $(b)$, and write on its underside the data connected with the specimen to be pinned, such as (1) name of locality, including altitude if necessary; (2) date-day, month, year-thus, 9. 11. 98; (3) collector's name; (4) any remark of interest, e.g. "Most troublesome species in district," or attach these remarks to the label $(c)$. Place the disc on a sheet of cork-carpet, and make a tine puncture with a stout pin; then pick up one of the fine No. 20 pins $(d)$, and thrust about one-third of an inch of it through the puncture made in the disc $(b)$. Lay the specimen on its back (turning it over with the aid of a needle), and thrust the pin, which now carries the disc, through the centre of the thorax, between

more than its bulk of dry plaster of Paris; cover this mixture with a layer of dry plaster of Paris to the depth of a quarter of an inch or so, and pour in above the whole a layer, half an inch in depth, consisting of plaster of Paris mixed with water to the consistency of cream. As soon as the top layer of plaster is dry the jar is ready for use. To obviate the risk of cracking the jar owing to the heat evolved when plaster of Paris is mixed with water, it may be advisable to stand the jar in warm water before adding the final layer. The exact amount of cyanide of potassium to be used is of no great consequence, but in the case of a properly prepared jar the odour should be readily perceptible on removing the lid; if it is not, the reason may be that the mixture is too dry, when a little water poured on to the top layer will probably set matters right. After some months' use the cyanide loses its efficacy (to obviate this so far as possible the jar should never be allowed to remain open), and the mixture must then be renewed. 


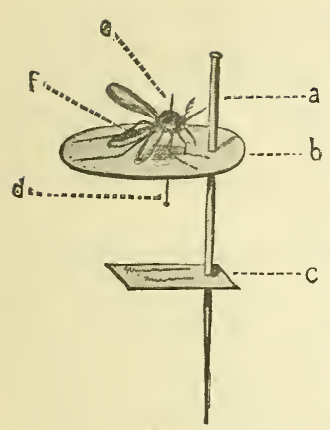

the bases of the legs, until the tip of the pin projects a little beyond the dorsal surface of the thorax* (e); invert the disc, and thrust an ordinary pin $(a)$ through the $b$ disc near the margin for the purpose of carrying both disc and specimen. The next and last thing to be done is to arrange the legs and wings as far as possible-i.e. the wings inust be made to project at an angle from the body, and not allowed to remain closed, and the legs must be disposed symmetrically on the card disc. These operations must be performed as gently as possible with the help of a needle mounted in a handle, and care must be taken that hairs and scales are not rubbed off in the process. Proceed in much the same way in pinning specimens to show the ventral and lateral surfaces.

\section{Preservation of Larve and Pupe.}

Specimens of larvæ and pupæ should always be preserved, especially when it is possible to breed some of them out, or otherwise to determine the species to which they belong. They should be killed and kept in alcohol or formol. $\uparrow$ If in alcohol, it should be about 60 per cent. strength.

Of formol a 4 per cent. solution (i.e. one part of ordinary commercial 40 per cent. solution to nine parts of water) is quite strong enough for killing and preserving.

Larvæ and pupæ (whether preserved in formol or alcohol) should

* Should it be found impracticable to proceed in the manner here prescribed, owing to the difficulty of making the specimen lie in the required position on its back, it may be pinned in the ordinary way through the middle of the thorax from the dorsal side; in this case, however, the specimen must be pinned first (i.e. before it is mounted on the card disc); it should be drawn twothirds of the way up the pin, and the latter should then be thrust through the disc, holding the pin with the forceps below the specimen; mount the disc on a common pin, as in the first method.

$\dagger$ Otherwise known as formaldehyde or formalin. 
be put in small glass tubes, and then corked; the corks may be coated with paraffin wax, though this is not absolutely necessary. Each tube should contain a scrap of paper, on which the necessary data (locality, date, whether from fresh or salt water, collector's name, etc., with, if possible, a reference to pinned specimens of the perfect insect, so that these may be identified) should be written in pencil.

The tubes should be packed in cotton-wool in a small tin box for transmission to England.

It is scarcely necessary to add that each species should be kept distinct, in a separate tube.

\section{Observations on Habits, Distribution, ettc.}

Detailed observations on the habits, distribution, seasonal occurrence, etc., of mosquitoes will always be useful, provided that care is taken to note the species to which they apply - the species being distinguished by means of letters or numbers written on the undersides of the discs to which the specimens are pinned.

While it is certain that in a natural state only an infinitesimally small proportion of all the mosquitoes that come into existence can possibly taste the blood of a warm-blooded animal, it is reasonable to suppose that primitively all Culicidce fed upon the juices of plants; some species are still exclusively vegetarian in both sexes; in others, while the males are vegetarian, the females suck animal blood-in some species only exceptionally, in other's habitually; and, finally, there are species in which both sexes suck animal blood. These characters should be noted.

Collectors in countries infested by mosquitoes will render especially valuable assistance by making observations and investigations on the following subjects :

1. The characters, breeding-ground, larvæ, and pupæ of Sabethes, especially noting the $\delta$ and $q$ characters of each species.

2. To find both sexes of the genera Wyeomyia and Limatus, as there are reasons for thinking they may have to be merged into Sabethes. 
3. To make detailed drawings of the antennæ, the frontal and the palmate hairs of the larvæ of all the Anopheles.

4. To observe the ova of Mucidus, Megarhinus, Eretmapodites, Deinocerites, Sabethes, Wyeomyia, Uranotania, Edes, etc.

\section{Transmission of Specimens to England.}

Pinned specimens of mosquitoes, like those of other insects, rapidly develop mould during the rainy season in tropical countries; and since mouldy specimens are practically worthless for purposes of scientific determination, the insects should be sent home as soon as possible after being collected. To contain the specimens, if a proper entomological store-box is not available, any small strongly made box (such as a cigar-box) will serve, in the bottom of which a layer of cork-carpet is firmly fixed. The greatest care must be taken to prevent specimens getting loose and rolling about in transit, since in this way a single loose disc might easily destroy or hopelessly damage all the other specimens in the box. To prevent this, the pins supporting the cards should be inserted as tightly as possible into the cork-carpet, and they should all be driven in to the same level. Other pins may be inserted between the discs to stop them turning round, and so rubbing against the next insect. A piece of naphthaline should be firmly fixed in each box to keep off mites, which often destroy collections during transit. The box containing the specimens should be well wrapped in cotton-wool or similar material, and firmly packed in an outer box for transmission (by parcel-post) to England. 


\section{EXPLANATION OF FIGURES.}

Fig. 1. Wing of a gnat or mosquito (Culex sp.), $\times$ about 16 .

$1^{\text {a }}$. Portion of 2 nd longitudinal vein, greatly enlarged, to show the covering of scales: $(a)$ median vein-scales; $(b)$ lateral.

$1^{\text {b }}$. Portion of hind margin of wing, greatly enlarged, to show the fringe: $(a)$ border-scales; $(b)$ fringe-scales.

Fig. 2. The same wing denuded of hairs and scales, to show the course and nomenclature of the veins.

C. costal vein (in Culicidae this runs right round the margin of the wing): the anterior margin of the wing is called the costa.

$\mathrm{I}^{\mathrm{a}}$, sub-costal vein.

I, 1st longitudinal vein.

II, 2nd " "

III, 3rd " " "

IV, 4th " " "

$\mathrm{V}, 5$ th $" \quad "$

VI, 6th " "

$a$, wing-folds or pseudo-veins.

Tr, supernumerary cross-vein.

$\operatorname{Tr}^{1}$, mid cross-vein.

$\mathrm{Tr}^{2}$, posterior cross-vein.

$\mathrm{Tr}^{3}$, marginal cross-vein.

It will be observed that the $2 \mathrm{nd}, 4$ th, and 5 th veins are forked (the branch nearer the costa is spoken of as the upper, that nearer the hind margin of the wing as the lower branch in each case). The relative lengths of the forks of the 2nd and 4 th veins vary in different genera and species.

Fig. 3. Wing of a midge (Chironomus plumosus, L.), $\times$ about 12, showing that the veins are destitute of scales. 
1.

2 a

$1^{b}$

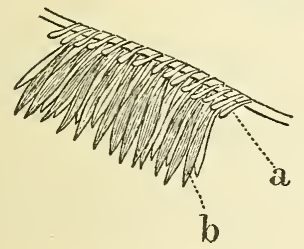

$1 \mathrm{a}$
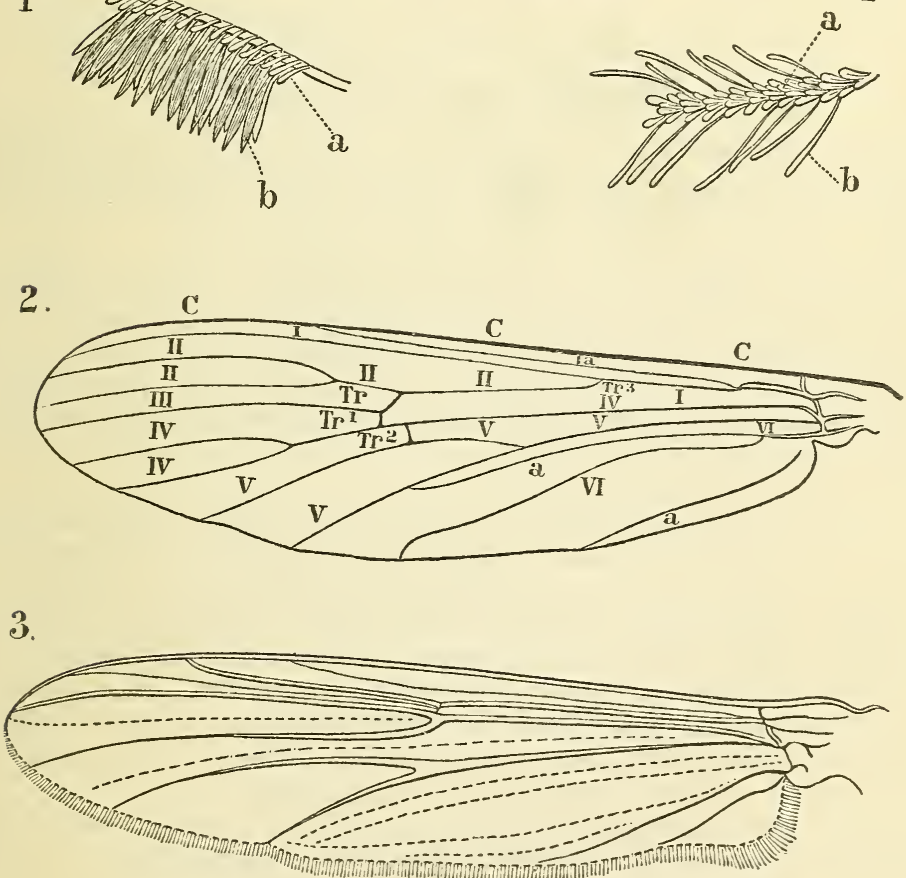


\section{INSTRUCTIONS FOR COLLECTING ARACHNIDA, MYRIOPODA, AND PERIPATUS.}

\section{Myriopoda ANd Arachnida.}

Habitut.-Millipedes are practically confined to damp localities. They may be found under logs of wood, stones, or decaying leaves, and frequently climbing bushes and trees, especially after heavy rains.

Scorpions, Spiders, and Centipedes are mostly nocturnal, and may be met with in both moist and dry situations, under stones, loose bark, felled tree-trunks, in burrows-in fact, in any suitable spot that affords shelter from the heat and light of day. Some spiders are diurnal and may be caught while darting about in the hot sun. Many Scorpions and large Spiders live in deep burrows, from which they have to be dug out.

The Trapdoor Spiders close the mouth of the burrow with a movable lid, and are hard to detect. They frequently, however, betray their presence to the collector by rapidly closing the lid at the sound of a footfall. Both Spider and its trapdoor nest should be procured if possible. Some species of this group in South Africa, Madagascar, South America, and other parts of the tropics make their homes, not in the ground, but upon the trunks of trees. They should be carefully looked for. Many of the smaller species of Solpugas live in Termites' nests and feed upon the occupants.

Small Spiders may be obtained in abundance by beating or shaking bushes and flowers over a sheet of paper or of white linen.

Most of the web-spinning species live on trees or bushes, and, if 


\section{INSTRUCTIONS FOR COLLECTING ARACHNIDA, ETC. 93}

in the centre of the web, will usually drop at a touch into a widenecked jar held beneath. If the web is apparently unoccupied, search for the owner should be made beneath the leaves of an adjoining bush, the hiding-place being often betrayed by a silk thread running from the web to the place of concealment.

Rolled leaves frequently contain Spiders and their cocoons. Leaf, Spider, and cocoon should all be preserved if possible. Sketches of webs, or notes as to their structure, are always interesting and useful.

Both Spiders and Centipedes may be sought for beneath stones on the seashore, or even in the tidal pools.

Millipedes are perfectly harmless, and may be handled with impunity. Scorpions, Centipedes, and large Spiders, on the contrary, are poisonous, and should be treated with caution. They can be safely picked up with forceps. Scorpions, too, may without much risk be seized by the end of the tail, the sting being firmly grasped between the finger and thumb; and even the largest Spiders, being unable to strike upwards, may be safely seized from above with a handkerchief.

Preservation and Packing.-Scorpions, Spiders, Centipedes, Millipedes, and their allies should, if possible, be preserved in alcohol. If alcohol be unobtainable, they may be packed in sawdust saturated with carbolic or naphthaline, or pinned in cork-lined boxes or wrapped in folded paper; but none of these methods yield such satisfactory results as immersion in alcohol in the form of methylated or any other kind of spirit that may be available.

Experiments with formalin as a preservative fluid for these animals have hitherto met with failure.

Specimens may be killed by plunging them direct into alcohol or hot water. Drowning in cold water is an admirable but tedious method. If alcohol be used for this purpose, it should be well diluted with water. If undiluted, it is liable to stiffen and harden the muscles and to shrink the softer tissues, so that the limbs cannot subsequently be straightened, and the form of other organs may be destroyed. After lying for twenty-four hours or thereabouts in weak spirit, specimens may be transferred with safety to stronger alcohol. 
Specimens collected in the same locality may be indiscriminately mixed in the same jar; but the smaller and more delicate examples should be placed in separate glass tubes or wrapped in pieces of paper, so that they may escape the chance of breakage by being shaken up with the larger and harder examples.

It is not advisable to plunge large Scorpions, Spiders, or Millipedes while still alire into a jar of spirit already containing other specimens. The latter are liable to be damaged by the writhing or snapping of the former.

Specimens from different localities must on no account be mixed together, unless a locality-label is affixed to each.

When packing for travel, care must be taken tliat the bottles or jars be either entirely filled with specimens, or, better still, half or three parts filled with specimens, and the rest of the space at the top with pieces of soft crumpled paper or wool wrapped in paper. By this means risk of damage from shaking during transit is reduced to a minimum. When glass tubes are used, they should be wrapped in paper and plugged with cotton-wool.

If glass tubes are not available, an excellent substitute may be made by rolling pieces of stiffish paper into the required size and shape and tying them round with cotton or string.

In the place of glass jars, which have the disadvantage of being both heavy and breakable, tobacco or other tins with an inlet tightfitting cover make a satisfactory receptacle for specimens of all kinds. The cover should, if possible, be soldered down to prevent possibility of leakage, or fixed by means of a bladder. Neither sealing-wax nor india-rubber should be used to close a vessel containing alcohol, since they are acted upon by that fluid.

If the duration of transit is likely to be short, specimens may be packed in wool saturated with spirit.

Serviceable forceps for purposes of collecting large specimens may be improvised by nailing two pieces of lath to a block of wood.

\section{Peripatus.}

Habitat. - Species of Peripatus should be diligently sought for in all tropical and sub-tropical countries. They may be found under stones 


\section{ARACHNIDA, MYRIOPODA, AYD PERIPATUS. 95}

or fallen tree-trunks or damp decaying leares in localities sheltered from the sun, but supplied with abundance of moisture.

Preservation. - Great care must be taken in killing specimens of Peripatus. The most satisfactory method is drowning in water. To hasten the process a few drops of ammonia may, if desired, be added to the water. If, while still alive, the animal be plunged direct into alcohol or any other preservative fluid, the body and limbs contract and the tissues shrink, so that the specimen is rendered less valuable for museum or anatomical purposes. During the process of drowning the body becomes fully distended. In this state it may be transferred to alcohol.

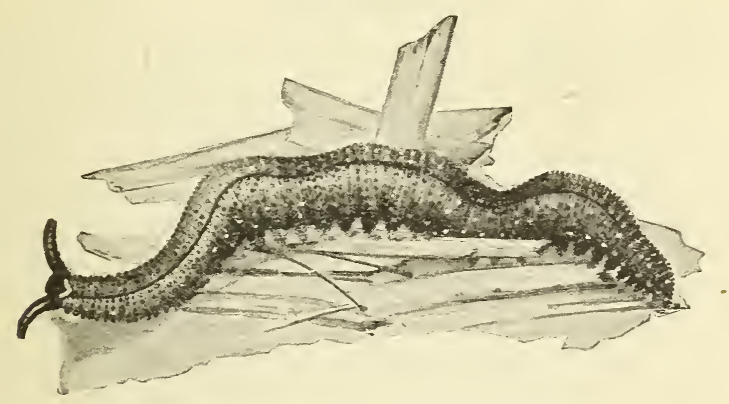

PERIPATUS BRAZILIFNSIS. FROM SANTAREM.

(NATURAL SIZE FROM LIFE.) 


\section{METHODS OF COLLECTING AND PRESERVING VARIOUS SOFT-BODIED INVERTEBRATE ANIMALS.}

\section{GENERAL.}

Alcohol is indispensable as preservative fluid; but certain precautions are necessary in its use. Except in a very few cases it is unnecessary to use it in its full strength, 70 per cent. being quite sufficient for preservation, and producing much less contraction and fragility in delicate organisms. Strong alcohol should be reduced with distilled water to the desired strength, as ordinary spring-water frequently contains a sufficient amount of carbonate of lime and other substances in solution to give a cloudy precipitate, which may effectually destroy the appearance of a specimen.

Furthermore, it is desirable that animals should first be placed in weak alcohol (from 35 to 50 per cent.) for from two to six hours. Some of the weak spirit should then be drawn off and stronger added until the desired strength is obtained. With delicate gelatinous structures the increase in the strength of the alcohol should be as gradual as possible.

Formalin or formol has been much used of late years on account of its portability and cheapness. Commercial formalin is a 40 per cent. solution of formaldehyde in water. The strength of formalin now most recommended for general purposes is a 10 per cent. solution (i.e. 4 per cent. formaldehyde), made by diluting one part of commercial formalin with nine parts of water. The mixture, when used for preserving, should be poured away after 24 hours, and fresh solution added; and, further, the bottles should be securely sealed. 
Commercial formalin now costs in London $15 s$. per gallon; accordingly the 10 per cent. solution costs only $1 s .6 d$. per gallon. Formalin is excellent for preserving some specimens; but caution and further experiment as to the use of it are necessary. A collector should not entrust all his specimens to this new preservative, but keep some in alcohol.

Commercial formalin generally contains a considerable percentage of free acid, and consequently will injure calcified structures, such as molluscan shells, unless the acid has been previously neutralized. This may conveniently be effected by placing a little chalk or pounded coral into the strong solution.

Before the final preservation of animals in formalin or alcohol, certain preliminary measures are necessary, or rather, desirable. Animals should be killed by means of a reagent which rapidly causes death, prevents contraction, and "fixes" the tissues as nearly as possible in the position they had during life.

The killing and fixing reagents most commonly used are chromic acid, osmic acid, and corrosive sublimate; after employing them, it is necessary to wash the animals in fresh or distilled water before placing them in formalin or alcohol. In the case of soft contractile organisms it is necessary to narcotize them first before attempting to kill, in order to prevent distortion. A solution of chloral hydrate, varying from 1 per cent. to 1 in 1,000 in sea-water or fresh-water, is often used for this purpose. Lo Bianco recommends immersion in weak alcohol. He generally uses a mixture of sea-water $100 \mathrm{ccm}$., and absolute alcohol $5 \mathrm{ccm}$. In other cases 70 per cent. alcohol may be carefully poured upon water in which the specimen lies, so that it forms a layer at the surface. It will gradually mix with the subjacent water, and in the course of a few hours will narcotize the animal, so that it may be treated with fixing reagents without fear of contraction. Tobacco smoke is employed for Actinice. Dr. Sorby has obtained beautiful results by poisoning with menthol.

Corrosive Sublimate.-A saturated solution in fresh-or sea-water may be used either hot or cold. It acts quickly, and preserves admirably for histological purposes. It is especially good combined with copper sulphate, acetic acid, or chronic acid. Objects hardened in it should be subsequently well washed in distilled water and in 
iodized alcohol (the recipe for which is given below *), to remove all traces of sublimate, which in alcohol crystallizes out in the tissues of the organisms, and so injures the preparation.

Chromic acid, 1 per cent. solution: objects must not be left in too long, or they become brittle; after immersion they must be washed in distilled water before being put into alcohol.

Glacial acetic acid suddenly kills animals plunged in it (see "Tunicata").

Osmic acid, 1 per cent. solution, kills and fixes small gelatinous organisms. Too prolonged use renders them brittle, and causes them to assume a dark brown tint. Objects should be washed in distilled water before placing them in alcohol. Osmic acid vapour is irritating to the eyes and organs of respiration.

For further information on mixtures for killing, fixing, and hardening used at the Zoological Station of Naples, see:-

Lo Bianco, "Mittheilungen Zoologische Station, Neapel," 1890, Band IX., pp. 435-474; full abstract of this paper in "American Naturalist," 1890, XXIV., pp. 856-865, and in "Journal of Royal Nicroscopical Society," 1891, p. 133. A verbatim translation into French is in "Bulletin Scientifique de la France et de la Belgique," 1891, Vol. XXIII., pp. 100-147.

\section{APPARATUS FOR COLLECTING.}

The Dredge.-This apparatus consists of a net fastened to a rectangular iron frame, by which its mouth is kept open; hinged to the frame on each shorter side is an arm, to one of which the hauling-rope is attached. The net is protected by. two flaps of canvas, which are attached to the frame and extended a little beyond the net all round, the flaps being tied together here and there at the lateial edges. The best and most practical account of a good dredge and how to make it is that of Mr. W. H. Dall in

* Iodizer alcohol, 35 per cent., or 70 per cent. alcohol, $100 \mathrm{ccm}$. ; tincture of iodine, $25 \mathrm{ccm}$. 
the "Bulletin of the U.S. Nat. Museum," 1892, Vol. XXXIX., Pt. G, pp. 26-30. If a ready-made naturalist's dredge has not been obtained, the apparatus can be made by a blacksmith. A good average size for moderate depths is 20 inches by 5 for the frame, and 2 feet length for the net. Dall recommends that a frame of galvanized iron should be riveted on near the back edge of the iron frame, and the canvas and net laced with copper wire into holcs in the galvanized iron; thereby the bad effects of iron rust on the net are avoided. The upper and lower outer edges of the frame are bevelled to enable the dredge to catch along the bottom. 'The rope is attached to the ring of only one of the arms, the two arms being fastened with cord. The object of this is to lessen the risk of losing the dredge if it gets fixed among rocks; when this happens the cord breaks, thus allowing the arms to separate and the dredge to be released. It may be necessary to fix a weight on the rope about 10 feet from the mouth of the dredge, in order to keep the edge of the frame along the bottom. The length of rope required for small depths is equal to about twice the depth. The feel of the rope is the best indication as to how the dredge is working.

When the dredge is hauled up, delicate specimens should be picker out before disturbing the contents. To separate specimens from the mud and fine sand, place the dredged material in a sieve and rotate it in a tub of water. Any very small specimens that pass through the sieve can be secured later by gently stirring up the mud, pouring off the liquid, and adding more water. After this process has been repeated a few times, the mud becomes washed away, and the specimens will then be seen lying at the bottom.

A tangle is useful for catching up spiny specimens. The apparatus consists of an iron bar, straight or bent at a right angle, and with five or six pieces of chain attached to it. Untwisted strands of rope are attached to the chain-links.

Towing-net. - A towing-net is used for surface or pelagic animals. A conical net of cheese-cloth, bolting-cloth, or coarse-woven bunting, about $2 \frac{1}{2}$ feet in length, is fastened to a copper ring about $1 \frac{1}{2}$ feet in diameter; it is best to double a strip of cotton cloth round the ring, and sew the net on to the cotton. Four equal lengths of strong fine cord are fastened at equidistant points round the ring, and tied 


\section{METHODS OF COLLECTING AND PRESERVING}

together about 3 feet in front of the ring. The single cord is attached to the knot, and its length is adjusted so that the upper edge of the ring is above the water. A zinc can is fixed at the bottom of the net. If it is required to collect from a depth of one or more fathoms, a weight is attached to the line near the knot at the junction of the four cords.

When the net is taken on board, the can is emptied, and the net turned inside-out into a fish-globe or other vessel full of sea-water. Some specimens may be removed with a pipette for special treatment (see below, Medusce). For the rest osmic acid is added to the seawater; the animals will die and sink to the bottom; the sea-water is drawn off, and the residue washed in fresh-water and graded into alcohol.

\section{PACKING.}

1. Too many specimens should not be placed in one bottle.

2. The spirit should be quite clean at the time of forwarding.

3. Perhaps the best packing-material is horse-hair. Wood shavings, sawdust, soft paper scrunched up into loose balls, are fairly good.

4. Many Crustaceans and Ophiuroids are well sent after being sewn on to stiff cardboard.

Corals.-Dry specimens of stony corals should be carefully wrapped in several thicknesses of soft paper-as much paper, indeed, as will prevent the angles and points from puncturing it-and should then be laid in sawdust, the coarser the better, and all packed down tight to prevent jostling together. The object of covering the specimens with plenty of paper is to prevent the filling-material (sawdust and suchlike) from getting in and choking their calicles and finer sculpturings.

Delicately branching or foliate specimens should be treated in the same way, but in addition should be protected from the weight of the others by being placed in separate boxes, or by partitions nailed into the case.

N.B.-Sawdust or cotton-wool should never come in direct contact with the specimens. 
VARIOUS SOFT-BODIED INVERTEBRATE ANIMALS. 101

\section{SPECIAL.}

\section{Protozon.}

Foraminifera.-The dead shells occur in shelly sands, which are sometimes very rich in them. The living organisms are found in the mud or sand of the sea-bottom, or adhering to sea-weeds.

Some species of Foraminifera are pelagic, and live at the surface of the ocean in warm temperate and tropical waters; these can be collected in the towing-net, or, better, into vessels of sea-water, as several species possess delicate spines liable to be broken in a net.

To separate Foraminifera from sand or mud, when the shells alone are required, Professor W. C. Williamson's method may be adopted. The sand or mud dredged from a few fathoms is dried, and the rougher material separated by a sieve or net. The finer portion is put into a bowl of water, and stirred up. The more delicate shells with their chambers full of air will float, and can be skimmed off and put into another bowl of water; the water is drawn off with a siphon, and the residue is dried. It is better, before drying the residue, to heat it with caustic potash, and again wash in water.

To obtain living Foraminifera, the specimens can be picked off from corallines and other sea-weeds; or the mud and fine sand that come up in the dredge are put into vessels of water, and stirred : the shells, full of protoplasm, will sink.

Mr. J. J. Lister uses a horse-hair sieve, with bolting-cloth fastened beneath, to obtain certain shallow-water species. The sieve is placed in a suitable pool of sea-water, and handfuls of sea-weed are well shaken in the water over the sieve. The bolting-cloth catches the Foraminifera which pass through the sieve. The specimens are killed by putting them in a mixture of warm saturated solution of corrosive sublimate (4 parts) and glacial acetic acid (1 part); they are then cleaned in water, and finally put into picrocarmine for some hours.

Radiolaria.-Many species live at and near the surface, where they sometimes occur in great.abundance. They may be captured with a towing-net or in vessels of sea-water.

Some are without a skeleton, and appear like minute oval or 


\section{METHODS OF COLLECTING AND PRESERVING}

spherical blobs of jelly; others are provided with a skeleton of silex or of vitreous, horny substance.

As a general rule the towing-net is emptied into a glass vessel of sea-water; on adding a few drops of 1 per cent. osmic acid, the Radiolaria die, and sink to the bottom; the sea-water is poured off or siphoned off, the residue washed in fresh-water, and treated with weak and later with strong spirit. A simpler method is to put the animals direct into weak spirit, and later into strong spirit. Another method consists in the use of a 3 to 5 per cent. solution of formalin.

\section{Porifera (Sponges).}

Sponges live in all depths, and occur both in the sea and in the fresh-waters of rivers, lakes, and ponds; and they vary extremely in colour, form, and consistency.

They often encrust stones, rocks, sea-weeds, etc.; or they may be massive or arborescent.

Fresh-water sponges are usually of a brilliant green colour, and may be mistaken for water plants; in dark places the green colour is replaced by pale buff. They grow on the piles of bridges and locks, or on the stems of water-weeds.

On the banks of the Amazon specimens are found high and dry on the branches of bushes and trees which have been submerged during the rainy season, the blackish or earthy clumps of sponges often being mistaken for ants' nests. Shallow-water sponges are often found in shady places under rocks or in caves.

Notes should be taken of the colour of living sponges.

Specimens growing on pier-piles may be raked up with a rake or a Dutch hoe with a bag of bolting-cloth conveniently fixed beneath. Forms living in deeper water are obtained with the dredge.

To preserve sponges, they should be killed as soon as possible by putting them into strong spirit, or into an 8 per cent. solution of formalin. The latter, however, is not recommended, as it appears to act rather as a temporary disinfectant than as a permanent preservative. Formalin should not be used for calcareous sponges. 'The preserving medium should be changed after twenty-four hours. 
Whien several specimens are put into one bottle, each should be tied up separately in rags. Large specimens may be preserved dry, by immersing for two hours in fresh-water, followed by immersion in ordinary alcohol for one day, and then by exposure to sun and air.

To preserve the delicate calcareous Ascon sponges so as to be available for purposes of research, Professor Minchin* takes with him, on his collecting excursions, bottles containing 1 per cent. osmic acid, distilled water, and picrocarmine solution. The sponge is put into a bottle containing equal parts of sea-water and 1 per cent. osmic for from five to ten minutes. The specimen is rinsed in fresh or distilled water, and placed in picrocarmine for from one to two houls. Lastly, it is washed in distilled water, and transferred to glycerine or alcohol.

\section{HydrozoA.}

Hydroida (Sea-firs, etc.).--The more commonly known species form branching treelike colonies rooted to stones, rocks, etc. Shallow-water forms will be found in pools left by the tide, and those from deeper water, often attached to stones or to the shells of molluscs and similar objects, are obtained by dredging.

The fresh-water forms Cordylophora and Hydra occur in rivers, docks, etc.

Specimens should be preserved in spirit or in 5 per cent. formalin.

Moseley t recommended the following method for obtaining specimens with expanded polyps:-The living specimens are placed in a tall jar, with just enough sea-water, well aerated by shaking, to cover them. When the polyps are expanded, a hot saturated solution of corrosive sublimate is poured in. In a few minutes the sublimate solution is poured off, and fresh-water added, to be followed by weak and then strong spirit.

specimens of the fresh-water Hydra should be looked for on water plants.

* “Quarterly Journal Microscopical Science,” January, 1898, p. 474.

$\dagger$ II. N. Moseley, "Admiralty Manual of Scientific Enquiry," ith edit. Zoology, p. 357. 


\section{METHODS OF COLLECTING AND PRESERVING}

Hydrocorallina.-This group includes the Milleporidce and Stylasteridae. Any observations on the living polyps would be valuable. It would be of special interest to discover the minute medusiform individuals which escape by rupture of the wartlike elevations which stud the surface in certain parts.

Moseley's method of sudden killing of specimens with expanded polyps by means of hot corrosive sublimate should be triéd.

Siphonophora.-These animals are very difficult to preserve satis factorily, owing to the tendericy of the swimming bells, polyps, and tentacles to break away. The method of killing and fixing with osmic acid, washing in fresh-water, and grading into alcohol or formalin, may be adopted (see below, Medusc). For other means of preserving, the collector is referred to Signor Lo Bianco's paper on the Naples methods, or to the cupric-sulphate method of Bedot, quoted by Mr. A. B. Lee:*

Medusce.-Medusæ in many instances represent one phase in a series of transformations undergone by an organism in the course of its life-history.

Many of the smaller forms are budded off from fixed Hydroids. In the case of some of the larger forms (e.g. Aurelia) the oval freeswimming embryo settles down and becomes a minute white polyp with long tentacles; the polyp divides transversely so as to resemble a pile of saucers; the latter become free, and ultimately develop into the adult form. It is important to obtain all these stages.

The discovery of new forms of fresh-water Medusæ would be an event of the greatest interest.

Recently Mr. E. T. Browne $\uparrow$. has obtained good results in preserving the smaller kinds of Medusæ by using formalin, after killing and fixing with a saturated solution of picric acid. The contents of the towing-net are emptied into a glass vessel of sea-water. By means of a pipette any particular specimen is removed to a watchglass of sea-water. Five drops of hydrochlorate of cocaine are added, and in a few minutes another five or ten drops. When the Medusa is motionless and has its tentacles extended, any

* "Microtomist's Vade Mecum," 5th edit., 1900, p. 487.

† E. T. Browne, "Proc. Liverpool Biol. Soc.," 1895, IX., p. 245; " Proc. Zool. Sisc.," 1896, p. 461 ; and "Journal of Biometrika," 1901, Vol. I., p. 108. 
superfluous water is drawn off, and a saturated solution of picric acid is added suddenly; if a precipitate of cocaine is thrown down, it is removed, and fresh picric acid added, the Medusa being left in for half an hour, and finally treated with 5 per cent., and later 10 per cent., solution of formalin.

Larger. Medusæ (Pelagia, Rhizostoma, etc.) are killed by adding to the sea-water in which they are swimming 3 per cent. of a 1 per cent. solution of osmic acid. As soon as they begin to assume a pale brown tint, they are washed in fresh-water for two minutes, and put into 35 per cent. alcohol, and later into 70 per cent. alcohol. $\mathrm{Mr}$. Hornell, ${ }^{*}$ of Jersey, reports favourably on 5 per cent. formalin.

For larvæ of Scyphomedusæ (Scyphistoma, Strobila) Signor Lo Bianco recommends killing with warm corrosive sublimate, washing in fresh-water, and grading into spirit.

\section{C'TENOphora.}

Small forms are treated with osmic acid and alcohol, according to the method given above for the large Medusæ.

Signor Lo Bianco recommends that they should be killed by allowing them to fall into chrom-osmic acid mixture $(100 \mathrm{ccm}$. of 1 per cent. chromic acid and 2 ccm. of 1 per cent. osmic acid), and allowed to remain in for from fifteen to sixty minutes, according to size, and then graded into alcohol up to 70 per cent.

Formalin should not be used for preserving Ctenophora.

\section{Anthozon.}

The first care must be to place the forms belonging to this group in fresh salt-water, to allow them to expand-a result which may not be obtained in some cases for twenty-four hours. Alcyonarians should be killed with chrom-acetic solution No. 2, † withdrawing the water in which they lie until there is left just enough to cover them, and then adding a volume of the chromacetic solution double that of the sea-water. The animals should be

* Hornell, "Natural Science," 1895, VII., p. 416.

† Concentrated acetic acid $100 \mathrm{ccm} ., 1$ per cent. chromic acid $10 \mathrm{ccm}$ 


\section{METHODS OF COLLECTING AND PRESERVING}

removed from this mixture the moment they are killed, since the acid will quickly attack the calcareous spicules, which are important for the identification of the Alcyonaria, and placed in 35 per cent. or 50 per cent. alcohol; it is well to inject the alcohol into the mouths of the polyps to keep them fully expanded. The preparation should finally be preserved in 70 per cent. alcohol.

Regarding the S'ea Anemones, no definite rule for preservation can be given. Much of the success of the preparation depends on the form employed, some species contracting much less readily and less perfectly than others. Some may be killed in a fair condition by pouring over them boiling corrosive sublimate, and then, before consigning them to alcohol, treating for a few minutes with 0.5 per cent. chromic acid.

Stony Corals should be allowed to expand fully, and should then be killed with boiling solution of corrosive sublimate and acetic acid used in volume equal to that of sea-water containing the coral. The colony should then be transferred to 35 per cent. alcohol, some of this fluid being injected into the mouth of each polyp. The injection should be repeated at every change of the alcohol, and the specimens should be preserved in 70 per cent. alcohol, after washing them well in iodized alcohol.

Professor Hickson writes, in reference to the Alcyonarian Corals, as follows:-All Stolonifera, including Tubipora, preserve well in spirit. Tubipora and some of the large Clavularias, however, hold in their cavities a large amount of sea-water, and consequently the spirit in the bottle soon becomes weak, and must be changed once or twice.

The only satisfactory way of killing Tubipora expanded is to throw a concentrated solution of corrosive sublimate on to a colony when expanded in a shallow pool on the reef; but if expanded colonies are removed as rapidly as possible from their position and plunged into strong spirit, the polyps are killed partially expanded in a manner useful for investigation.

Thick coriaceous Alcyonarians, like Alcyonium or Sarcophytum, are capable of contracting so tightly that spirit and other preservatives fail altogether to penetrate their tissues, unless special care be taken. Nearly all specimens taken from a dredge and placed 


\section{VARIOUS SOFT-BODIED INVERTEBRATE ANIMALS. 107}

whole into spirit are almost useless for anatomical investigation. If they can be made to expand in a basin of sea-water, and are then plunged into a mixture of chromic acid and strong acetic acid, or into strong spirit or corrosive sublimate, the structure of the polyps is preserved.

In preserving these forms, however, it is important to bear in mind that, if two or three slices about $\frac{1}{4}$ or $\frac{1}{8}$ inch in thickness are preserved separately, they afford the most valuable material for investigation and study. Five per cent. formalin gives satisfactory results if the polyps can be induced to expand in a basin of sea-water after capture.

Nearly all the Gorgonians have such a dense covering of spicules that preserving fluids cannot penetrate into their tissues. We are consequently almost entirely ignorant of the canal system of any but the most common species.

When a Gorgonian is captured, therefore, in the dredge, a part of the "bark" should be stripped off and preserved separately in strong spirit, or allowed to remain attached to the axis, if the spirit in which the specimen is preserved can be kept of good strength, i.e. not less than 70 per cent.

The Pennatulids can be fairly well preserved by immersion whole into spirit; but it is always advisable, if more than one specimen of a species is obtained, to make a long incision into the axis with a knife before plunging into spirit, and any pinnæ which can be snipped off with a pair of scissors and preserved separately yield good material for a natomical study.

\section{Echinoderifa.}

Starfish may be eprepared with the ambulacral feet in full distension by allowing them to die in from 20 to 30 per cent. alcohol. Echinoids should be placed in a small quantity of water, and killed with chrom-acetic mixture No. 2, being r'emoved from it as quickly as possible, as the acid corrodes the test. To preserve the internal parts, it is necessary to make two opposite openings in the test, so that the alcohol may penetrate the interior readily. 


\section{METHODS OF COLLECTING AND PRESERVING}

Holothurians, such as Thyone and Cucumaria, after the tentacles are fully expanded, should be seized a little below the bases of the tentacles by forceps, using a slight pressure, and the anterior portion of the body should then be immersed in concentrated acetic acid. Alcohol (90 per cent.) should then be injected into the mouth, and the specimens placed in 70 per cent. alcohol. The injection should be repeated each time the alcohol is changed.

Synapta should be fixed by immersion in a tube containing a mixture of equal parts of sea-water and ether (or chloroform), where they remain completely expanded. They should then be washed for a short time in fresh-water, and passed into alcohol, taking care to increase the strength of this very gradually.

\section{VERMes.}

Cestodes, Trematodes, Turbellaria, as well as Nemathelminths, are most satisfactorily killed with corrosive sublimate, either cold or hot. Sagitta, however, succeeds best in copper sulphate and sublimate or chrom-osmic mixture.

Nemerteans should be narcotized in a solution of chloral hydrate in sea-water 1 per cent., where they should remain for from six to twelve hours. They are then to be hardened in alcohol. Gephyreans may be narcotized with 1 per cent. solution of chloral hydrate in seawater, or in alcoholized sea-water, from three to six hours; or may be killed at once in 0.5 per cent. chromic acid: this last method may be also applied to Hirudinea. Chætopods are best narcotized in sea-water containing 5 per cent. of absolute alcohol, or by adding gradually to the surface of the sea-water in which they are contained a mixture of glycerine 1 part, 70 per cent. alcohol 2 parts, and sea-water 2 parts, hardening them subsequently in alcohol. The Hermellidae, Aphroditida, and the Eunicidce may be killed in cold corrosive sublimate. Some of these, such as Diopatra, should, however, be narcotized in alcoholized sea-water.

Serpulidce, before treatment with corrosive sublimate, should be narcotized in 1 per cent. chloral hydrate, which causes them to protrude wholly or partly from their tubes. 


\section{VARIOUS SOFT-BODIED INVERTEBRATE ANIMALS. 109}

\section{Crustacea.}

Cladocera, Copepods, and Schizopods may be killed in corrosive sublimate dissolved in sea-water. Ostracods may be thrown at once into 70 per cent. alcohol. Cirripeds die expanded in 35 per cent. alcohol; and if some specimens contract, it is easy to draw out the cirri with forceps. Amphipods and Isopods may pass directly into 70 per cent. alcohol, except the Bopyrids and Entoniscids, which should be killed in the mixture of equal parts of 90 per cent. alcohol and sublimate solution.

To avoid the casting off of the appendages of the Decapods, they should be allowed to die in fresh-water, care being taken not to allow them to remain in it longer than is necessary, as it causes a distortion of the membranous appendages. Pycnogonids will die in 0.5 per cent. chromic acid, with the appendages fully extended.

\section{PolyzoA.}

Polyzoa are horny, calcareous, or gelatinous; they incrust other objects, or form masses or arborescent growths. They are nearly all colonial animals, and usually the small separate "zooecia" can be made out with the naked eye or with a lens. Polyzoa are mostly marine; but there are also a number of fresh-water species.

'These animals may be preserved in strong spirit or in 10 per cent. for'malin.

Specimens can be obtained with polyps expanded by killing suddenly with warm corrosive sublimate animals with polyps already expanded; or narcotization with chloral hydrate or alcohol may be resorted to.

\section{BRACHIOPODA.}

Signor Lo Bianco recommends narcotizing in alcoholized sea-water. Before placing in alcohol for final preservation, a small chip of wood is placed between the ralves of the shell. Without this precaution sea-water will be retained between the shut valves, and the soft parts will putrefy. 


\section{METHODS OF COLLECTING AND PRESERVING}

\section{Tunicata.}

The minute tailed Ascidians, known as Appendicularia, sometimes occur in abundance at the surface of the sea. Signor Lo Bianco recommends that they be killed by leaving them for five minutes in a mixture of chrom-osmic acid (see "Ctenophora"); they are then washed and graded (see p. 98) in alcohol.

The pelagic Tunicata (Pyrosoma, Salpa, Doliolum) are killed and fixed with osmic acid, washed in fresh-water, and transferred to strong spirit or 8 per cent. formalin.

Simple and compound Ascidians should be narcotized by placing them for some hours in chloralized sea-water containing hydrate of chloral 1 in 1,000. They may then be put into strong spirit or 8 per cent. formalin, which should be changed after twenty-four hours, because Ascidians contain much water.

$\mathrm{Mr}$. A. B. Lee* strongly recommends for Compound Ascidians a process employed by Professor Van Beneden. The corm is placed in clean sea-water for a few hours. When the zooids are extended, the corm is seized with the fingers and dropped into glacial acetic acid, and left there for from two to six minutes. It is then removed with the fingers, and washed well in 50 per cent. alcohol, and graded into successively stronger alcohols up to 70 per cent. This method avoids the use of steel, and will not injure the fingers if they are washed at once.

\section{Mollusca.}

Lamellibranchs and Heteropods should be narcotized in alcoholized sea-water. To avoid the closure of the valves of Lamellibranchs on immersion in 70 per cent. alcohol, little plugs of wood should be placed between the margins of the valves. The same result may be effected in the case of Prosobranchs by tying the internal edge of the operculum to the shell.

Of the Opisthobranchs the Eolids may be best preserved by pouring over them concentrated acetic acid in volume equal to or double that of the sea-water containing them. Dorids should first be narcotized by gradually adding 70 per cent. alcohol to their

* A. B. Lee, "Microtomist's Vade Mecum," 5th edit., 1900, p. 460. 


\section{VARIOUS SOFT-BODIED INVERTEBRATE ANIMALS. 111}

sea-water, and then killed with concentrated acetic acid or boiling sublinate. The larger forms may be killed in from 1 to 5 per cent. chromic acid.

Pteropods are preserved well in Perenyi's fluid for fifteen minutes, whence they are passed to 50 per cent. alcohol. Gymnosomatous forms should be first narcotized with 1 per cent. chloral hydrate, and then killed in acetic acid or sublimate.

Decapod Cephalopods may be fixed directly in 70 per cent. alcohol, if an opening be made on the ventral surface to allow the alcohol to reach the internal parts. After twenty-four hour's the alcohol should be poured off and replaced by a fresh quantity. After three days' immersion in this second quantity of alcohol, it is recommended that Cephalopods be preserved in 5 per cent. formalin. Formalin does not destroy the pigments of the integument. 


\section{HINTS FOR COLLECTING AND PRESERVING SHELLS OF MOLLUSCS.}

The following notes supply a few general rules as to finding and preserving shells :-

Of Shell-bearing Molluses there are three classes-Marine, Freshwater, and Land. The first two include Univalves and Bivalves, the last only Univalves.

1. Marine shells may be obtained:-(1) By searching on and under rocks at low water, or on coral reefs among sea-weed attached to them, or floating on the sea, or on a sandy beach. Bivalves may be found by digging in the sand or mud, on a beach or at the mouth of a river: their presence is generally indicated by a circular breathing-hole in the sand. (2) By dredging, by which means only deep-sea shells can be obtained; but after a storm these may often be found upon the shore, before they have lost their-lustre.

Limpets, etc., should be detached with a thin blade passed quickly under the shell, taking care not to break the edges. Small shells on and in sea-weed, and limpets, etc., adhering to stones will drop off and sink to the bottom in a vessel of cold fresh-water.

2. Fresh-water shells may be obtained in any river, lake, pond, marsh, or reservoir: Univalves, chiefly on the banks, on reeds and plants growing near the edges, and on the under surface of leaves, and stems of aquatic plants; Bivalves, generally at the bottom, among stones or buried in the sand, or among the roots of aquatic plants.

3. Land shells. - These resemble, more or less, in their habits the garden snail, though varying greatly in character, size, and colour. They mostly abound in a chalk or limestone district, and in moist and wooded situations. Some species inhabit low and damp spots, 
roots of trees, hollows and crevices of rocks and walls; some lie under stones or pieces of wood, or in the earth; others climb shrubs, and in tropical climates even lofty trees. Their haunts vary according to the weather and the season. They come ont early in the morning, and after rain. Some bury themselves in moist places during the dry season, or burrow under leaves, grass, or stones, of ten closing the mouths of their shells with a white secretion to prevent evaporation during the period of torpidity.

The smallest shells, especially of land species, and young imperfect shells should be collected.

In all cases "live shells," i.e. shells in which the animal is alive, are to be chosen ; but when these cannot be procured, "dead shells," which have not lost their lustre or their colour, especially those of rare species, should be preserved.

With regard to the mode of preserving shells :-

1. No attempt should be made to clean them, or to remove the furry skin, more or less thick, with which they are often covered, beyond removing with a soft brush any mud or sand adhering to them.

2. The animals of land and fresh-water shells may be killed by immersing them for a few minutes in boiling water, after which the bodies may be easily extracted whole with any suitable instrumente.g. a fork or a pin, according to size. Hot water should not be used with marine shells: it often destroys their lustre. They should be buried, if time permits, in sand, or other dry material, until the animal dries up (in small shells) or rots (in large specimens); or they may be drowned in cold fresh-water, and hung up in the air to dry or rot away. In the former case, if an operculum (with which many species, both marine and land, close their mouths, more or less partially) exists, it will, generally in the case of land shells, remain in its place, adhering to the shell. In the latter the decayed matter should be washed out, and the operculum, if any, replaced and fixed, say, on cotton filling the shell. This applies equally to land shells.

3. Care should be taken not to injure the edge or lip of the mouth of Univalves, or the ligament of the linge of Bivalves. When Bivalves gape on dying in water, or if the ligament be broken, the 


\section{ON COLLECTING AND PRESERVING SHELLS.}

valves, after the animal has been extracted, should be closed and tied together. If the ligament of a gaping Bivalve should become dry and stiff, it can be softened by putting it in water.

4. The localities in which each species is found should be noted, and, in the case of dredging, the depth of water.

With regard to the mode of packing shells for transport:-

All solid shells may be wrapped in one or two folds of paper of any kind. Fragile and minute shells should be put, generally separately, into a box or bottle-with or without cotton, as required. Such packets may be heaped up in any box, heavy shells at the bottom, without pressure, and any blank at the top filled with paper or other elastic material. Sawdust injures the lustre of many species. 


\section{DIRECTIONS FOR COLLECTING AND PRESERVING PLANTS.}

I HAVE thought it better to reprint the "Directions for Collecting and Preserving Plants in Foreign Countries for a Herbarium," by Robert Brown, than to attempt any fresh general directions which could only fail to equal these in conciseness and lucidity. I have interpolated within square brackets a few minor suggestions, and have added a section on the lower plants requiring special treatment. I am indebted to Messrs. H. and J. Groves for the part dealing with Characeæ, and to Mr. Edmund Grove for the special directions with reference to Diatoms.

George Murray.

\section{Directions for Collecting and Preserving Plants For a Herbarium.}

This is a much simpler process than is generally imagined by those unpractised in it, and travellers have been often deterred from collecting specimens by the time and trouble required for preparing them in the way that has by many been recommended.

The chief circumstances to be attended to are, to preserve specimens of plants in such a manner that the moisture may be quickly absorbed, the colours as much as possible preserved, and such a degree of pressure given to them as that they may not curl up in the act of drying.

For this purpose let a quantity of separate sheets of paper be obtained of a folio size.* Common brown paper is upon the whole

[* The size of British MIuseum Herbarium paper is $17 \frac{1}{2}$ inches by $11 \frac{1}{4}$. Dryingpaper and presses of a corresponding size should be used, and specimens should be disposed so as not to exceed these limits. Applications for a special dryingpaper should be made to the Keeper of Botany by travellers in little-known countries.] 
the best, except for the very delicate kinds, which require paper of a smoother and somewhat more absorbent texture. Blotting-paper, however, especially in warmer climates, would absorb the moisture too rapidly, and by repeated damping and drying would soon be rendered useless.

Two boards [or light presses made of galvanized iron wire] should be provided-one for the top and the other for the bottom of the mass of papers.

For pressure at home, or when stationary for any length of time in a given spot, nothing serves better than a weight of any kind (a folio book, a large stone, etc.) put upon the topmost board; and the great advantage of this is, that the weight follows the shrinking of the plants beneath.

Whilst travelling, three leathern straps with buckles should be procured; two to bind the boards transversely, and one longitudinally. It will be further desirable to have a number of pieces of pasteboard of the same size as the paper, to separate different portions of the collection, either such as are in different states of dryness, or such as by their hard woody nature might otherwise press upon and injure the more delicate kinds.

Thus provided, gather your specimens,-if the plants be small, root and stem,-if large, cut off branches of 1 or $1 \frac{1}{2}$ foot long; selecting always such as are in flower, and others in a more or less advanced state of fruit.

Place them side by side, but never one upon another, on the same sheet, and lay upon them one, two, or three sheets, according to the thickness of the plants, or their more or less succulent nature; and so on, layer above layer of paper and specimens, subjecting them then to pressure.

As soon as you find that the paper has absorbed a considerable portion of the moisture (which will be according to the more or less succulent nature of the plants and the heat or dryness of the season or climate), remove the plants into fresh papers, and let the old papers be dried for use again, either in the open air or sun, or in a heated room, or before the fire. [In drying papers out of doors in countries visited by sudden rains, it is a good plan to insert an eyelet in one corner of each sheet and string the sheets up. This enables 
them to be gathered in a moment, and prevents their being blown to a distance.]

As to the spreading out of the leaves and flowers with small weights, penny-pieces, etc., it is quite needless. The leaves and flowers are best displayed by nature in the state in which you gather them, and they will require little or no assistance with the hand, when laid out upon papers, to appear to the best advantage, especially if put in carefully on being fresh gathered.

If the specimens cannot be laid down immediately on being gathererl, they should be preserved in a tin box, or, failing that, in a rush basket, where they will keep fresh for a day or two, if the atmosphere be not very much heated.

Some very succulent plants, such as Cacti, Semperviva, Seda, orchicleous plants which grow on trees, etc., require to have the specimens plunged in boiling water for a few seconds before they are pressed, to destroy life and thus accelerate the process of drying:

Plants with very fine but rigid leaves, as the Fir tribe and the Heaths, and some with compound winged leaves, to prevent their leaves falling off or their parts separating, may either be treated in the same manner, or dried in very hot paper or with a hot iron.

In many cases, especially in warmer climates, the traveller will find the process accelerated by exposing the parcel (hung up and properly secured) to the open air when the weather is favourable, and the circulation of air through it will be promoted if the sheets on which the specimens are laid be placed alternately back and edge. In tropical countries he will find it necessary to shift his specimens at least once a day, and by changing them into hot paper, and crowding such specimens as are dry, he will be enabled to form a considerable collection in small compass and in a very short time. Four or five shiftings will generally be sufficient to complete the process, which is ascertained by the stiffness of the stems and leaves, and by the specimens not shiinking when removerl. They should then be placed between dry papers [such as ordinary newspaper], and formed into parcels of moderate thickness, and either packed in boxes or well secured as parcels covered with oil-cloth.

Palms, having their fructification and leaves very large, can hardly be subjected to pressure; a few flowers should be pressed, 


\section{8}

and the whole cluster of flowers and fruit, as well as a leaf, may be simply dried in the air, and afterwards packed in boxes for transportation.

The greater number of cryptogamic plants may be dried in the common way, such mosses as grow in tufts being separated by the hand. But both mosses and lichens, as they can at any future time be expanded by damping, may be dried by the traveller without pressure, and put up, either each species separately or several together, in small canvas or paper bags, carefully marking the place of growth and the date when gathered.

If the fruits of plants are of a small size so as to be preserved in a herbarium, they should be gathered with the leaves and branches as are the flowers; if of a large size, they should be kept separate.

Dry fruits demand no care, except that those which split into valves should be tied round with a little packthread.

Pulpy fruits are only to be preserved in spirits, [or in formalin diluted with from five to ten parts of water]. In all cases the separate fruits, whether dry or preserved in a fluid, should have a number attached to them, referring to the flowering specimens of the plant. Seeds, whether for examination or intended to be sown, should be gathered perfectly ripe, put up in brown paper bags, and kept dry in a box.

With the specimens, fruits and seeds, there should be slips of paper, on which are to be written the uses, native names, and general appearance of the plant, whether herbaceous, a shrub, or tree, its sensible qualities, and the colour and form of the flowers; its situation, if dry or damp, the nature of the soil, the elevation above sea-level, and the date when gathered.

As soon as a sufficient number of specimens are collected, no time should be lost in transporting them to their place of destination, since, in warm climates especially, they are liable to the attacks of insects. These attacks, which are often completely destructive of the specimens, may in many cases be prevented by pitching the boxes, and by putting in them, or in each parcel, cotton dipped in petroleum, spirits of turpentine, or small pieces of camphor [or naphthaline], and the captain of the vessel should be particularly requested to keep them in a dry or airy part of the ship. 
Specimens of the woods of from 6 to 8 inches in length, the entire round of the trunk or branch of small, and segments from centre to circumference of the larger kinds, in both cases with the bark, should also be preserved - not only of the more remarkable trees, but also of the woody climbers, which often exhibit peculiarities of structure highly interesting to the kctanist. When specimens of woods are preserved, they should be marked with numbers corresponding with the flowering branches of the tree in the collection of specimens; and when flowers cannot be obtained, a small branch with leaves or fruits should always be taken.

Gums, resins, and other remarkable products should also be collected, their uses if known noted, and reference made by numbers to the plants they belong to.

\section{Characee.}

The most generally convenient method of collecting Characex is by means of a drag and line. The drag consists of a bulb of lead about from $\frac{1}{2}$ to $1 \mathrm{lb}$. in weight, with three or more hooks of strong galvanized iron wire. The drags with three hooks used by angler's for fishing up lines answer the purpose well. The line should be of stout water-cord about $\frac{1}{8}$ inch thick, and twenty yards will generally be found sufficient. Large pieces of water can be much more satisfactorily explored for Characeæ by means of a boat than from the shore, the plants being often confined to a particular part or depth of the lake or pond. In small or shallow pieces of water it is desirable to collect specimens with a walking-stick, or, better still, by hand, as by these means whole plants with the roots can be obtained, while a drag is apt to break up the more brittle species.

Care should be taken in the case of the dicecious species to collect both sexes, and collectors should not content themselves with getting those specimens only which grow at the margin of a pond or other piece of water, these being often small and stunted and sometimes sterile. Most of the Characeæ fruit in the summer; but a few arrive at maturity in the spring.

It is undesirable to carry the specimens loose in the vasculum. If put as straight as possible when collected, and spread in a thin layer 
on a double thickness of newspaper, which can then be rolled up, they will carry well, and will, if necessary, keep for days. They must of course be kept moderately moist, but should not be allowed to get sodden.

There are few plants of which more beautiful specimens can be made than Characeæ, if carefully treated; and, on the other hand, there are few which present a more forlorn and draggled appearance when badly dried. The Nitellex should always be "floated out" in the same way as Algr ; that is, a sheet of paper placed in a vessel of water, and a root or small tuft of the plant (after having been washed) placed on it, and arranged as naturally as possible with the fingers or some sharp instrument. The shallow "baths" used by photographers are excellent for the purpose; but an oblong, white enamelled-iron tray about 2 inches deep is equally serviceable and more portable. Failing either of these, a large dish or basin may be used. A sheet of perforated zinc laid under the paper' will be found of great assistance in removing the specimens from the water. Good, firm white printing-paper should be used for floating the specimens on. In the case of diœcious species the sexes should not be mixed, but either placed on separate sheets of paper, or perhaps preferably a specimen of each placed side by side on the same sheet.

When the specimen has been removed from the water, it should be drained, and a piece of thin calico or linen (previously washed so as to have no "dressing") should be placed over it, to prevent its adhering to the drying-paper. The calico should be removed when the drying-paper is first changed. With the very gelatinous species waxed paper should be substituted for calico.

Most of the Characeæ can be put into press without "floating out," and for these a doubled sheet of thinner paper is usually sufficient, but the calico should always be used. Characeæ require considerable pressure. A few good fruiting whorls should be kept in a test-tube of spirit or other preservative for examination.

\section{Alg.e.t.}

In collecting sea-weeds, the best kind of receptacle is an ordinary sponge-bag. Glass bottles are dangerous companions between tide- 
marks, and for the same reason a knife for scraping off specimens should not be carried. A stout stick with a chisel end is most convenient, and a cotton bag in a landing-net ring at the other end of it is useful in recovering detached floating specimens. Wadingboots are of great advantage; but where there are deep pools, the risk attending immersion is to be reckoned with. Good specimens from beyond low-water mark are to be obtained after a gale,

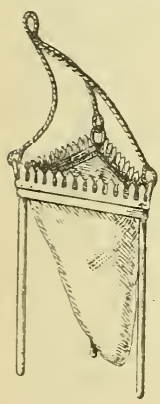

Fig. 1. though many of them are damaged. For dredging, especially from a rowing-boat, Reinke's dredge is the best (see fig. 1).

To obtain the microscopic Hoating plant-life of the sea and of fiesh-waters (Phyto-plankton) a tow-net of the ordinary pattern, made of No. 20 Miller's silk (to be purchased from Emil Fiechter, 69, Hartington Road, Liverpool), may be used at any depth from a boat or ship going with little more than steerage way. Surface organisms at sea may be got in excellent condition by pumping with the deck-hose through such a tow-net suspended from a boat-davit, or in less abundance by running the bath-tap through a silk bag for a few hours. To those who employ this method indiarubber hose is to be recommended in preference to canvas or leather hose, on account of impurities discharged from both.

In preparing sea-weed for the herbarium, great care must betaken in spreading each specimen with a small camel's-hair brush on a paper mount inserted below it while floating in a basin. The specimen should then be dried in the ordinary way; but a layer of muslin should be placed over the sheets of specimens to prerent their adhering to the upper sheet of drying-paper.

In preserving minute Phyto-plankton, marine Diatoms, and the like, a fluid preparation is best.** Either

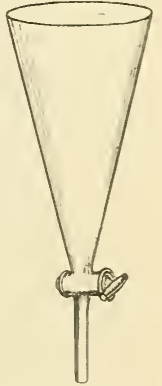

FIG. 2.

* The contents in the tail of the tow-net should be emptied into a funnel with a stop-cock (see fig. 2), and withdrawn below after settling; failing this, by settling and decanting; or by picking up with a dipping-tube. 
chromic acid 0.25 per cent. solution or platinic chloride 0.5 per cent. solution is excellent as a fixing and preserving fluid; but where minute calcareous organisms are involved, formalin (5 per cent.) gives good results for them as well as for all the other kinds, and is to be recommended for general use.

Minute fresh-water Algæ are well preserved in carbolic acid (about 1 per cent.), or in camphor water, or weak spirit where these are not to be obtained. Such submerged plants as Myriophyllum, Utricularia, Nymphcea, Nuphar, and Nitella should be squeezed, and after the water has stood for some time the upper part may be decanted and the sediment preserved. Scrapings from moist and dripping rocks yield good results.

To the special collector of Diatoms some directions may be given in addition to what has been said above.

\section{Diatoms.}

The mud of lakes, pools, and backwaters of rivers, and of swampy places on moors, will repay attention. Where it looks yellow, or shows the presence of Diatoms by giving off little bubbles of gas, it should be scraped up by a fine muslin net attached to a wire frame. The contents of the net should be turned out into a pan, stirred well, and the supernatant sediment poured into a widemouthed bottle. Repeat this until there is a good quantity in the bottle, then wash the net and pan thoroughly, and try another place.

In alpine and subalpine places the surfaces of boulders in lakes and streams should be scraped in the same way. These are generally much purer gatherings than the muds. Perpendicular rocks by the sides of streams should be scraped, and the rock-faces above the surface of the water should be examined for any little white tufts or patches of Diatoms which have grown there when the waters were higher and have become sun-dried. Wooden cattle- and horse-troughs often yield specimens.

The bottles when taken home should be well shaken, the contents poured into filtering-paper, left to dry, and folded up as they are, 
labelled with locality, approximate height above sea-level, date, and character of the water, whether fresh, brackish, cold, or thermal.

Water-weeds, Sphagna, etc., growing in lakes and pools, should be gathered, washed, and gently squeezed in water, and the sediment treated like the muds. Floating patches of scum which have risen to the surface, buoyed by bubbles of gas on a warm sunny day, should be secured with the net. These are often rich in Diatoms. It must be remembered that small quantities are very difficult to manipulate afterwards.

Marine Diatoms from the surface should be collected by tow-net as described above under "Phyto-plankton."

Ripple-markings on warm, sunny days often exhibit a yellowbrown colour on the sides opposite the sun. This sand should be scraped, and treated in a pan as recommended for the muds. The process should be often repeated because the proportion of Diatoms to sand-grains is often small. Rock-pools between tide-marks should be examined, and sloping or horizontal rock surfaces scraped. Algæ in such pools and beyond low-water mark should be treated as noted under "Fresh-water Weeds." Shells, especially living ones, covered with Zoophytes and small Algæ should be scraped, and the scrapings sent as they are. The contents of the stomachs of Holothurians, Àscidians, herbivorous Molluses, are often very rich in Diatoms. Dredgings and rubbish from trawling-boats are often fruitful in diatomaceous remains which have sunk from the surface.

If the surface of peat deposits shows white patches, a slice should be preserved. Any light-coloured strata of low specific gravity either under peat or occurring by themselves among other strata deserve attention.

\section{Fungr.}

Hard woody Fungi need no special preparation, beyond keeping them in a dry place. Most of these are found growing on trunks of trees; but when a terrestrial one is met with, it should be dug up with care, since sometimes such forms spring from underground tuberous bodies.

It is not possible to make satisfactory specimens of soft Fungi such as Agarics and Phalloideæ in any but a dry climate. Much the best 


\section{ON COLLECTING AND PRESERVING PLANTS.}

plan in any damp climate is to preserve them in fairly strong spirit, or in formalin diluted with from five to ten parts of water. A note of the colours should be made against the number in the collecting list, or on the ticket; and, if possible, in the case of an Agaric, the colour of the spores should be observed. This is best done by cutting off the pileus, and placing it for several hours, say overnight, on a sheet of paper; and the spores cast during that period will be found to have deposited a map of the gills on the paper. The colour may then be noted; and if possible the spore-cast should be preserved (numbered) by painting a thin film of gum on the reverse side of the paper, which should be thin. The pileus should be placed where there is no draught while casting its spores. In the case of Phalloideæ young and mature specimens should be obtained when possible.

Leaf Fungi are best preserved by pressing and drying, and the name of the host-plant sbould be noted, or if unknown then a specimen should be taken for identification.

Mycetozoa should be dried, and carefully preserved from crushing by fixing them in chip-boxes. 


\section{SUGGESTIONS AS TO COLLECTING AND PRESERVING FOSSILS.}

\section{Field Observations and Labelling.}

1. The scientific value of a fossil depends largely on the accuracy with which the circumstances of its discovery are recorded. Whenever possible, a note should be made, not only of the precise locality, but also of the exact position in the exposed section whence the specimen was obtained.

2. When more than one fossiliferous band is observed in a section, the fossils from each stratum ought to be kept apart, and their exact sequence noted. Measurements of the thickness of the several beds are of great value.

A sketch or diagram of the section should be made, the beds numbered, and a corresponding number (with date) should be added to the label of locality attached to each specimen.

3. Be careful to distinguish between fossils from the regularly bedded stratified rocks of a section, and other's which may occur in infilled fissures across those rocks. Instances are known in which the contents of fissures filled in at a comparatively recent geological period are nearly as hard as the surrounding rock. Such filled-up chasms are especially to be looked for in limestones, and can be readily distinguished by the irregular and chaotic arrangement of their fragmental contents.

4. It is desirable to leave the fossil adhering to a fragment of matrix when the rock is sufficiently hard, or at least to preserve the impression left by it on the matrix. In sandstones the counterpart is often quite as raluable as the fossil itself, and shows 
features not otherwise preserved. When the rock is soft or pulverulent, traces of it retained in the crevices of the fossil are frequently of value. When the fossil consists of several separate parts (e.g. a vertebrate skeleton), a slab showing the parts in natural association is of much greater scientific value than would be the same fragments removed from the matrix. In short, it ought to be possible to verify from the fossil itself the collector's statement as to the deposit in which it was found, and the natural grouping of its several parts.

Photographs or sketches of the fossil in sitû are most desirable.

In case of the specimen being embedded in a slab of matrix, the position of the slab (whether with its face downwards or upwards) should be indicated.

5. Each specimen (or portion of specimen) ought to be wrapped up separately in paper, protected with cotton-wool,* or a small box when necessary, each packed with its own special label, and marked also on the outside. $f$ It is advisable to carry a small bottle of red paint (or red sealing-wax dissolved in methylated spirit), and number each specimen or fragment to correspond with a record in a note-book, thus preserving a second memorandum in case the loose label is lost or displaced in unpacking. The red paint is also useful for making streaks and other distinctive marks across the cracks in fissured specimens before they are removed from the rock-a precaution of much service later on in finally fixing together the pieces when separated.

\section{Hints on Collecting from Certain Formations.}

1. It must be remembered that in certain slaty rocks the planes of fracture are not the original bedding-planes, but surfaces induced by cleavage. The original bedding can frequently be detected by colour-streaks, and fossils must be looked for on planes parallel with the latter.

* In case cotton-wool, or moss, cannot be procured, soft clay or earth may he used, to protect the face of the specimen.

$\uparrow$ It is useful to carry several canvas bags slung on a strap, and preserve one for each horizon, whilst the actual collecting is in progress. The bag can be tied round with string, and labelled outside. 
Such slaty rocks, though apparently barren, may prove (like the Welsh Cambrian rocks) to be very fossiliferous, if the organic remains are sought for on the edges of slabs, sometimes at right angles to the cleavage planes.

2. Even when limestones appear to be unfossiliferous, it is well to examine them-and especially the cherty bands and nodules so frequent in them-with a good hand-lens to detect microscopic organisms. Shells of Foraminifera and Radiolaria, spicules of Sponges, etc., may frequently be detected by a lens on smooth, wetted surfaces.

3. Similarly, apparently unfossiliferous clays are not to be neglected. Samples may be taken and "washed" at home, the result being frequently abundant remains of Foraminifera and Ostracoda, etc., from marine deposits, and seeds of plants from comparatively moder'n fresh-water deposits.

4. When a formation contains nodules or concretions, special attention ought to be paid to these. They have usually been formed around decaying organic matter, and a large proportion of the best-preserved fossils occur in them.

The clay-ironstone nodules found in the beds associated with seams of coal usually contain remains of coal plants, insects, and Crustacea enclosed within them, often of great beauty.

Many concretions enclose fossil fishes. The late Mr. Charles Moore found, after long experience, that the nodules of White Lias, containing fishes, were most successfully opened by first breaking them in two near the centre, and then splitting open each half at the inner transverse fracture. The two halves of the split surfaces were afterwards glued together.

\section{Treatment of Fossils in the Field.}

1. As a general rule, it is best to do the least possible trimming and cleaning of a fossil in the field. Final preparation for the cibinet can be far better done at leisure afterwards.

2. Large friable specimens, such as vertebrate skeletons, large Ammonites, or groups of shells, in a matrix which is only moderately hard or liable to fall to pieces on drying, need special treatment. 
The fossil ought to be first carefully uncovered as it lies in the rock. Then thin paper may be gently pressed over, covering the whole, and as far as possible filling every crevice. Next, plaster of Paris must be poured over this prepared face, and allowed to harden in a moderately thick layer. Finally, the specimen may be excavated and transported as a slab, the plaster covering serving as an adequate support. N.B. - If paper be not used, the plaster cannot be readily removed from the fossil, and may completely damage it.

Strips of wood, or thin iron rods, fixed down to the specimen by plaster of Paris and string, may be used, to give rigidity to friable or heavy specimens in lifting them from the quarry to a waggon for transport.

3. Some large specimens-e.g. bones in Pleistocene deposits-need to be hardened before removal from the matrix. This can be done by uncovering the upper face of the fossil, and pouring slowly upon it a warm, weak solution of gelatine or glue, or the preparation known in commerce as "soluble glass." Then, after adequate time for drying, proceed as above (No. 2).

4. Bones which are only moderately delicate can be transported best swathed in long strips of linen or calico (like the Egyptian mummies), and, after wrapping, this may be hardened by the copious application of ordinary flour paste ; or the strips may be dipped in flour paste before winding them round the bones. Melted paraffin wax is sometimes found useful to hold together fragile spécimens.

5. In cases where the specimen, from either its size or condition, must be got out in pieces, or in the case of a skeleton in separate bones, each part of such bone, or of such more or less entire skeleton, should be carefully marked with a number corresponding to one on the adjoining part, and also with that on a rough sketch in the traveller's note-book. Red or white paint (carried in a tube) can also be used to mark the connecting-points in a skeleton or in the parts of a single bone.

\section{Preparation of Fossils.}

1. All friable fossils, such as shells in Tertiary or recent clays, need immediate attention. They may be slowly dried in the sun or 
in an oven, and hardened by treatment while still warm with a weak solution of gum-tragacanth. This is better than gum-arabic, because it does not leave a glossy surface.

2. Fossil leaves in clay curl up on drying, and are frequently destroyed. These may also be preserved by the application of gumtragacanth or a thin solution of gelatine.

3. Friable bones are best hardened by first warming, and then dipping for a few moments in a warm, weak solution of gelatine.

4. Pyritized fossils cannot always be preserved. When decaying, allow them to soak for some time in water to dissolve the sulphate of iron; then dry carefully, and dip them while warm in melted paraffin wax.

5. Ordinary gum, with a little glycerine or glue, may be used for mending small specimens. Shellac is too brittle for most purposes. The best cement for large specimens is liquid glue, with a small admixture of plaster of Paris. Dental cement is very useful, especially when it is desired to fix a fragment so that it can be separated again.

\section{Packing Fossils.}

1. In packing fossils always use flexible material, such as crumpled paper, shavings, straw, moss, grass, or cotton-wool-never sawdust, sand, or grain (chaft). Boxes should be tightly packed, leaving no room for shifting of contents.

2. Boxes are better small and numerous than large and few. Heavy cases suffer more from concussion in transport than small boxes.

Small boxes, carefully packed and placed in a larger case, will travel well.

The opening of cases by Customs officers in docks* and on the frontier of foreign states is often more fatal than a very long journey to the contents of boxes. Bribery in such cases seems permissible, to ensure lenient treatment of collections.

* If addressed "To the Director of the Pritish Museum (Natural History), Cromwell Road, London, S.W.," the cases will not be opened by the Customs officers, but sent on at once under seal. 


\section{ON COLLECTING MICROSCOPIC AND OTHER ORGANISMS IN ROCKS.}

THE interiors of chalk flints and nodules of chert from the Greensand frequently have hollows containing loose whitish or greenish powder. This should be collected, for it usually has small organisms such as Foraminifera or Sponge spicules scattered through it; and they may be obtained by levigating the loose powder, or, where the material is silicified, by treating it with dilute acid.

The thin shaly partings between layers and beds of limestone often contain microscopic organisms, and should be examined; also the heaps of débris from quarries and other workings in limestone frequently have small fossils weathered out ; and this kind of material is often much more easily worked by washing than that fresh from the quarry.

The surface of ploughed fields, or fields in the autumn when the crops have been gathered off, frequently yield fossils in those instances in which limestone or other rocks, are near the surface. Often molluscan and other shells and many other calcareous fossils become silicified, and are thus rendered more durable than the limestone matrix; and they remain when the rest of the rock has been dissolved. Thus it happens that nodules and stónes picked from the surface of fields for the repair of roads, etc., often contain good fossils; and heaps of such materials by the roadsides will repay careful scrutiny.

The materials thrown out from ditches, trenches, well-sinkings, and all kinds of excavations should be examined for fossils; and a good pocket-lens should be used to detect microscopic Foraminifera or Ostracoda in decayed shales, etc.

The outcropping edges of rock-beds in old disused quarries and in 
natural sections should be searched for fossils weathering out; and more particularly the talus at the foot contains fossils washed out from the rocks above.

Stone fences round fields, etc., often reveal fossils much more distinctly than rocks freshly quarried; but care is required to extract the fossils without damaging the fences.

Specimens of prominent beds of limestone and chert should be obtained for examination by microscopic sections, even if no fossils can be seen by the eye alone. Small cubes 1 or 2 inches across will serve for this purpose, but the locality requires to be carefully noted. Specimens of dark cherts, or cherty nodules, should be more particularly obtained, as they usually contain Radiolaria in better condition for showing their structures than transparent cherts. Small cubes of the softer kinds of calcareous rocks, such as the various varieties of beds of chalk and cubes of siliceous shales and marls, should be collected for the preparation of microscopic sections or for subsequent levigation.

The beds of streams cutting through rocky or shaly banks should be searched when the water is low in summer and autumn, for fossils will often be found in layers of sand and gravel which have been naturally washed out of the rocky beds on the banks; also if hard beds of limestone form the floor of the stream, these will be found to have fossils standing out in relief, owing to the natural action of streams.

Beds of fissile shale should be split open with the hammer and chisel or a broad-bladed thin knife, and their surfaces searched for Graptolites, Trilobites, or other Crustacea, small dark annelid jaws, Polyzoa, Conodonts, etc. Such forms in shale require careful packing, otherwise they soon get defaced during transport. 


\section{NOTES ON COLLECTING MINERALS.}

From the collector's point of view, Minerals differ in many respects from both Animals and Plants: the individuality being little pronounced, a specimen may be broken in two, and yet often be as satisfactory as before in its illustration of the characters of the material ; the characters themselves are independent both of climate and seasons and of mere longitude and latitude; the material, after collection, is comparatively permanent, and is free from that liability to decay which is a special feature of organic matter.

Meteorites. - Of the mineral products of Nature some are interesting as having fallen from the sky (meteorites): most of these (meteoric stones) are of grey stony matter, which is completely covered with a thin black crust, and contains particles of metallic iron dispersed through it ; the others consist of metal (meteoric iron), which, though containing on the average about 10 per cent. of alloyed nickel, has an aspect like that of the iron of commerce. As native iron is extremely rare, any natural material consisting either wholly or partially of metallic iron is of special interest and worthy of collection.

Minerals.-The specimens which show the characters pertaining to mineral species and varieties in the most perfect way are found, not at the earth's surface, but in the course of the working of mines and quarries. The people connected with the latter know when a specimen has unusual merit, and they are in more or less direct communication with mineral dealers; specimens of exceptional character thus already find their way from these districts into the market, and a traveller without special knowledge of minerals can be of little help.

Rocks.-In general, rock-specimens are of little value, except in connection with a complete survey and description of the region by 
one who has given special atteution to the study of mineralogy and geology, and has himself collected the specimens: rock-specimens collected here and there, and without correlative information as to the geological structure of the district, are rarely worth the trouble and expense of transport. But if trouble and expense are to be left entirely out of account, a traveller in a region which is comparatively unknown, or which contains neither mines nor quarries, may occasionally be of service by collecting material representative of the rocks met with during his journey. Such material should be taken, not from the margin of the rock which has been long exposed to the action of the weather and is more or less altered, but from the inner part showing uniformity of character. To break off such specimens, the traveller should provide himself with a hammer of which head and shaft are reasonably proof against fracture. "Mineralogical hammers" are articles of commerce, and are of various weights and sizes; the head is of well-tempered steel, one end of it being flat and square with an edge about 1 inch long, the other end having the shape of a chisel, the chisel-edge, also about 1 inch in length, being at right angles to the shaft: for most purposes a hammer of 2 pounds' weight is sufficient. Strong chisels, 4 or 5 inches long, are also occasionally useful. A small trimming-hammer, from $\frac{1}{2}$ to $\frac{1}{4}$ pound in weight, is convenient for use in the reduction of specimens to a proper shape and size. The size adopted for the specimen must depend largely on the sizes of the individual mineral constituents of the rock, since the specimen is to illustrate the average characters of the mass, and also on the conveniences for transport: a good average size, if the specimens are intended for exhibition, is, length 4 inches, breadth 3 inches, thickness from $\frac{1}{2}$ to 1 inch. As rock-material is very heavy, the reduction in size should be made at the place itself; another piece of the rock can then be immediately got, if by any mischance the specimen be spoiled in the course of the trimming. Where a rock shows variations of character, specimens should be selected in illustration thereof.

The interest of a rock-specimen lies very largely in the relations of the mass of which it is a part to the other rock-masses in the district; unless information as to the locality of the mass to which 
the specimen belonged is preserved, the specimen itself generally becomes valueless; for this and other reasons water-worn pebbles are not worthy of transport. Hence it is important to specify as precisely as possible the place from which each specimen has been broken, and also to take precautions against the possibility of a subsequent confusion of the specimens. For this purpose a gummed label should be fastened on each specimen immediately after it has been trimmed, and a number should be written thereon referring to a corresponding entry in a note-book in which all the memoranda relative to the locality and the specimen are recorded: among these may be included the hour and the date when the specimen was got, as giving a rough indication of the relative positions of the different masses on the line of route. The specimen should then be wrapped in newspaper to prevent friction with others; and as a measure of precauiion against the loss of the note-book and also as a convenience, the locality should be specified on the inside edge of the wrapper. It is also convenient if the wrappers of specimens from each particular district are distinguished by some external mark.

The specimens may be stowed in manilla bags, which are then sewn sufficiently tightly to prevent the shaking about of the contents. Wooden boxes should be small and strong, for large boxes containing rock-specimens are almost unmanageable during transport. Paper or straw makes good packing-material; but sawdust is useless, as the specimens accumulate at the bottom of the box with the sawdust above them.

A mineral specimen comprising delicate crystals should be wrapped first of all in soft tissue-paper, next in cotton-wool, and lastly in newspaper; it may then be enclosed separately in a small box, which may be put with others in a larger one.

Before collecting specimens which offer such difficulties as regards transport, the traveller will do well to spend some time in the Mineral Gallery, and to see for himself the kind of material which is found useful for exhibition and study. 


\section{N D E X.}

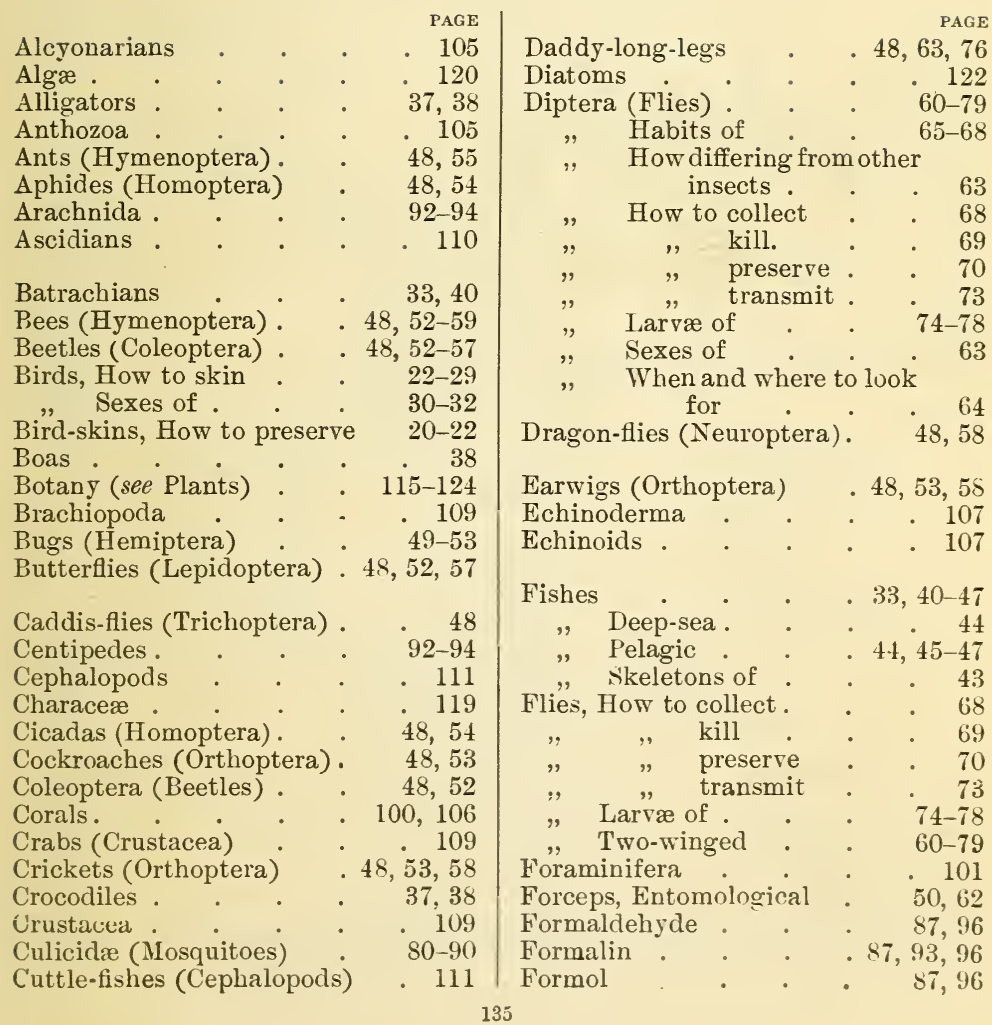


Fossils

$\begin{array}{ccc}" \quad \text { How to collect } \\ " \quad \text { pack . } \\ ", & \text { prepare }\end{array}$

Fresh-water shells

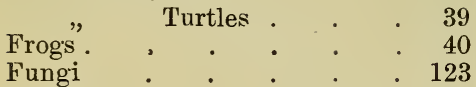

Gavials $\quad . \quad$. $\quad . \quad$. $\quad . \quad 38$

Gnats . . . . 80-91

Gorgonians . . . . 107

Grasshoppers (Orthoptera) 48, 53, 58

Hemiptera (Bugs) . . 4 49,53

Heteropods . . . . 110

Holothurians . . . . 108

Homoptera . . . 4 48, 54

Horned animals, How to skin . 8

Hydrocorallinæ . . . . 104

Hydroida . . . . . 103

Hydrozoa . . . . . 103

Hymenoptera . . . $48,52,58$

Insects

$48-91$

" Collecting apparatus $48,60,83$

" Forceps for . . 50,62

"How to collect . . 51

" $"$ mount . 52-55

$"$ " pack. . . 56

" Larvæ of . . . 56

" Store boxes for $\quad \cdot \quad 63$

Invertebrates, How to collect . 96

, $"$ pack .100

", preserve. 96

" Soft-bodied . 96-111

Jelly-fish (Medusæ) . 104

Labelling specimens . $\quad .15,47,125$

Labels, Example of . . . 15

Lamellibranchs . . . . . 110

Land-shells . . . . 112

Lantern-flies (Homoptera) $\quad 48,54$

Leathery turtle . . . . 39
Lepidoptera (Butterflies and

Moths) . . . 48, 52,57

Lion, How to skin . . . 8

Lizards . . . . $\quad 37$

Locusts (Orthoptera). $\quad$. 48, 53, 58

Mammals, European . $\quad$. $\quad$. 14

, Large . . . 7

" List from Asia . $\quad 13,14$

, $\quad$ " of African . . 12

" North American . 14

" Small . . 15-19

" " How to measure 15

" South American . 14

, How to skin . . . 7, 15

Mantides (Orthoptera) . 41, 53, 58

Marine shells . . . . 112

May-flies (Neuroptera) . 48, 52, 58

Medusæ . . . . . 104

Meteorites . . . . . 132

Midges . . . . 75,80

Millipedes . . . . 92-94

Minerals . . . . 132-134

Mollusca . . . . 110-114

Mosquitoes (Culicidæ) $\quad 80-90$

" Habits and distribution . . 88

How to collect . 85

",$\quad$ kill . $\quad 85$

", Lar" and pupæ of $\quad 87$

" Sexes of . . 84

" : Transmission of $\quad 89$

Moths (Lepidoptera). • 48, 52, 57

Mycetozoa . . . . . 124

Myriopoda . . . . $\quad$. $92-94$

Neuroptera (Termites, etc.) 48, 52, 58

Organisms in rocks 130,131

Pennatulids . . . . 107

Peripatus . . . . . 94

Phasmas (Orthoptera) . 48, 53, 58

Pins, Entomological . . . 62 


\begin{tabular}{|c|c|c|c|c|c|c|}
\hline & & & & 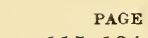 & & PAGE \\
\hline lar & & & . & $115-124$ & Siphonophora & 104 \\
\hline 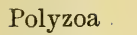 & & & & . 109 & fishes & 43 \\
\hline orifera $(S$ & Spon & es) & . & . 102 & imals & 7,15 \\
\hline 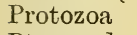 & . & . & . & 10 & Sna & \\
\hline & - & 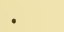 & . & . 111 & • & $92-94$ \\
\hline & 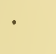 & & & 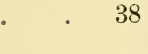 & s (Porifera) & $\begin{array}{l}102 \\
. \quad 107\end{array}$ \\
\hline$a d$ & & & . & 101 & nsects (Orthopter & $, \tilde{5} 3,5$ \\
\hline & & . & . & 4 & $\mathrm{St}$ & . 106 \\
\hline & & . & . & $33-40$ & Swc & 45 \\
\hline Irtl & & & . & . $\quad 39$ & & \\
\hline & & - & . & . 132 & $\begin{array}{l}\text { ptera) } \\
\text { in . }\end{array}$ & $\begin{array}{c}.48,5 \\
.\end{array}$ \\
\hline & & . & . & & & \\
\hline & & . & . & . & ra (Caddis-flie & \\
\hline & & & & 110 & Tunicata & . 110 \\
\hline & $\operatorname{cts}$ & Iom & pte & 48,54 & Pelagic. & \\
\hline & & - & . & $92-94$ & Turtles & 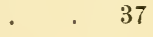 \\
\hline & & $\cdot$ & $\cdot$ & - 106 & & \\
\hline & & . & . & - 39 & Vermes (Worms) & . 10 \\
\hline & & . & . & 3 & & \\
\hline & & & & & & -8 \\
\hline & & & . & . $\quad 112-114$ & (roptera) & . $48,52,5$ \\
\hline 1 & & & & . 109 & (Vermes) & \\
\hline
\end{tabular}

\section{NOV. 1902}





\section{$1-1$ \\ 1}

$-2$

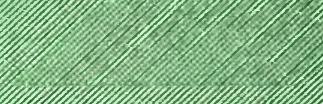

Y $P 19$

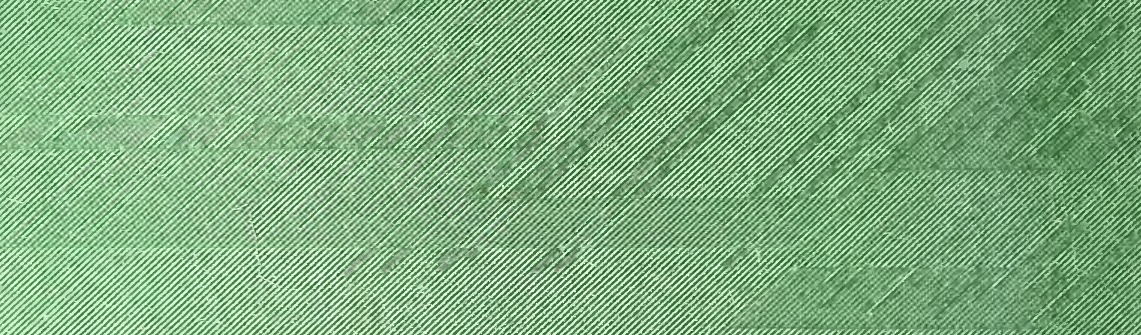

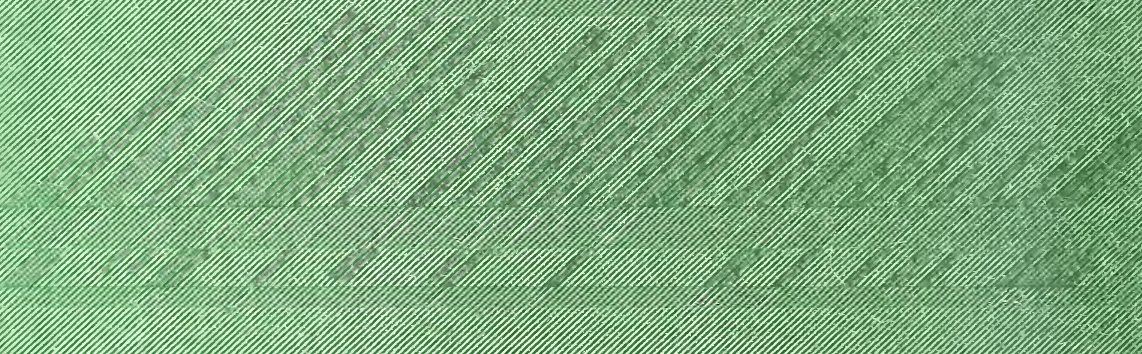

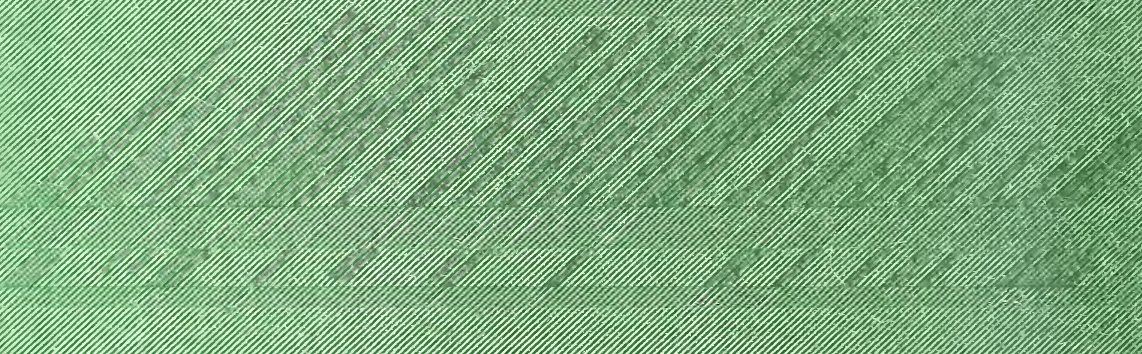

